University of Rhode Island

DigitalCommons@URI

Open Access Dissertations

1986

\title{
OPIATE RECEPTOR SUBTYPE MODULATION OF DOPAMINERGIC ACTIVITY THE EFFECTS OF MU, KAPPA AND SIGMA OPIATES ON THE DEVELOPMENT OF DOPAMINERGIC SUPERSENSITIVITY
}

Robert W. Dunn

University of Rhode Island

Follow this and additional works at: https://digitalcommons.uri.edu/oa_diss

\section{Recommended Citation}

Dunn, Robert W., "OPIATE RECEPTOR SUBTYPE MODULATION OF DOPAMINERGIC ACTIVITY THE

EFFECTS OF MU, KAPPA AND SIGMA OPIATES ON THE DEVELOPMENT OF DOPAMINERGIC SUPERSENSITIVITY" (1986). Open Access Dissertations. Paper 147.

https://digitalcommons.uri.edu/oa_diss/147

This Dissertation is brought to you for free and open access by DigitalCommons@URI. It has been accepted for inclusion in Open Access Dissertations by an authorized administrator of DigitalCommons@URI. For more information, please contact digitalcommons-group@uri.edu. 
OPIATE RECEPTOR SUBTYPE MODULATION OF DOPAMINERGIC ACTIVITY

THE EFFECTS OF MU, KAPPA AND SIGMA OPIATES

ON THE

DEVELOPMENT OF DOPAMINERGIC SUPERSENSITIVITY

BY

ROBERT W. DUNN

A DISSERTATION SUBMITTED IN PARTIAL FULFILLMENT OF

THE

REQUIREMENTS FOR THE DEGREE OF

DOCTOR OF PHILOSOPHY

IN

PHARMACOLOGY AND TOXICOLOGY

UNIVERSITY OF RHODE ISLAND

1986 
DOCTOR OF PHILOSOPHY DISSERTATION

OF

ROBERT W. DUNN

\section{Approved :}

\section{Dissertation Committee:}

Chairman
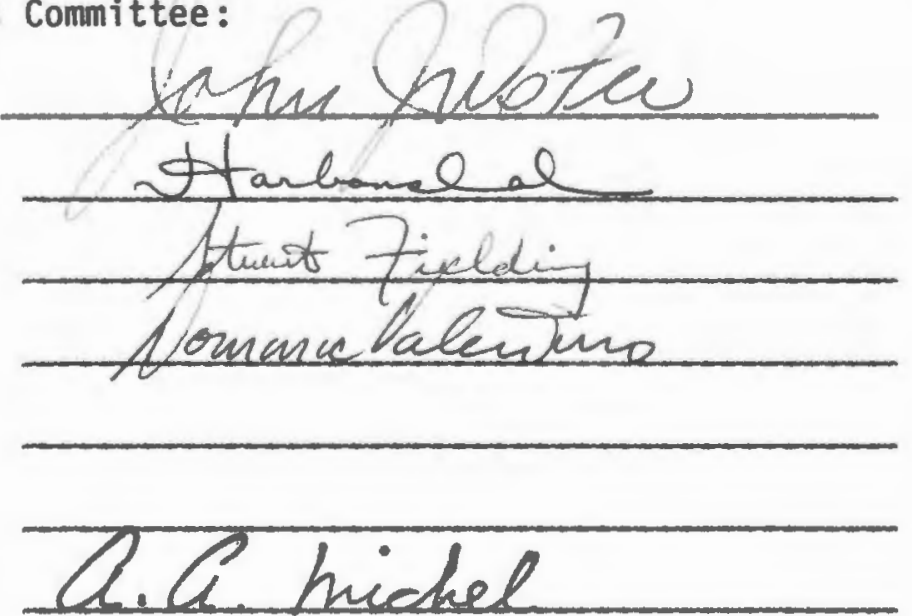

Dean of the Graduate School

UNIVERSITY OF RHODE ISLAND 


\section{ABSTRACT}

The purpose of this research was to examine the effects of mu $(\mu)$, kappa ( $k$ ) and sigma $(\sigma)$ agents namely, morphine $(\mu)$, ethylketocyclazocine $(\kappa)$, SKF $10,047(\sigma)$, pentazocine $(\kappa, \sigma)$, cyclazocine $(\kappa$, $\sigma)$ and the mu antagonists, naloxone and naltrexone on dopamine mediated behaviors and the development of haloperidol-induced dopaminergic supersensitivity (DA-SS) in the mouse. Three behavioral paradigms were utilized which are predictive of mesolimbic and/or striatal dopaminergic effects: locomotor activity (mesolimbic); apomorphine-induced stereotyped behavior (striatal) and apomorphineinduced climbing behavior (mesolimbic/striatal). Morphine, SKF 10,047, pentazocine and cyclazocine produced increases in locomotor activity suggesting increased dopaminergic activity, while naloxone and naltrexone had no effect on locomotion. Ethylketocyclazocine (EKC) induced a biphasic effect of sedation followed by an increase in locomotor activity at three hours postadministration. EKC and SKF 10,047 antagonized apomorphine-induced climbing because of motor deficits, sedation and ataxia, respectively, while the other opiates had no effect. Only EKC inhibited apomorphine-induced stereotypy, due to initial motor deficits and sedation. Thus, these compounds were not dopamine antagonists, insofar as apomorphine-induced behaviors were only antagonized at debilitating doses which incapacitated mice. Furthermore, both EKC and SKF 10,047 increased locomotion, unlike neuroleptics which generally cause motor depression.

The stimulant properties of the $k$ and $\sigma$ opiates warranted further investigation. EKC at $5 \mathrm{mg} / \mathrm{kg} \mathrm{sc}$ produced a biphasic effect over time 
with a peak effect from 180 to 210 minutes. EKC $(5 \mathrm{mg} / \mathrm{kg})$ hyperactivity was dependent upon catecholamine synthesis and transmission since $\alpha$-MPT $(300 \mathrm{mg} / \mathrm{kg})$, reserpine $(5 \mathrm{mg} / \mathrm{kg})$, tetrabenazine $(5,40$ $\mathrm{mg} / \mathrm{kg}$ ), haloperidol (1 $\mathrm{mg} / \mathrm{kg})$, apomorphine $(0.1 \mathrm{mg} / \mathrm{kg})$, muscimol (1 $\mathrm{mg} / \mathrm{kg})$ and prazosin $(2.5 \mathrm{mg} / \mathrm{kg})$ blocked EKC-induced locomotor activity. SKF 10,047 at $40 \mathrm{mg} / \mathrm{kg}$ SC not only increased locomotor activity but also induced stereotypy and climbing behavior with an ED50 for climbing at 90 minutes equal to $14.6 \mathrm{mg} / \mathrm{kg} \mathrm{SC}$. SKF 10,047 (40 mg/kg) -induced climbing was dependent on catecholamine transmission and a direct serotonin receptor interaction since $\alpha-M P T$ ( 300 $\mathrm{mg} / \mathrm{kg})$, tetrabenazine $(5,40 \mathrm{mg} / \mathrm{kg})$, haloperidol (1 $\mathrm{mg} / \mathrm{kg})$, apomorphine $(0.1 \mathrm{mg} / \mathrm{kg})$, muscimol (1 mg/kg), prazosin $(2.5 \mathrm{mg} / \mathrm{kg}$ ) and methysergide $(10 \mathrm{mg} / \mathrm{kg})$ antagonized this behavior. Both EKC-induced hyperactivity and SKF 10,047-induced climbing were not antagonized by naloxone $(10,100 \mathrm{mg} / \mathrm{kg})$. Furthermore, naloxone, EKC and SKF 10,047 potentiated apomorphine-induced climbing.

The $\mu, \kappa$, $\sigma$ and mixed $\kappa, \sigma$ agents all produced effects suggesting dopaminergic activity, i.e., locomotion, stereotypy, climbing and potentiation of apomorphine effects. Therefore, each was tested for its ability to attenuate haloperidol-induced DA-SS in the climbing and stereotyped behavior paradigms. In the acute climbing paradigm, haloperidol-induced DA-SS was dose-dependently attenuated by SKF 10,047, EKC, cyclazocine, pentazocine, naloxone and naltrexone, with morphine inactive. In the chronic (5-day) climbing and stereotypy models, only the concomitant administration of either SKF 10,047 or cyclazocine and haloperidol inhibited the development of DA-SS, while 
morphine alone produced DA-SS. These results suggest differential opiate modulation of DA-SS in the acute vs. chronic paradigms. Furthermore, sigma agonists were most effective in attenuating haloperidol-induced DA-SS, presumably through dopamine agonist properties. 


\section{ACKNOWLEDGMENTS}

I wish to express my appreciation and graditude to Hoechst-Roussel Pharmaceuticals, Inc. and the University of Rhode Island for the opportunity to continue my education and attain a Ph.D. in Pharmacology. Also, a special thanks to Drs. H. Lal, S. Fielding, D. Valentino and $\mathrm{J}$. DeFeo for their encouragement, help and guidance.

In addition, my thanks to Ms. Wendy Parker for her excellent secretarial assistance in the preparation of this dissertation. And above all, my most warm and sincere gratitude to Dr. Nancy HutchinsonDunn for her devoted inspiration and understanding. 
Abstract ..................... . . . $i \uparrow$

Acknowl edgments . . . . . . . . . . . . . . . . v

Table of Contents .................... . . vi

List of figures . . . . . . . . . . . . . . . . ix

List of Tables . . . . . . . . . . . . . . . . . . xi

I. General Introduction ............... 1

II. Introduction - Literature Survey . . . . . . . . . . 4

A. Nigrostriatal and Mesolimbic Dopamine Pathway . . . 4

1. The Nigrostriatal System . . . . . . . . . 4

2. The Mesolimbic System ............ 5

B. Functional Differentiation: Mesolimbic vs. Striatal .............. 5

C. Dopaminergic Supersensitivity . . . . . . . . . 14

D. Opiate Receptor Subtypes . . . . . . . . . 22

E. Similarities of Opiate and Dopaminergic Agents Modulation of Dopaminergic Nigrostriatal and Mesolimbic Systems by Opiates . . . . . . . . 28

F. Hypotheses ............... . . 32

III. Materials and Methods ............ . . 34

A. Acute Studies .............. . . 34

B. Acute Supersensitivity Studies . . . . . . . 34

C. Chronic Supersensitivity Studies . . . . . . . . 34

D. Locomotor Activity Experiments . . . . . . . . . 34

E. Apomorphine-Induced Stereotypy . . . . . . . . 35

F. Apomorphine-Induced Climbing . . . . . . . . 36

G. SKF 10,047-Induced Climbing ......... . . 37 
H. Ethylketocyclazocine-Induced Hyperactivity . . . . 37

I. Drugs . . . . . . . . . . . . . 38

IV. Results ................. . . 39

A. Apomorphine-Induced Behaviors . . . . . . . . 39

1. Locomotor Activity ........... . 39

2. Stereotyped Behavior .......... 39

3. Climbing Behavior . . . . . . . . . 39

B. Locomotor Activity of Opiate Subtypes in Mice . . . 39

C. Effects of Opiate Subtypes on Apomorphine-Induced Climbing and Stereotypy ........... 40

D. The Effect of 72-Hour Pretreatment of Haloperidol $(1.25 \mathrm{mg} / \mathrm{kg})$ :

1. on Apomorphine-Induced Locomotor Activity . . . 41

2. on Apomorphine-Induced Stereotypy . . . . . . 41

3. on Apomorphine-Induced $\mathrm{Climbing} \mathrm{.} \mathrm{.} \mathrm{.} \mathrm{.} \mathrm{.} \mathrm{.} 41$

E. The Effects of Simultaneous Administration of Opiate Agents and Haloperidol 72 Hours Prior to Apomorphine at $0.4 \mathrm{mg} / \mathrm{kg} \mathrm{SC}$ in the Climbing Mouse Assay . . . . 42

F. The Effects of Chronic (5-Day) Haloperidol $(1.25 \mathrm{mg} / \mathrm{kg}$ ) Administration on Apomorphine-Induced Locomotor Activity ............. . . 43

G. The Effects of Chronic (5-Day) Simultaneous Administration of Opiate Agents and Haloperidol 72 Hours Prior to Apomorphine at $0.4 \mathrm{mg} / \mathrm{kg} \mathrm{sc}$ on Stereotyped Behavior . . . . . . . . . . . 44

H. The Effects of Chronic (5-Day) Simultaneous Administration of Opiate Agents and Haloperidol 72 Hours Prior to Apomorphine at $0.4 \mathrm{mg} / \mathrm{kg} \mathrm{sc}$ in the Climbing Mouse Assay . . . . . . . . . 45

I. Acute Interaction Effects of Apomorphine $(0.4 \mathrm{mg} / \mathrm{kg})$ and Either Naloxone, EKC or SKF 10,047 on Climbing Behavior in Mice ............... . . . 46 
J. Ethylketocyclazocine-Induced Hyperactivity in Mice. . . . . . . . . . . . . . . . 47

K. Effects of Various Blocking Agents on EKCInduced Hyperactivity ............. . 47

L. SKF 10,047-Induced Climbing Behavior in Mice . . . 48

M. Effects of Various Blocking Agents on SKF 10,047Induced Climbing Behavior.......... . 48

V. Discussion ................... 49

VI. Conclusions .................. . . 77

VII. Figure Legends $1-20$. . . . . . . . . . . . 80

VIII. Figures $1-20$. . . . . . . . . . . . . . 84

IX. Tables 1-46 ................... 104

X. References ................... 161 
1. Mesolimbic and Nigrostriatal Dopamine Pathways . . 84

2. Opiate Receptor Subtypes

Prototypical Agonists, Antagonists and Mixed

Agonist-Antagonists ........... . 85

3. Chemical Structures of Morphine and its

Antagonists ................ . 86

4. Chemical Structures of Benzomorphans . . . . . . 87

5. Opiate Receptor Subtypes

Antinociceptive Activity - Behavioral Excitation

Activity in Mice .............. 88

6. Effects of Apomorphine on Locomotor Activity . . . 89

7. Effects of Morphine on Locomotor Activity . . . . . 90

8. Effects of Naloxone on Locomotor Activity . . . . . 91

9. Effects of Naltrexone on Locomotor Activity . . . . 92

10. Effects of Ethylketocyclazocine on Locomotor

Activity ................. 93

11. Effects of Pentazocine on Locomotor Activity . . . 94

12. Effects of Cyclazocine on Locomotor Activity . . . 95

13. Effects of SKF 10,047 on Locomotor Activity . . . . 96

14. Effects of Acute Haloperidol Administration

72 Hours Prior to Apomorphine on Locomotor Activity . 97

15. Effects of Chronic Haloperidol Administration

72 Hours Prior to Apomorphine on Locomotor Activity . 98

16. Effects of Chronic Simultaneous Administration of Morphine and Haloperidol on Apomorphine-Induced

Stereotyped Behavior .. . . . . . . . . 99

17. Effects of Chronic Simultaneous Administration of Naltrexone and Haloperidol on Apomorphine-Induced Stereotyped Behavior ............. 100 
No.

18. Effects of Chronic Simultaneous Administration of Ethylketocyclazocine and Haloperidol on Apomorphine-Induced Stereotyped Behavior . . . . 101

19. Effects of Chronic Simultaneous Administration of Cyclazocine and Haloperidol on ApomorphineInduced Stereotyped Behavior . . . . . . . . . 102

20. Effects of Chronic Simultaneous Administration of SKF 10,047 and Haloperidol on ApomorphineInduced Stereotyped Behavior .......... 103 


\section{List of Tables}

\begin{tabular}{|c|c|c|c|c|}
\hline o. & & & & Page \\
\hline $1 ., 1 a$ & Effects of Apomorphine on Locomotor Activity & . & . & 104 \\
\hline 2. & Apomorphine-Induced Stereotyped Behavior in Mic & e & $\cdot$ & 06 \\
\hline 3. & Apomorphine-Induced Climbing Behavior in Mice & - & • & 07 \\
\hline $4 ., 4 a$. & Effects of Morphine on Locomotor Activity & - & • & 08 \\
\hline $5 ., 5 a$ & Effects of Morphine on Locomotor Activity & - & • & \\
\hline $6 ., 6 a$. & Effects of Naloxone on Locomotor Activity & $\cdot$ & $\cdot$ & 2 \\
\hline 7., 7a. & Effects of Naltrexone on Locomotor Activity & • & • & \\
\hline 8., 8a. & $\begin{array}{l}\text { Effects of Ethylketocyclazocine on Locomotor } \\
\text { Activity . . . . . . . . . . . . . . }\end{array}$ & & . & 6 \\
\hline 9., 9a. & Effects of Pentazocine on Locomotor Activity & - & · & 8 \\
\hline $0 ., 10 \mathrm{a}$ & Effects of Cyclazocine on Locomotor Activity & . & . & \\
\hline $1 ., 11 \mathrm{a}$. & Effects of SKF 10,047 on Locomotor Activity & . & • & \\
\hline 12 . & $\begin{array}{l}\text { Effects of Acute Administration of Opiate } \\
\text { Agonists, Antagonists and Mixed Agonist-Antagon } \\
\text { on Apomorphine-Induced Climbing in Mice. . . }\end{array}$ & & . & \\
\hline 13. & $\begin{array}{l}\text { Effects of SKF } 10,047 \text { and EKC on Apomorphine- } \\
\text { Induced Stereotypy } . . \\
\end{array}$ & & & \\
\hline $14 ., 14 a$. & $\begin{array}{l}\text { Effects of Acute Haloperidol Treatment on Apomor } \\
(0.4 \mathrm{mg} / \mathrm{kg}) \text {-Induced Locomotor Activity } . .\end{array}$ & & & \\
\hline 15. & $\begin{array}{l}\text { Apomorphine-Induced Stereotyped Behavior Effects } \\
\text { of Haloperidol }(1.25 \mathrm{mg} / \mathrm{kg}) 72 \text { Hours Pretreatmer }\end{array}$ & & & \\
\hline 16. & $\begin{array}{l}\text { Haloperidol-Induced Supersensitivity in the Clin } \\
\text { Mice Assay } . . \\
\end{array}$ & nbir & & 1 \\
\hline & $\begin{array}{l}\text { Climbing Mice Supersensitivity } \\
\text { Simultaneous Administration of Vehicle and Opiat } \\
\text { Agonists, Antagonists and Mixed Agonist-Antagoni }\end{array}$ & & & \\
\hline
\end{tabular}


18. Climbing Mice Supersensitivity

Simultaneous Administration of Haloperidol and Opiate Agonists, Antagonists and Mixed Agonist-Antagonists ............. 131

19. Climbing Mice Supersensitivity

Simultaneous Administration of Haloperidol

and Naloxone.............. 132

20. Climbing Mice Supersensitivity

Simultaneous Administration of Haloperidol

and Naltrexone ............ 133

21. Climbing Mice Supersensitivity

Simultaneous Administration of Haloperidol

and EKC ................. 134

22. Climbing Mice Supersensitivity

Simultaneous Administration of Haloperidol

and Pentazocine ................. 135

23. Climbing Mice Supersensitivity

Simultaneous Administration of Haloperidol

and Cyclazocine ................ 136

24. Climbing Mice Supersensitivity

Simultaneous Administration of Haloperidol

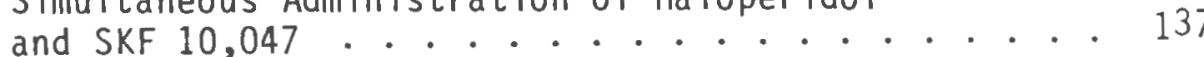

25., 25a. Effects of Chronic Haloperidol Treatment on Apomorphine $(0.4 \mathrm{mg} / \mathrm{kg})$-Induced Locomotor

Activity ................. . . 138

26. Apomorphine-Induced Stereotyped Behavior Effects of 5-Day Administration of Morphine $(10 \mathrm{mg} / \mathrm{kg} \mathrm{sc})$ and Haloperidol $(1.25 \mathrm{mg} / \mathrm{kg} \mathrm{ip}) . . .140$

27. Apomorphine-Induced Stereotyped Behavior Effects of 5-Day Administration of Naltrexone

$(40 \mathrm{mg} / \mathrm{kg} \mathrm{sC})$ and Haloperidol $(1.25 \mathrm{mg} / \mathrm{kg} \mathrm{ip}) . . . .141$

28. Apomorphine-Induced Stereotyped Behavior Effects of 5-Day Administration of EKC $(20 \mathrm{mg} / \mathrm{kg} \mathrm{sC})$ and Haloperidol $(1.25 \mathrm{mg} / \mathrm{kg}$ ip $) .. .142$

29. Apomorphine-Induced Stereotyped Behavior Effects of 5-Day Administration of Cyclazocine $(2.5 \mathrm{mg} / \mathrm{kg} \mathrm{sc})$ and Haloperidol $(1.25 \mathrm{mg} / \mathrm{kg} \mathrm{ip}) . .143$ 
Apomorphine-Induced Stereotyped Behavior Effects of 5-Day Administration of SKF 10,047

(40 mg/kg sc) and Haloperidol (1.25 mg/kg ip).... 144

31. Climbing Mice Supersensitivity

Chronic Simultaneous Administration of Morphine and Haloperidol ................ 145

32. Climbing Mice Supersensitivity Chronic Simultaneous Administration of Naloxone and Haloperidol . . . . . . . . . . . 146

33. Climbing Mice Supersensitivity Chronic Simultaneous Administration of Naltrexone and Haloperidol ............. 147

34. Climbing Mice Supersensitivity Chronic Simultaneous Administration of EKC and Haloperidol . . . . . . . . . . 148

35. Climbing Mice Supersensitivity Chronic Simultaneous Administration of Pentazocine and $\mathrm{Haloperidol}$

36. Climbing Mice Supersensitivity Chronic Simultaneous Administration of Cyclazocine and Haloperidol . . . . . . . . . . 150

37. Climbing Mice Supersensitivity Chronic Simultaneous Administration of SKF 10,047 and Haloperido

38. The Effects of Naloxone on Apomorphine-Induced Climbing Behavior .............. 152

39. The Effects of Ethylketocyclazocine on ApomorphineInduced $\mathrm{Cl}$ imbing Behavior . . . . . . . . . 153

40. The Effects of SKF 10,047 on Apomorphine-Induced Climbing Behavior .............. 154

41. Induction of Hyperactivity in Mice by Ethylketocyclazocine at $5 \mathrm{mg} / \mathrm{kg} \mathrm{sc} \mathrm{.......} 155$

42. Ethylketocyclazocine-Induced Hyperactivity in Mice. 156

43. Ethylketocyclazocine-Induced Hyperactivity in Mice: Effects of Various Blocking Agents . . . . . . . 157 
44.

Induction of $\mathrm{Climbing}$ Behavior in Mice by SKF 10,047 at $40 \mathrm{mg} / \mathrm{kg} \mathrm{SC}$.......... 158

45 . SKF 10,047-Induced Climbing in Mice . . . . . . 159

46. SKF 10,047-Induced Climbing in Mice: Effects of Various Blocking Agents 160 


\section{GENERAL INTRODUCTION}

Schizophrenia is a psychosis which is characterized by disordered thinking and emotions while often accompanied by delusions and auditory hallucinations. The schizophrenic fluctuates rapidly between contradictory affects, thoughts and actions (Bleuler, 1950). The original theory of schizophrenia was the dopamine hypothesis which states that schizophrenia is related to dopamine hyperactivity in the central nervous system. This theory was based on the fact that phenothiazines and butyrophenones which have effective antipsychotic and tranquilizing effects in the clinic, are dopamine-receptor blockers (Carlsson and Linquist, 1963). Furthermore, amphetamine, which releases norepinephrine and dopamine and blocks catecholamine reuptake, can elicit psychotic symptoms in chronic schizophrenics (Janowsky and Davis, 1974) and also produces a paranoid psychosis in normal individuals which closely resembles paranoid schizophrenia (Angrist and Gershon, 1970).

In recent years, experimental evidence in man and animals has shown that there is more to schizophrenia than simply an excess of dopamine activity. Studies of the neuroanatomy and physiology of the brain have revealed the dopamine system to be regulated by its own feedback mechanisms as well as by more complex interactions between this system and other neurotransmitters and neuromodulators. Recent1y, it was suggested that dopaminergic instability in psychosis may develop from an excess amount of feedback and modulation (King et al., 1982). 
An inherent problem with chronic neuroleptic treatment in the clinic and in animal experimentation is that it leads to dopamine receptor supersensitivity, manifest as extrapyramidal side effects and tardive dyskinesias in man and enhanced responsiveness to dopamine and its analogues in animals. Many strategies have been employed in an attempt to enhance the efficacy of neuroleptic therapy while minimizing side effect liability and, in particular, the development of dopaminergic supersensitivity. Of particular interest are the reports that combined administration of antipsychotics and lithium (Gallager et al., 1978; Pert et al., 1978; Verimer et al., 1980; Seeger et al., 1981), L-dopa and other dopamine agonists (Friedhoff et al., 1977; Ezrin-Waters and Seeman, 1978; Christensen and Nielsen, 1979; List and Seeman, 1979; Seeger et al., 1981; Reches et al., 1982) and naloxone (Seeger et al., 1980) have attenuated dopaminergic supersensitivity to varying degrees.

It is possible that schizophrenia is not only associated with the dopaminergic system but may also be influenced by the opiate system. There are many dynamic interrelationships both functionally and anatomically between the dopaminergic and opiate systems (Lal, 1975). Although the endorphinergic system may not play a primary role in the etiology of schizophrenia, the opiate receptor-antagonist naloxone has no deleterious effect and may possibly improve some symptoms of this disease in the clinic (Verebey et al., 1978; Watson et al., 1978; Pickar et al., 1982; Lo et al., 1983; Blum et al., 1984). Van Ree and De Wied (1981) proposed that dopamine overactivity or imbalance in schizophrenia may be linked to a disturbance in endorphinergic 
homeostasis. Moreover, extrapyramidal movement disorders may be associated with either increases or decreases in endogenous opioid activity (Sandyk, 1985). If psychosis is a result of an instability of both dopamine and endogenous opiate systems, it is of interest to investigate the effects of combined treatment of haloperidol and various opiate receptor subtype agents, namely, mu, kappa and sigma (Martin et al., 1976) on the development of dopaminergic supersensitivity. The results of the studies in this dissertation may be relevant for the clinical treatment of schizophrenia, i.e., the amelioration of psychotic symptoms and side effects, as well as a better understanding of the nature of the interactions of dopamine and opiate systems in the development of dopaminergic supersensitivity. 


\section{INTRODUCTION - LITERATURE SURVEY}

A. The Nigrostriatal and Mesolimbic Dopamine Pathways

The major pathways of dopaminergic neurons in the central nervous system, namely, the nigrostriatal, mesolimbic and tuberoinfundibular systems, were originally mapped by histofluorescence and anterograde or retrograde degeneration techniques (Anden et al., 1965; Ungerstedt, 1971). In the study of schizophrenia, the nigrostriatal and mesolimbic areas appear to be primarily responsible for the extrapyramidal effects and the antipsychotic effects, respectively (Costall and Naylor, 1976; Crow et al., 1977).

1. The Nigrostriatal System (Figure 1)

Anatomical and histochemical studies have shown that the nigrostriatal dopaminergic cell bodies originate in the $A 9$ DA cell group in the zona compacta of the substantia nigra and its rostromedial extension in the ventral tegmental area, ascend adjacent to the lateral hypothalamus and terminate in the neostriatum or corpus striatum, i.e., the caudate nucleus and putamen (Anden et al., 1966; Ungerstedt, 1971; Cooper et al., 1978). Also, the axons from the A8 DA cell bodies caudal to the substantia nigra join the nigrostriatal system since they show retrograde degeneration after lesions of the corpus striatum (Ungerstedt, 1971). 
2. The Mesolimbic System (Figure 1)

Cell bodies in this pathway originate in the AlO cell group dorsocranial to the interpenducular nucleus of the ventral tegmental region and ascend closely but more medially with the axons of the nigrostriatal system and terminate in the nucleus accumbens, the olfactory tubercle and the prefrontal cortical area (Anden et al., 1966; Ungerstedt, 1971; Cooper et al., 1978).

B. Functional Differentiation: Mesolimbic vs. Striatal

In recent years, a generalized approach to antipsychotic effectiveness has been based on the relative effects of dopamine antagonists on the nigrostriatal and mesolimbic areas. Many of the extrapyramidal effects of neuroleptic treatment may be mediated by the effects in the basal ganglia, namely, the caudate, putamen and globus pallidus, while the antipsychotic effects may be mediated by the antidopaminergic effects in the mesolimbic and mesocortical areas. Although it is an oversimplification to state that psychosis is due to dopamine overactivity in a particular brain region such as the mesolimbic system, much research has been generated in an attempt to qualify and quantify the activity and adaptation of mesolimbic and striatal areas to dopaminergic agents.

In general, animal studies have followed two approaches: effects following either intracerebrally or extracerebrally-administered drugs. Dopamine appears to function as a mediator of various motor activities, in particular, locomotor and stereotyped 
behavior. Pijnenburg and Van Rossum (1973) originally discovered that dopaminergic mechanisms within the nucleus accumbens regulate locomotor activity. Bilateral injection of dopamine $(5 \mu \mathrm{g})$ into the nucleus accumbens of nialamide- (a monoamine oxidase inhibitor) pretreated rats resulted in a significant increase in locomotor activity compared to saline controls while noradrenaline- (5 $\mu \mathrm{g})$ treated rats showed a slight enhancement of locomotion. On the other hand, bilateral injection of dopamine (25-100 $\mu \mathrm{g})$ into the caudateputamen of nialamide-pretreated rats elicited strong stereotypy, especially chewing, biting and licking, whereas lower doses (6.25, $12.5 \mathrm{\mu g}$ ) showed less intense behavior characterized by repetitive head and front limb movement and some chewing and biting (Costall et al., 1974). Furthermore, noradrenaline $(100 \mu \mathrm{g})$ did not show hyperactivity or stereotypy in this paradigm.

Further investigations revealed subtle functional differences between structures within the mesolimbic and striatal regions. Costall and Naylor (1975) showed that bilateral injection of dopamine $(1-200 \mu \mathrm{g})$ into the nucleus accumbens septi increased locomotor activity and caused stereotyped sniffing behavior while injections into the olfactory tubercle produced periodic hyperactivity but no stereotypy. Following pretreatment with nialamide, these effects were enhanced and biting and gnawing were observed in the olfactory tubercle-injected group. In addition, although there is a structural resemblance between the hydroxyl and nitrogen substituents of the dopamine agonist apomorphine and dopamine itself, apomorphine, which induced stereotyped biting following direct injection into the 
caudate-putamen (Ernst and Smelick, 1966), did not induce hyperactivity or stereotypy following intraccumbens injection (Pijnenberg et al., 1976; Costall et al., 1977). These results suggested differential dopaminergic mediation of stereotyped responses emanating from the nucleus accumbens versus the caudate putamen.

Additional evidence for predominant dopamine receptor mediation of hyperactivity and stereotyped behavior in the nucleus accumbens and caudate-putamen (respectively) was reported by Costall et al. (1977). Intracerebral dopamine $(6.25-50 \mu \mathrm{g})$ dose dependently increased these behaviors in their respective areas while intraperitoneal injections of haloperidol $(0.2-0.8 \mathrm{mg} / \mathrm{kg})$ blocked these effects and $10 \mathrm{mg} / \mathrm{kg}$ of either aceperone (an alpha-adrenergic antagonist) or propranolol (a beta-adrenergic antagonist) had no effect. Interestingly, intraaccumbens injections of alpha- and/or beta-adrenergic receptor agonists such as adrenaline, noradrenaline, which augments dopamine release (Reisine et al., 1982), and isoprenaline were potent inducers of hyperactivity but to a lesser extent than dopamine (Costall et al., 1976; Vance and Blumberg, 1983) and were inhibited only by intracerebral injection of the dopamine antagonist fluphenazine and not by either the alpha antagonist, piperoxan, or the beta antagonist, propranolol (Costall et al., 1976). It was concluded that hyperactivity mediated by the nucleus accumbens may not be specific for dopamine agonists; however, this behavior is specifically antagonized by dopamine blockade. 
A copious amount of data related to mesolimbic versus striatal functioning has been generated by extracerebral administration of dopaminergic agents. Since metabolic breakdown and inability to penetrate the blood-brain barrier prevents systemic administration of endogenous amines, dopamine agonists and releasers such as apomorphine and amphetamine, respectively, serve as classical drugs in animal research.

Following systemic administration, apomorphine and amphetamine induced a series of behavioral effects characterized by stereotypy and hyperactivity (Randrup and Munkvad, 1967; Costall and Naylor, 1977; Ljungberg and Ungerstedt, 1978). Drug interaction experiments were employed to ascertain the relative importance of endogenous amines in amphetamine-induced locomotor activity and stereotyped behaviors. The tyrosine-hydroxalase inhibitor, alphamethyl-p-tyrosine, depletes brain noradrenaline and dopamine through synthesis inhibition and antagonizes amphetamine behavioral responses (Weissman et al., 1966; Stolz and Rech, 1970). However, if noradrenaline is selectively depleted by dopamine-betahydroxylase inhibitors, there is little or no effect on amphetamineinduced hyperactivity or stereotypy (Scheel-Kruger and Randrup, 1967; Thornburg and Moore, 1973). Furthermore, following either systemic or intraaccumbens (but not intracaudate) injection, dopamine antagonists were more efficacious than noradrenaline antagonists in blocking amphetamine-induced locomotor activity in rodents (Rolinski and Scheel-Kruger, 1973; Pijnenburg et al., 1974). Also, systemic administration of neuroleptics dose-dependently 
antagonized intraaccumbens dopamine-induced hyperactivity (Costall and Naylor, 1976). In addition to antagonizing amphetamine and dopamine effects, dopamine antagonists have been shown to inhibit apomorphine-induced locomotion and gnawing (Ljungberg and Ungerstedt, 1978).

Although drug interaction experiments have provided valuable information concerning dopaminergic involvement in locomotion and stereotypy, lesioning techniques have been used to further delineate the brain areas which are functionally significant in the manifestation of these drug-induced behaviors. Basically, striatal or mesolimbic structures are destroyed by either electrolesions or 6-hydroxydopamine (6-OHDA), a chemical analog of the catecholamines which selectively destroys dopaminergic and noradrenergic nerve fibers (Uretsky and Iversen, 1970). Interpretation of lesioning studies must be guarded because varying the size of a lesion in particular areas may yield diverse results as well as varying amounts of depletion of dopamine and norepinephrine.

There is much evidence that dopaminergic neurons in the corpus striatum mediate amphetamine-induced stereotypy. Bilateral electrolytic lesions of the caudate (Divac, 1972; Fog, 1972) or globus pallidus (Costall and Naylor, 1975) and 6-OHDA lesions of either the caudate (Asher and Aghajanian, 1974; Creese and Iversen, 1974; Kelley et al., 1975), the globus pallidus (Costall and Naylor, 1977) or the substantia nigra (Creese and Iversen, 1972; 1973) all attentuate amphetamine stereotypy. On the other hand, both electrolesions and 6-OHDA lesions of the nucleus accumbens (Asher and 
Aghananian, 1974; Kelley et al., 1975; Costall et al., 1979) and 01 factory tubercle (Asher and Aghajanian, 1974; Costall and Naylor, 1977) had no effect on the intense forms of amphetamine stereotypy, i.e., biting, gnawing, while slightly attenuating the sniffing component of this behavior. These studies suggested a striatal mediation of amphetamine-stereotyped behavior with little or no involvement of mesolimbic structures.

The functional integrity of the mesolimbic system was essential for the expression of amphetamine hyperactivity. Both electrolytic and 6-OHDA lesions of the nucleus accumbens effectively reduced amphetamine-induced hyperactivity (Iversen et al., 1975; Kelley et al., 1975; Costall et al., 1979). By contrast, striatal lesions had little or no effect on this behavior. Electrolesions of the substantia nigra and caudate, as well as 6-OHDA lesions of the caudate, did not effect amphetamine hyperactivity (Costall and Naylor, 1973; Kelley et al., 1975; Costall et al., 1979). However, 6-OHDA lesions of the substantia nigra yielded apparently confusing results in that some groups reported no effect (Creese and Iversen, 1972; Brook and Iversen, 1975) while others found a reduction in amphetamine hyperactivity (Creese and Iversen, 1975; Roberts et al., 1975). The reduction of activity was most likely due to a dopaminergic disruption in the mesolimbic system since intranigral 6-OHDA not only reduced nigrostriatal dopamine but also mesolimbic dopamine due to the probable diffusion of drug into the Al0 area following injection into the $A 9$ cells, two areas of close proximity (Kelley et a1., 1975; Costall and Naylor, 1977). 
The interpretation of apomorphine-induced behaviors differs from amphetamine behaviors due to the difference in physiological responses to these drugs. Amphetamine acts presynaptically to release catecholamines and block reuptake, whereas apomorphine acts directly as an agonist at postsynaptic dopamine receptors (Ernst, 1967). 6-OHDA lesions in the nigrostriatal system may result in an enhanced or "supersensitive" response to low intensity stereotypy, i.e., sniffing but not biting induced by peripherally-administered apomorphine, although contradictory findings have been reported. 6OHDA lesions of the caudate nucleus and substantia nigra resulted in an enhanced apomorphine-induced stereotyped behavior due to a supersensitivity of remaining intact dopamine receptors (Creese and Iversen, 1975; Kelley et a1., 1975). On the other hand, 6-OHDA or electrolesions of the caudate have been reported to have no effect on apomorphine-induced stereotypy (Divac, 1972; Costall and Naylor, 1973; 1977; Asher and Aghajanian, 1974) while lesions of the substantia nigra actually reduced this behavior (Baum et al., 1971; Costall et a1., 1972; Loew and Vigouret, 1975). Also, both electrolytic and 6-OHDA lesions of the globus pallidus markedly reduced apomorphine stereotypy (Costall and Naylor, 1975; 1977; Loew and vigouret, 1975). However, when 6-OHDA was administered intraventricuarly to neonatal rats, a greater destruction of the nigrostriatal pathway resulted in an enhanced responsiveness to apomorphineinduced locomotor activity and stereotypy while amphetamine responses were abolished (Creese and Iversen, 1973). These results suggested a supersensitivity to remaining intact dopamine receptors. 
Experiments involving apomorphine-induced hyperactivity following peripheral administration are even more debatable. Some investigators have reported hyperactivity following apomorphine administration (Maj et a1., 1972; Iversen et al., 1975) while others showed no marked increase in locomotor activity (Costall and Naylor, 1977). Differences in the equipment used to measure hyperactivity, i.e., photocell chambers vs. electromechanical sensors, may yield conflicting results. Additionally, apomorphine has narrow doseresponse and time-course "windows" for differentiating between locomotor vs. stereotyped behavior where stereotypy becomes the predominant apomorphine-induced behavior at higher dose levels.

6-OHDA lesions of the nucleus accumbens (Iversen et a)., 1975; Kelley et al., 1975) and olfactory tubercle (Costall and Naylor, 1977 ) enhanced locomotor activity following apomorphine administration. However, Kelley et al. (1975) reported that intraaccumbens lesions resulted in a significant reduction in dopamine levels in the olfactory tubercle. Furthermore, following a more selective intraaccumbens lesion, Costall and Naylor (1977) reported no change in apomorphine-induced hyperactivity. And lastly, whereas direct injection of apomorphine into the nucleus accumbens failed to initiate hyperactivity (Pijnenberg et al., 1976), direct injection into the olfactory tubercle increased locomotor activity in rats (Pijnenberg et al., 1976; Costall and Naylor, 1977). Therefore, apomorphine-induced hyperactivity depends upon the integrity of at least the olfactory tubercle and probably to some extent an intact nucleus accumbens within the mesolimbic system. 
An alternative means for measuring apomorphine effects is the climbing mouse assay. Peripheral administration of apomorphine initiated rearing and cage climbing in mice (Hester et a1., 1970; Costentin et a1., 1975; Protais et al., 1976; Costall et al., 1978). This behavior is specific for apomorphine since other dopamine agonists such as d-amphetamine, piribedil, amatadine and L-dopa do not induce climbing behavior (Protais et al., 1976; Nohria, 1983). Apomorphine-induced climbing is mediated by dopaminergic receptors since this behavior is specifically antagonized by neuroleptics (Protais et al., 1976; Costall et al., 1978) and GABA agonists (Dunn et al., 1980) but not by alpha- or beta-adrenergic antagonists (Costall et a1., 1978).

Lesions of mesolimbic and striatal areas have generated conflicting results. Costall and associates (1979) showed that electrolytic lesions of the nucleus accumbens attenuated apomorphineinduced climbing while Protais et al. (1976) showed no effect with the same lesion (although the extent of these lesions may have differed). In contrast, intraaccumbens 6-OHDA which decreased dopamine in the nucleus accumbens and olfactory tubercle, enhanced apomorphine climbing, probably due to a supersensitive response at intact dopamine receptors in these areas (Costall et al., 1979b; 1980). Similar disagreements between these investigators were observed following lesions of the striatum. Electrolytic striatal lesions either decreased (Protais et al., 1976) or had no effect (Costall et al., 1979) on apomorphine-induced climbing while intrastriatal 6-OHDA either enhanced this behavior (Protais et al., 
1976) or had no effect (Costall et al., 1979b; 1980). Furthermore, spontaneous climbing behavior, like spontaneous locomotor activity, is reduced by either low doses of apomorphine (less than or equal to $0.1 \mathrm{mg} / \mathrm{kg}$ ) which act via presynaptic autoreceptors to decrease dopamine release (Strombom, 1975; DiChiara et al., 1976; Costall et a1., 1982) or by electrolesions of the caudate-putamen, nucleus accumbens or olfactory tubercle (Costall et al., 1982). Most probably, climbing behavior is modulated through mesolimbic as well as striatal dopaminergic neurons.

C. Dopaminergic Supersensitivity

Dopaminergic supersensitivity (DA-SS), i.e., enhanced responsiveness to dopamine or its analogues, is a well-established biochemical and pharmacological phenomenon following either chronic neuroleptic treatment or lesioning of dopaminergic nerve tracts (for reviews, see Owen, 1980; Rupniak et a1., 1983). In man, chronic blockade of dopamine receptors in patients treated with classical neuroleptics may lead to the appearance of tardive dyskinesias (Klawans and Rubovits, 1972). Tardive dyskinesias, believed to be the result of overactive dopaminergic systems, are characterized by stereotyped, repetitive and involuntary movements of the mouth, lips and tongue, occasionally accompanied by choreiform movements of the limbs and trunk (Burki, 1979b). Various biochemical and behavioral animal models have proved to be predictive of an antipsychotic's liability for producing DA-SS. 
Biochemical indices for DA-SS include receptor binding studies and the measurement of dopamine metabolites. Chronic neuroleptic treatment results in an increase in striatal dopamine receptor populations (Bmax) labelled by the tritiated dopamine antagonists $3 \mathrm{H}-$ haloperidol and $3 \mathrm{H}$-spiperone in rats (Burt et al., 1977; Hitri et a1., 1978; Theodorou et al., 1981) and by $3 \mathrm{H}$-pimozide in mice (Schwartz et al., 1978). However, changes in affinity (KD) for the dopamine receptor was controversial (probably due to differing methodologies) with a reported no change (Burt et al., 1977), decrease (Schwartz et al., 1978; Theodorou et al., 1981) and increase (Hitri et al., 1978). Also, some investigators have reported either no effect (Hitri et al., 1978) or increases (Theodorou et al., 1981; Hall et al., 1983) in mesolimbic dopamine receptor populations following chronic neuroleptic treatment. Likewise, 6-OHDA lesions of the nigrostriatal (Creese et al., 1977; Goldstein et al., 1980) and mesolimbic (Goldstein et al., 1980) systems resulted in increases of dopamine receptors in these regions.

Increase in dopamine receptor population following chronic antipsychotic treatment is directly related to compensatory changes in dopamine synthesis and release. The major indices of dopamine turnover are its principle metabolites, 4-hydroxy-3-methoxyphenylacetic acid (HVA) and 3,4-dihydroxyphenylacetic acid (DOPAC), indicative of extraneuronal enzymatic degradation by catechol-0-methyl transferase and intraneuronal metabolism by monoamine oxidase, respectively (Roffler-Tarlov et al., 1971). Acute neuroleptic administration produced a biphasic effect in metabolite levels where initial in- 
creases in striatal HVA and DOPAC levels are followed by a return to control levels at 2 to 3 days and then an eventual decrease in metabolic concentrations (Hyttel, 1977; Martres et a1., 1977). In addition, 72 hours after the administration of $4 \mathrm{mg} / \mathrm{kg}$ haloperidol, there was an increased ability of apomorphine to lower HVA levels (Martres et al., 1977).

Chronic haloperidol treatment resulted in tolerance to striatal dopamine turnover as reflected by an attenuation of the large increases in HVA and DOPAC levels seen following acute treatment (Lerner et al., 1977; Burki, 1979a; Meller et al., 1980; Nicolaou, 1980; Melamed et al., 1983). However, 7 days after chronic haloperidol treatment, apomorphine still showed an increased ability to lower HVA levels (Smith et al., 1977) similar to acute treatment (Martres et al., 1977). These metabolic effects following acute and chronic haloperidol treatment have also been observed in mesolimbic areas, i.e., nucleus accumbens and olfactory tubercle (Matsumoto et a1., 1983). Although, neuroleptic treatment enhances dopamine turnover, it appears that dopamine concentration remains the same due to corresponding increases in the rates of synthesis and release (Melamed et al., 1983); however, decreases in dopamine concentrations have also been reported (Hyttel, 1975).

The increase in dopamine turnover following acute neuroleptic administration is attributable to a blockade of presynaptic autoreceptors which regulate dopamine release and/or postsynaptic receptor blockade as well as negative feedback mechanisms or loops (Snyder et al., 1974; Iversen et al., 1976). Tolerance following 
chronic neuroleptic treatment may be due to adaptational processes at neuroleptic sites which result from an incomplete blockade of the increased number of dopamine receptors, decreased negative feedback and effects on tyrosine hydroxylase kinetics (Lerner et al., 1977; Meller et al., 1980; Melamed et al., 1983).

The findings and conclusions of these metabolic studies were further substantiated by electrophysiological studies. Following acute neuroleptic administration, extracellular recordings of neuronal activity in the A9 (substantia nigra) and AlO (ventral tegmental area) areas of the rat brain showed an increase in both the firing rate of dopamine neurons and the number of active neurons that could be identified (Bunney et al., 1973). This increased firing rate correlates with an increase in dopamine turnover. It was postulated, similar to the metabolic studies, that this increase was due to autoreceptor blockade, postsynaptic blockade and the nigrostriatal feedback loop's attempt to maintain homeostasis. On the other hand, chronic neuroleptic treatment resulted in an almost complete absence of spontaneous firing of dopamine neurons, a silence due to the gradual development of a depolarization block (Bunney and Grace, 1978). This tonic depolarization block appeared to be mediated by the nigrostriatal feedback pathways and caused by the initial increases in the activity of dopamine neurons.

While these biochemical and electrophysiological events are occurring at the neuronal level, corresponding behavioral activities can be observed which are predictive of DA-SS. The most commonly used methods for assessing dopamine receptor hypersensitivity 
involve measurement of increased locomotor activity and stereotyped behavior following administration of dopamine agonists. As earlier described, increased locomotor activity and stereotypy following chronic neuroleptic administration would be indicative of DA-SS in mesolimbic and striatal areas, respectively.

The results of supersensitivity experiments involving locomotor activity are controversial. Animals were chronically administered neuroleptics and following withdrawal, spontaneous locomotor activity and/or dopamine agonist-induced motor activity were measured. While some investigators reported increases in spontaneous motor activity in rats or mice after termination of chronic administration of "typical" neuroleptics such as haloperidol, chlorpromazine, penfluridol and alpha-flupenthixol (Jackson et al., 1975; Von Voigtlander et al., 1975; Shakian et al., 1976; Gianutsos and Moore, 1977; Gianutsos et al., 1978; Hulperin et al., 1983), others reported no difference compared to controls (Tarsy and Baldessarini, 1974; Smith and Davis, 1976; Dunstan and Jackson, 1977; Costall and Naylor, 1978; Davis et al., 1978). Also, chronic administration of the atypical neuroleptics, clozapine and thioridazine, has either enhanced (Smith and Davis, 1976) or had no effect (Gianutsos and Moore, 1977) on spontaneous motor activity.

Equally as confusing were the results when dopamine agonists or releasers were peripherally administered following chronic neuroleptic treatment. Whereas some groups found either increased apomorphine-induced locomotion (Gianutsos and Moore, 1977; Gianutsos et al., 1978; Montanaro et al., 1982; Fayle et al., 1985) or increased 
d-amphetamine-induced locomotion (Von Voigtlander et al., 1975; Dunstan and Jackson, 1977; Gianutsos et al., 1978), others reported either no difference or slight decreases compared to controls (Sahakian et al., 1976; Smith and Davis, 1976; Dunstan and Jackson, 1977; Costall et al., 1978; Rupniak et al., 1983).

The most reliable model for studying locomotor activity involved direct injection of dopamine through cannulae into the nucleus accumbens. This procedure consistently showed increased locomotion in animals treated chronically with neuroleptics (Jackson et al., 1975; Davis et al., 1978; Moore et al., 1980; Halperin et al., 1983). Direct injection of dopamine yielded site-specific activity (mesolimbic supersensitivity) while peripheral injection of dopamine agonists results in a whole spectrum of peripheral as well as central nervous system effects which may mask or interfere with locomotor activity per se.

On the other hand, enhanced stereotyped behavior in response to systemic administration of dopamine agonists following chronic neuroleptic treatment showed a more consistent and robust effect reported by numerous laboratories (Klawans and Rubovits, 1972; Tarsy and Baldessarini, 1974; Sahakian et al., 1976; Costall et al., 1978; Gianutsos et al., 1978; Nielsen et al., 1978; Waddington and Gamble, 1980; Montanaro et al., 1982). In addition, Christensen and his associates (1976) reported DA-SS as measured by methylphenidate- and apomorphine-induced gnawing after a single administration of various neuroleptics. The high intensity components of apomorphine-induced stereotyped behavior included gnawing, licking and biting while the 
lower intensity responses included sniffing and some locomotion. Direct injection of dopamine into the striatum and in particular, the caudate putamen, after chronic neuroleptic administration also resulted in an enhanced stereotypic response compared to controls (Jackson et a1., 1975; Moore et a1., 1980; Halperin et a1., 1983).

In comparison, striatal DA-SS as measured by apomorphine-induced stereotyped behavior is a more consistent and reliable model than mesolimbic supersensitivity as measured by locomotor activity following chronic antipsychotic treatment. Direct injection of dopamine into either the striatum or nucleus accumbens proved to be reliable models for detection of striatal and mesolimbic DA-SS, respectively. However, these models are somewhat tedious and cumbersome.

DA-SS, as measured by the apomorphine-induced climbing mouse assay, has been shown to be a predictive model. Enhanced responsiveness to apomorphine as measured by climbing behavior was observed in all reported studies 48-72 hours following either acute (Costentin et a1., 1975; Protais et a1., 1976; Martres et al., 1977) or chronic (Von Voigtlander et al., 1975; Protais et al., 1976; Day and Greenblatt, 1979; Wilcox et a1., 1980) neuroleptic treatment. The climbing mouse assay appears to be particularly sensitive for measurement of DA-SS since both acute and chronic dopamine receptor blockade results in an increased dopamine receptor sensitivity whereas neither locomotor activity nor stereotyped behavior has consistently shown DA-SS after acute treatment. 
Thus, it appears that a consequence of neuroleptic treatment is the development of dopamine receptor supersensitivity as measured by various behavioral or biochemical techniques in animals and the physical manifestation of tardive dyskinesias in man. It was of interest to various laboratories to attempt to attenuate DA-SS by means of a concurrent treatment of certain compounds in combination with antipsychotics. It was demonstrated that chronic administration of either direct or indirect dopaminergic agonists such as apomorphine, L-dopa/carbidopa, amantadine and bromocriptine, in combination with haloperidol, significantly reversed the increase in ${ }^{H}$ neuroleptic binding in the striatum (Friedhoff et a1., 1977; List and Seeman, 1979; Allen et al., 1980; Reches et al., 1982), the increase in adenylate cyclase activity (Friedhoff et al., 1977) and the enhanced stereotyped activity induced by apomorphine (Christensen and Nielsen, 1979; Allen et al., 1980). It was also reported that the combination of L-dopa and haloperidol partially prevented the development of ventral tegmental intracranial selfstimulation (ICSS) supersensitivity (Seeger et al., 1981). Therefore, the administration of dopamine agonists counteracted the ability of dopamine antagonists to induce DA-SS.

In addition, chronic lithium in combination with haloperidol was reported to either attenuate (Pert et al., 1978) or have no effect (Staunton et al., 1982a) on the haloperidol-induced increase in $3 \mathrm{H}-$ spiroperidol binding, decreased the enhanced effect of apomorphineinduced stereotyped behavior (Pert et al., 1978; Staunton et al., 1982b), partially prevented the development of ventral tegmental 
ICSS supersensitivity (Seeger et al., 1981) and blocked the development of presynaptic DA-SS as measured either electrophysiologically (Gallager et al., 1978) or behaviorally by the low dose apomorphine-induced inhibition of locomotor activity (Verimer et al., 1980).

It has been demonstrated that neuroleptic-induced DA-SS can be attenuated by concomitant administration of dopamine agonists or lithium. Knowing that opiate systems share certain anatomical and functional properties with dopaminergic systems, might simultaneous treatment of an opiate agent with haloperidol be prophylactic in the development of DA-SS?

D. Opiate Receptor Subtypes

The concept of multiple opiate receptors (summarized in Figure 2 ; structures figures 3, 4) has evolved over the years from pharmacological observations of differences seen between the various analgesic agents. The landmark studies in this area were performed by Martin and his coworkers (Gilbert and Martin, 1976; Martin et al., 1976). On the basis of neurophysiological and behavioral evidence in the dog, Or. Martin postulated that there were three different opiate receptors in the central nervous system, namely, $\mu$ (mu), $\kappa$ (kappa) and o (sigma) receptors, represented by the prototype drugs, morphine, ketocyclazocine and $\mathrm{N}$ allylnormetazocine (SKF 10,047), respectively. Although there are other endogenous opiate receptors which preferentially interact with enkephalins and endorphins, namely, delta $(\delta)$ and epsilon $(\varepsilon)$ receptors; they will not be covered in this dissertation. 
The morphine syndrome $(\mu)$ was characterized by miosis, bradycardia, hypothermia and analgesia. The ketocyclazocine and ethylketocyclazocine syndrome $(k)$ was associated with pupillary constriction, decreased flexor reflexes and sedation. SKF 10,047 ( $\sigma)$ caused mydriasis, tachypnea, tachycardia and mania or "canine delirium" which was proposed to be the equivalent of psychotomimetic effects in man.

Martin's group extended these studies and observed the ability of these agents to precipitate and suppress signs of abstinence in both morphine- and cyclazocine-dependent, chronic spinal dogs. Antagonists were $1 / 20$ to $1 / 60$ as potent in precipitating abstinence in the cyclazocine-, compared to the morphine-dependent dog. It was also observed that the ketocyclazocine and cyclazocine ( $k$, o agonist; $\mu$ antagonist) precipitated abstinence syndromes were qualitatively similar to each other but different from the morphine abstinence syndrome. SKF 10,047 precipitated (suggesting antagonist activity at the $\mu$ receptor) while morphine suppressed the abstinence syndrome in morphine-dependent dogs. On the other hand, ethylketocyclazocine neither suppressed nor precipitated withdrawal in morphine-dependent dogs; however, it did suppress the cyclazocine abstinence syndrome. On the basis of these findings, ethylketocyclazocine could not be an agonist, partial agonist or competitive antagonist at the morphine receptor. It was inferred that both ethylketocyclazocine and cyclazocine must produce their agonistic action at another receptor. Furthermore, ethylketocyclazocine's actions were different from those of $\mathrm{N}$-allylnormetazocine. 
Therefore, Martin postulated the existence of 3 separate opiate receptors.

Recently, much evidence has been generated which supports this 3-receptor theory while some findings are to the contrary. In-vivo evidence obtained from antinociceptive testing in rats and mice show that when chemical agents were the nociceptive stimuli, both $\mu$ and $k$ agonists were effective (Tyers, 1980; Ward and Takemori, 1983). However, $k$-agonists were more potent against pressure nociception than against heat nociception while the converse was true for $\mu-$ agonists (Tyers, 1980; Sewell et al., 1981; Upton et al., 1982; 1983). SKF 10,047 (o agonist) had potent antinociceptive activity in chemically-induced writhing (Pasternak et al., 1981; Aceto and May, 1983) but was inactive against heat (Aceto and May, 1983) and pressure nociception (Dunn, unpublished observation).

The prototypic opiate compounds also have differential effects on locomotor activity. Morphine ( $\mu$-agonist), pentazocine ( $\kappa, \sigma-$ agonist, $\mu$-antagonist), cyclazocine ( $\kappa, \sigma$-agonist, $\mu$-antagonist) and SKF 10,047 ( $\sigma$-agonist, $\mu$-antagonist) increased locomotor activity (Rethy et a1., 1971; Holtzman and Jewett, 1972; 1973; Iwamoto, 1981) whereas ketocyclazocine and ethylketocyclazocine ( $k$-agonist, $\mu$ antagonists) decreased locomotion (Tepper and Woods, 1978; Iwamoto 1981). Naloxone and naltrexone either had no effect (Parker, 1974) or slightly decreased locomotor activity (Castellano and PuglisiAllegra, 1982). Only morphine-induced locomotion was antagonized by naloxone or naltrexone (Rethy et al., 1971; Iwamoto, 1981) while the 
other agents were insensitive to the $\mu$ antagonists (Holtzman and Jewett, 1972; 1973; Iwamoto, 1981).

Interestingly, decreased brain catecholamine levels were noted following morphine-, pentazocine- and cyclazocine-induced locomotion (Rethy et al., 1971; Holtzman and Jewett, 1972; 1973). Furthermore, the catecholamine synthesis inhibitor, alpha-methyltyrosine, blocked the increased locomotor activity induced by these compounds (Buxbaum et a1., 1973; Holtzman and Jewett, 1972; 1973). Also, spiperone $(0.03 \mathrm{mg} / \mathrm{kg})$, a postsynaptic dopamine-receptor blocker and apomorphine $(0.1 \mathrm{mg} / \mathrm{kg})$, a presynaptic dopamine inhibitor at this dose, attenuated morphine- and SKF 10,047-induced locomotor activity (Iwamoto, 1981). These results suggested that mu- and sigma-agonistinduced locomotor activity may be dependent on catecholamine transmission and, more specifically, dopaminergic transmission (antinociceptive and locomotor activity for opiate subtypes are summarized in Figure 5).

Characterization of three receptor subtypes was possible by concomitant testing of two in-vivo models. In the flurothyl-induced seizure test in rats, $\mu$ and $\sigma$ agonists raised seizure thresholds, $k$ agonists had no effect, while in the rat $Y$-maze test, the behavioral profiles of $\mu$ and $\kappa$ agonists could be differentiated from SKF 10,047 (o) and cyclazocine $(\kappa / \sigma)$ (Cowan, 1981). In drug discrimination models measuring generalization and antagonism, rat and monkey data generally support the three-receptor theory (Teal and Holtzman, 1980; Herling and Woods, 1981). Finally, cortical EEG spectral analysis has been employed as a sensitive tool to delineate 
qualitative and quantitative similarities and differences between the $\mu$, and opiate agents (Young et al., 1981).

Perhaps some of the more compelling evidence for the existence of $\mu, \kappa$ and $\sigma$ receptors can be found in the in-vitro studies. In the last few years, there has been considerable controversy concerning the $\mu, k$ and $\sigma$ receptors. The type of tissue used in the assay is of utmost importance. It has been shown that rabbit vas deferens contains $k$ receptors exclusively and does not respond to $\mu$ or $\sigma$ agonists (Oka et al., 1980). It was originally thought that the guinea pig ileum contained mainly $\mu$ receptors and the mouse vas deferens contained mainly $\mu$ and $\delta$ (delta) opiate receptors (Lord et a1., 1977). It has now been shown that ethylketocyclazocine is a pure agonist in the guinea pig ileum and mouse vas deferens and effectively antagonizes selective $\mu$ agonists in the rat vas deferens (Gillan et a1., 1981).

Receptor binding studies using CNS tissues have provided more concrete results. Initial sudies using $3_{\text {H-ethylketocyclazocine in }}$ competitive binding assays concluded there were no distinct $k$ receptors (Chang et al., 1980; Hiller and Simon, 1980). Chang et a1. (1980) suggested that $k$ agonists have agonistic activity toward $\mu$ and $\delta$ receptors whereas $\sigma$ agonists were agonists at $\sigma$ receptors and antagonists at $\mu$ receptors. In a later study, when (D-Ala $2, D-$ Leu ${ }^{5}$ ) enkephal in and morphiceptin were added in concentrations which occupied $98 \%$ of the enkephalin $(\delta)$ and morphine $(\mu)$ receptors, ${ }^{3} \mathrm{H}-$ diprenorphin binding was only partially inhibited (Chang et al., 1981). Therefore, a third binding site exhibited high affinity for 
several benzomorphan drugs (cyclazocine, ethylketocyclazocine, SKF 10,047, etc.). Wood and coworkers (1981) identified a $k$ receptor in

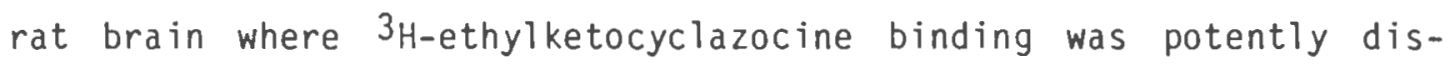
placed by $\kappa$, partial $\mu$ and agonist-antagonist analgesics while $\mu, \delta$, and $\sigma$ receptor agonists were much less active at this binding site. In a study using $3 \mathrm{H}$-cyclazocine, ${ }^{3} \mathrm{H}$-ethylketocyclazocine and ${ }^{3} \mathrm{H}-$ SKF 10,047 and various other agents, competitive displacement and kinetic analysis revealed 3 cyclazocine binding sites (in order of decreasing affinity): 1) $\mu$ receptor, 2) a non- $\mu$, non- $\sigma$ binding site (which may represent the $k$ receptor) and 3) a putative $\sigma$ receptor (Zukin and Zukin, 1981a). Other displacement studies in rat brain suggested the existence of distinct binding sites for $k$ - and $\sigma-$ opiates which differed from morphine ( $\mu$ ) and enkephalin ( $\delta$ ) binding sites (Wolozin et al., 1982). In another series of studies, it was suggested that the $\sigma$ receptor and the PCP (phencyclidine) binding site may be one in the same (Zukin and Zukin, 1981b) with the $(+)$ isomers of $\mathrm{N}$-allylnormetazocine and cyclazocine being highly specific sigma opiate/PCP ligands (Zukin et al., 1984; Mendelsohn et al., 1985; Sircar et al., 1986). This may explain why behaviorally PCP and sigma agonists produce similar psychotomimetic effects. However, other investigators have shown a distinction between sigma and PCP binding sites in mice, rat and guinea pig brains (Su, 1982; Tam, 1983; Martin et al., 1984; Gundlach, 1985; Downes et al., 1986).

Behavioral and biochemical data suggest the existence of multiple opiate receptors. Discovery and development of specific 
ligand antagonists for each receptor subtype would be beneficial in clarifying the presence, both functionally and anatomically, of specific mu, kappa and sigma receptors.

E. Similarities of Opiate and Dopaminergic Agents - Modulation of Dopaminergic Nigrostriatal and Mesolimbic Systems by Opiates

The opiate and dopaminergic systems share certain dynamic interrelationships, both functionally and anatomically, in the central nervous system and, especially in the nigrostriatal and mesolimbic systems. Functionally, both morphine and haloperidol induce catalepsy in rats which can be antagonized by apomorphine or benztropine (Lal et al., 1975). However, there was a qualitative difference in the catatonia; neuroleptic-induced catalepsy was marked by muscular hypotonia whereas hypertonia characterized narcotic-induced catatonia (Wauquier et al., 1974). Likewise, the endogenous opiates, $\beta$-endorphin, met-enkephal in and leu-enkephalin, produced sedation and catalepsy following microinjection into the periaqueductal gray in rats (Jacquet and Marks, 1976). Narcotics and neuroleptics effectively block either apomorphine or amphetamine-induced stereotypy in the rat and L-dopa and amphetamine-induced jumping in mice, as well as apomorphine-induced emesis in dogs (Lal et al., 1975). Moreover, morphine and haloperdol antagonized apomorphine-induced aggression in the rat, apomorphine- and amphetamine-induced aggression in mice and morphine withdrawal aggression in rats (Lal et al., 1975). Motivational behavior such as lateral hypothalmic self-stimulation 
in rats was also effectively blocked by haloperidol and morphine (Wauquier et al., 1974).

On the other hand, whereas opiate agonists as well as neuroleptics antagonized dopamine-dependent behaviors, opiate antagonists such as naloxone potentiated apomorphine- and amphetamine-induced behaviors. Naloxone has been reported to potentiate apomorphine-induced hyperthermia in rabbits (Quock, 1977), the anticataleptic effect of $L$-dopa in reserpinized mice (Namba et al., 1980), the antitremor effect of L-dopa in oxotremorine-treated mice (Quock and Lucas, 1983), apomorphineinduced turning in rats with unilateral electrocoagulation lesion of the substantia nigra (Quock and Welsh, 1980), apomorphine-induced climbing in mice (Quock and Lucas, 1981; Quock et a1., 1983) and apomorphine- and d-amphetamine-induced stereotypy in rats (Adams et al., 1981).

Biochemical binding techniques have shown these behaviors are probably not a result of the direct action of opiate agents on dopamine receptors since the acute administration of opiates had no effect on 3H-neuroleptic binding (Burt et al., 1976; Puri et al., 1978; Carlson and Seeger, 1981; 1982). Conversely, acute haloperidol showed competitive binding to the opiate receptor similar to an opiate agonist while other butyrophenones bind and resembled antagonists or mixed agonist-antagonists (Creese et al., 1976). Hence, opiates do not directly act as antagonists at dopamine receptor sites but neuroleptics may act at opiate receptor sites. 
These opiate receptor sites were biochemically demonstrated by $3 \mathrm{H}$-naloxone binding to be located in large amounts in rat brain with the greatest concentration in the corpus striatum (Pert and Snyder, 1973). Opiate and enkephalin receptors have been located presynaptically on dopamine neurons in the mesolimbic (Pollard et al., 1977a) and striatal (Pollard et al., 1977b) systems, respectively. In fact, the highest concentration of enkephalins was found in the globus pallidus followed by the caudate nucleus and the nucleus accumbens (Hong et a1., 1977). Furthermore, biochemical (Pollard et al., 1978) and autoradiographic techniques (Murrin et al., 1980) have shown that one-third of the striatal opiate receptors are located presynaptically on dopamine neurons while twothirds of the opiate receptors are located on intrinsic neurons with the majority of these making postsynaptic contact with dopamine neurons. Since opiate and enkephalin receptors and neurons are in close proximity and contact with dopamine neurons in the striatal and mesolimbic systems, they may serve to modulate dopaminergic transmission in these areas.

Additional evidence for opiate regulation of dopaminergic processes was reported following chronic morphine administration. Iwamoto and his associates (1973) found that following chronic morphine pellet implantation in mice, naloxone-induced withdrawal jumping behavior was accompanied by an increase in dopamine levels with the greatest elevation occurring in the corpus striatum while norepinephrine and serotonin levels remained relatively constant. Chronic morphine treatment has also led to the development of 
postsynaptic DA-SS as measured by apomorphine-induced stereotyped behavior in rats (Cox et al., 1976) and guinea pigs (Carlson and Almasi, 1978); apomorphine-induced aggression in rats (Puri and Lal, 1973; Gianutsos et al., 1974); apomorphine-induced locomotion in rats (Bhargava, 1980) and apomorphine-induced climbing in mice (Baume et al., 1979; Martin and Takemori, 1986). Also, repeated intraventricular injections of beta-endorphin in rats resulted in the development of DA-SS (Bhargava, 10s1).

Biochemically, chronic administration of morphine was similar to haloperidol in that an initial rise in HVA levels was followed by a significant decrease for several days (Baume et al., 1979). One explanation for the diminished activity of dopamine neurons was due to the increased activity of the feedback loop when the postsynaptic receptors became hypersensitive to dopamine (Martres et al., 1977). Also, apomorphine caused a greater reduction in dopamine turnover in morphine-dependent rats (Kuschinsky, 1975; Gianutoss et al., 1974; Puri et al., 1977) suggesting DA-SS and probable supersensitive presynaptic dopamine autoreceptors (Kuschinsky, 1975). Unlike haloperidol-induced DA-SS where there was an increase in dopamine receptors (Burt et al., 1977), chronic morphine treatment was reported to either decrease (Puri et al., 1978), slightly increase (Baume et al., 1979) or have no effect (Carlson and Seeger, 1982) on

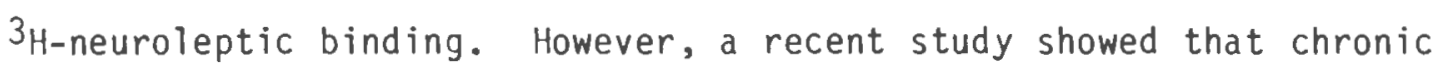
morphine administration in mice resulted in a significant increase in ${ }^{3} \mathrm{H}$-spiroperidol binding sites in whole brain (Martin and 
Takemori, 1986). Also, there may be an increase in affinity, although fewer binding sites (Puri et al., 1978; Bhargava, 1983).

It would appear that dopaminergic transmission is modulated to some extent by the opiate system, especially in the nigrostriatal and mesolimbic areas. Since morphine and haloperidol display some similar behavioral and biochemical effects with each capable of eliciting DA-SS, might dopamine metabolism be modified by mu antagonists and/or non-mu opiates in such a way to down regulate the dopamine system? Namely, since naloxone has been shown to potentiate certain dopaminergic mediated behaviors and because simultaneous administration of dopamine agonists with dopamine antagonists compensates for the development of DA-SS, would the concomitant administration of mu antagonists with the dopamine antagonist, haloperidol, attenuate DA-SS? What effects would the kappa agonist, ethylketocyclazocine or the sigma agonist, SKF 10,047 (agents which also possess mu antagonistic properties) have on the development of haloperidol-induced DA-SS? This disseration investigates these possibilities using both acute and chronic behavioral paradigms predictive of mesolimbic and striatal dopaminergic activity, namely locomotor activity and stereotyped behavior, respectively, as well as the climbing mouse model.

F. Hypotheses

The following hypotheses will be investigated concerning the mediation of the dopamine receptor by the opiate receptor subtype agents, particularly concerning the development of haloperidolinduced dopaminergic supersensitivity (DA-SS). The opiate receptor 
subtype agents specifically investigated include: the mu agonist, morphine; the mu antagonists, naloxone and naltrexone; the mixed kappa, sigma agonists and $\mathrm{mu}$ antagonists, pentazocine and cyclazocine; the kappa agonist and mu antagonist, ethylketocyclazocine; and the sigma agonist and mu antagonist, $N$ allylnormetazocine (SKF 10,047).

1. Opiates are not dopamine-receptor antagonists and therefore, will not attenuate apomorphine-induced climbing and stereotyped behaviors in mice.

2. Opiates which stimulate catecholamine neuronal activity will cause either increased locomotor activity (indicative of mesolimbic activity), stereotypy (indicative of striatal activity) or climbing behavior (indicative of mesolimbic and/or striatal activity) in mice.

3. The acute and/or chronic simultaneous administration of the opiate receptor subtype agents and haloperidol will attenuate the development of dopaminergic supersensitivity as measured by apomorphine-induced climbing and stereotyped behavior in mice. 


\section{MATERIALS AND METHODS}

For all experiments, male CD-1 albino mice (Charles River) weighing 20-30 g were used. They were group housed (20 per cage) in a room where the temperature was $22 \pm 10 \mathrm{C}$ with 1 ights on between $6 \mathrm{a} . \mathrm{m}$. and 6 p.m. Food and water were available ad libitum. All experiments were carried out between $10 \mathrm{a} . \mathrm{m}$. and $4 \mathrm{p} . \mathrm{m}$.

\section{Acute Studies.}

Following a one-hour acclimation period, compounds were administered to male mice $(C D-1)$ and tested for their effects on either locomotor activity, stereotypy or climbing behavior.

\section{Acute Supersensitivity Studies.}

Each opiate agent was simultaneously administered sc with haloperidol ip to male mice (CD-1) 72 hours before testing. Controls were given appropriate treatments. Mice were then group housed ( 9 per cage) until test day under the standard laboratory conditions detailed above.

\section{Chronic Supersensitivity Studies.}

Each opiate agent was simultaneously administered SC with haloperidol ip to male mice $(C D-1)$ for 5 days. Controls were given appropriate treatments. Mice were group housed ( 9 per cage) until test day, 72 hours after last dosing under the standard laboratory condtions detailed above.

Locomotor Activity Experiments.

Locomotor activity was measured on electromagnetic sensors (Stoelting Co. \#13404) in sound-attenuated chambers. CD-1 male mice 
were placed in opaque plastic cages (2 mice per cage) measuring 10.5" $x$ 8" $x$ 6" which rested upon each sensor. Following a one-hour adaptation or exploratory period where mice became acclimated to their cages, each animal was administered drug and testing commenced.

To measure the effects of individual opiate agents, mice were administered drug sc, then activity was assessed immediately after injection for 6 hours. To measure supersensitivity effects of acute and chronic pretreatment of haloperidol, apomorphine HCl was administered sc, then activity was measured for 2 hours. The combined activity of each pair of mice provided activity counts. The counts were recorded by a Data General Nova $2 / 10$ computer within 15-minute intervals over the first 2 hours of testing, then at hourly intervals for the remaining 4 hours during the 6-hour test. These counts were transformed into square-root values to normalize the data and to make the means and variances independent, with the resulting variances homogeneous. Control scores were compared with scores from compoundtreated subjects using a one-way analysis of variance (ANOVA) followed by a Dunnet's multiple comparison (Kirk, 1968) on a DEC (Digital Equipment Corporation) PDP $11 / 10$ computer.

\section{Apomorphine-Induced Stereotypy.}

Prior to injection, CD-1 male mice were placed in clear plastic cages (2 mice per cage) measuring $10.5^{\prime \prime} \times 8^{\prime \prime} \times 6^{\prime \prime}$ and were allowed to acclimate for 60 minutes. For antagonism studies, compounds were administered ip 30 minutes before apomorphine at $1.5 \mathrm{mg} / \mathrm{kg} \mathrm{sc}$. For acute and chronic supersensitivity studies, 72 hours following appropriate treatments (and one hour after cage acclimation), mice 
received apomorphine at $0.4 \mathrm{mg} / \mathrm{kg} \mathrm{sc}$. In both designs, mice were scored for stereotypy during 2-minute observation periods at 10,20 and 30 minutes after injection. Scores were assigned according to the following rating scale modified from Costall et al. (1972): 0 -normal behavior, mice essentially the same as before injection; 1 -locomotor activity and sniffing; 2 - discontinuous locomotor activity, rearing, intense, continuous sniffing, licking and gnawing.

Stereotypy scores were individually totaled (maximum score $=6$ per mouse over 3 readings) and tranformed into square-root values to normalize the data and to make the means and variances independent, with the resulting variances homogeneous. Control scores were compared to scores from compound-treated subjects by a one-way ANOVA followed by the Duncan's multiple range test by using a SAS (Statistical Analysis System) program on an IBM 3033 computer.

\section{Apomorphine-Induced $\mathrm{Cl}$ imbing.}

Prior to injection, $C D-1$ male mice were placed individually in wire mesh test cages measuring $4^{\prime \prime} \times 4^{\prime \prime} \times 10^{\prime \prime}$ and were allowed to acclimate for 60 minutes. For antagonism studies, compounds were administered 30 minutes before apomorphine at $1.5 \mathrm{mg} / \mathrm{kg} \mathrm{sc}$. For potentiation studies, compounds were administered prior to apomorphine at either 0.4 or $0.8 \mathrm{mg} / \mathrm{kg} \mathrm{sc}$. For acute and chronic supersensitivity studies, 72 hours following appropriate treatments (and one hour after cage acclimation), mice received apomorphine at $0.4 \mathrm{mg} / \mathrm{kg} \mathrm{sc}$. In both designs, mice were scored for climbing activity during observation periods at 10,20 and 30 minutes after injection. Scores were assigned according to the following rating scale (Protais et al., 
1976): 0 - no climbing, 4 paws on bottom of cage; 1 - rearing, 2 paws clinging to the side of the cage; 2 - full climbing, 4 paws clinging to the side or top of the cage.

Climbing scores were individually totaled (maximum score $=6$ per mouse over 3 readings) and transformed into square-root values to normalize the data and to make the means and variances independent, with the resulting variances homogeneous. Control scores were compared to scores from compound-treated subjects by a one-way ANOVA followed by the Duncan's multiple range test by using a SAS program on an IBM 3033 computer.

\section{SKF 10,047-Induced Climbing Behavior.}

Same as above for apomorphine-induced climbing where SKF 10,047 was administered SC. ED50 values with $95 \%$ confidence limits were calculated by linear regression analysis. For antagonism studies, SKF 10,047 at $40 \mathrm{mg} / \mathrm{kg}$ sc was administered 90 minutes before testing. Compounds were administered at appropriate pretreatment times.

\section{Ethylketocyclazocine-Induced Hyperactivity.}

Same as above for apomorphine-induced climbing where ethylketocyclazocine was administered SC and hyperactivity, not climbing, was measured. Hyperactivity scores were assigned according to the following rating scale: 0 - no locomotor activity, animal in resting position on the bottom of the cage; 1 - locomotion and circling, confined to the bottom of the cage; 2 - more continuous locomotion on bottom and sides of cage. For antagonism studies, ethylketocyclazocine at $5 \mathrm{mg} / \mathrm{kg} \mathrm{sc}$ was administered at 180 minutes 
before testing. Compounds were administered at appropriate pretreatment times.

Drugs.

The following drugs were used in these studies: apomorphine $\mathrm{HCl}$ (Merck), haloperidol (McNeil), alpha-methyl-para-tyrosine (Sigma), atropine (Sigma), bicuculline (Regis), clonidine $\mathrm{HCl}$ (Boehringer), cyclazocine (Sterling-Winthrop), ethylketocyclazocine (SterlingWinthrop), methylsergide (Sandoz), iuscimol (Regis), N-allylnormetazocine (NIDA), naloxone (Endo), naltrexone (Endo), pentazocine (Sterling-Winthrop), dl-p-chlorophenylalanine methyl ester $\mathrm{HCl}$ (Sigma), propranolol $\mathrm{HCl}$ (Ayerst), phentolamine $\mathrm{HCl}$ (Ciba), prazosin (Pfizer), reserpine (Aldrich), tetrabenazine (Hoffman-La Roche) and yohimbine (Sigma).

Drugs which were not water soluble were suspended in distilled water and one drop of Tween 80, i.e., haloperidol, ethylketocyclazocine, dl-p-chlorophenylalanine methyl ester, prazosin and yohimbine. Cyclazocine, N-allyl-normetazocine and pentazocine were solubilized in distilled water with the addition of one drop of lactic acid and $\mathrm{pH}$ adjusted with $0.25 \mathrm{~N} \mathrm{NaOH}$. The final volume was prepared to account for the salt content and the dosage is expressed as $100 \%$ base. The injection volume was $10 \mathrm{ml} / \mathrm{kg}$. 


\section{RESULTS}

Apomorphine-induced behaviors. Locomotor Activity. Generally, apomorphine at 1.5 and $5 \mathrm{mg} / \mathrm{kg}$ produced $\mathrm{s}$ ight but not significant increases in locomotor activity in mice over the first hour (14\% to 21\%) following subcutaneous administration with little or no effect during the second hour (Table 1, Fig. 6).

Stereotyped behavior. Apomorphine dose-dependently increased stereotyped behavior in mice at doses from $0.3 \mathrm{mg} / \mathrm{kg}$ to $3.0 \mathrm{mg} / \mathrm{kg}$ with an ED50 equal to $0.80(0.76-0.84) \mathrm{mg} / \mathrm{kg} \mathrm{sc}$ (Table 2). At the lower doses, locomotion and sniffing were prevalent while at the higher doses, discontinuous activity was marked by intense sniffing, rearing, licking and gnawing.

climbing behavior. Apomorphine at doses from 0.3 to $3.0 \mathrm{mg} / \mathrm{kg}$ produced climbing behavor in mice characterized by elongated, deliberate and sustained verticalization in the wire mesh stick cages. The ED50 value for climbing was $0.58(0.55-0.61) \mathrm{mg} / \mathrm{kg} \mathrm{sc}$ (Table 3$)$. Locomotor activity of opiate subtype agents in mice. Morphine at 2.5, 5 and $10 \mathrm{mg} / \mathrm{kg}$ produced dose-dependent increases from $23 \%$ to $41 \%$ in locomotor activity, during the first hour of testing and increases from $79 \%$ to $101 \%$ during the second hour where these increases were significant (Table 4, Fig. 7). These increases in locomotion were consistently seen at higher doses (Table 5) and would correspond to the characteristic "morphine mania" observed in rodents. In general, the mu antagonists, naloxone (Table 6, Fig. 8) and naltrexone (Table 7. Fig. 9) at doses from 10 to $40 \mathrm{mg} / \mathrm{kg}$ had no effects on locomotor activity. The kappa agonist, mu antagonist ethylketocyclazocine (EKC) 
at 5,10 and $20 \mathrm{mg} / \mathrm{kg}$ showed an interesting biphasic effect on locomotor activity in mice (Table 8, Fig. 10). At $5 \mathrm{mg} / \mathrm{kg}$, initial significant decreases in locomotion (with almost complete cessaton of activity at 30 minutes) over 75 minutes were followed by increases which peaked between three $(+46 \%)$ to four hours $(+85 \%)$. At the higher doses (10 and $20 \mathrm{mg} / \mathrm{kg}$ ), decreased activity lasted for three hours followed by increases beginning at four hours and lasting throughout the six hours of testing. The mixed kappa and sigma agonists, mu antagonists, pentazocine and cyclazocine, enhanced locomotor activity beginning at about 30 minutes for the first two to three hours of testing (Table 9, Fig. 11 and Table 10, Fig. 12, respectively). Pentazocine at doses from 20 to $80 \mathrm{mg} / \mathrm{kg}$ increased activity by $27 \%$ to $78 \%$ while cyclazocine at doses from 2.5 to $10 \mathrm{mg} / \mathrm{kg}$ augmented locomotion by $33 \%$ to $112 \%$ compared to controls. This hyperactivity was followed by slight decreases in activity at five hours for pentazocine and at four hours for cyclazocine. On the other hand, the prototype sigma agonist, SKF 10,047 at 10 to $40 \mathrm{mg} / \mathrm{kg}$ produced an increase in locomotor activity from 15 minutes through five hours (Table 11, Fig. 13). The hyperactivity ranged from $25 \%$ to $86 \%$ over control levels of locomotion.

Effects of opiate subtype agents on apomorphine-induced climbing and stereotypy. It was of interest to determine the acute effects of opiate agents on the reliable and consistent apomorphine-induced behaviors (apomorphine did not produce reliable increases in locomotion), namely climbing and stereotypy. Morphine, naloxone, naltrexone, pentazocine and cyclazocine had no effect on apomorphine 
$(1.5 \mathrm{mg} / \mathrm{kg})$-induced climbing behavior. However, EKC at $20 \mathrm{mg} / \mathrm{kg}$ and SKF 10,047 at $40 \mathrm{mg} / \mathrm{kg}$ significantly decreased the maximal climbing induced by apomorphine at $1.5 \mathrm{mg} / \mathrm{kg}$ by $52 \%$ and $25 \%$, respectively (Table 12). General depressive effects including ataxia and flaccidity were observed following EKC and SKF 10,047 administration, which may have interfered with the ability of the mice to climb. However, in both cases the lower doses of EKC and SKF 10,047, namely 5 and 10 $\mathrm{mg} / \mathrm{kg}$, respectively, had no significant effects on climbing. EKC and SKF 10,047 at the doses which were active in attenuating apomorphineinduced climbing, were then tested for their effects on apomorphineinduced stereotyped behavior. EKC at $20 \mathrm{mg} / \mathrm{kg}$ significantly attenuated apomorphine-induced stereotypy while SKF 10,047 at $40 \mathrm{mg} / \mathrm{kg}$ had no effect (Table 13).

The effect of 72-hour pretreatment of haloperidol (1.25 mg/kg) on apomorphine-induced locomotor activity. There was no significant effect of 72-hour haloperidol pretreatment on apomorphine-induced locomotor activity (Table 14, Fig. 14).

The effect of 72-hour pretreatment of haloperidol $(1.25 \mathrm{mg} / \mathrm{kg})$ on apomorphine-induced stereotypy. There was no significant effect of 72-hour haloperidol pretreatment on apomorphine-induced stereotyped behavior (Table 15).

The effect of 72-hour pretreatment of haloperidol $(1.25 \mathrm{mg} / \mathrm{kg})$ on apomorphine-induced climbing. Haloperidol 72 hours prior to apomorphine at $0.4 \mathrm{mg} / \mathrm{kg}$ sc significantly increased climbing (approximate two-fold increase) compared to vehicle controls (Table 16). 
The effects of simultaneous administration of opiate agents and haloperidol 72 hours prior to apomorphine at $0.4 \mathrm{mg} / \mathrm{kg} \mathrm{sc}$ in the climbing mouse assay. Since acute pretreatment (72 hours) of haloperidol produced an enhanced responsiveness or supersensitivity to apomorphine-induced climbing (CMA-SS), the effects of various opiate agents on this behavior was investigated. The concurrent treatment of these agents and vehicle (72 hours pretreatment) had no significant effects on apomorphine-induced climbing behavior (Table 17). However, every agent except morphine had a significant effect on attenuating the enhanced responsiveness to haloperidol pretreatment on apomorphine-induced climbing (Table 18). Simultaneous administration of haloperidol at $1.25 \mathrm{mg} / \mathrm{kg}$ and either naloxone at $20 \mathrm{mg} / \mathrm{kg}$, naltrexone at $20 \mathrm{mg} / \mathrm{kg}$, EKC at $20 \mathrm{mg} / \mathrm{kg}$, pentazocine at $80 \mathrm{mg} / \mathrm{kg}$, cyclazocine at 1.25 and $5 \mathrm{mg} / \mathrm{kg}$ or SKF 10,047 at 10 and $40 \mathrm{mg} / \mathrm{kg}$ significantly reduced CMA-SS by $44 \%, 51 \%, 56 \%, 42 \%, 53 \%$ and $64 \%$, or $54 \%$ and $75 \%$, respectively (Table 18 ).

Dose-response relationships were assessed for those agents which effectively attenuated haloperidol-induced supersensitivity (Tables 19 to 24). Generally, increasing doses of naloxone (Table 19), naltrexone (Table 20), EKC (Table 21), pentazocine (Table 22), cyclazocine (Table 23) and SKF 10,047 (Table 24) resulted in an increased suppression of haloperidol-induced supersensitivity in the climbing mouse assay whereas these agents alone did not significantly effect this behavior (Tables 19 to 24 ).

Increasing doses of naloxone ( 5 to $20 \mathrm{mg} / \mathrm{kg}$ ) in combination with haloperidol, dose-dependently decreased $(37 \%$ to $62 \%)$ the enhanced 
responsiveness to apomorphine following haloperidol pretreatment (Table 19). Likewise, naltrexone at doses from 5 to $20 \mathrm{mg} / \mathrm{kg}$ dosedependently decreased CMA-SS by $34 \%$ to $59 \%$ (Table 20). The combination of EKC with haloperidol was also effective in attenuating the enhanced responsiveness to apomorphine following haloperidol treatment alone (Table 21). Although the effects of EKC at doses from 2.5 to 20 $\mathrm{mg} / \mathrm{kg}$ were variable, significant reduction of CMA-SS was seen at 5 $\mathrm{mg} / \mathrm{kg}(-35 \%)$ and $20 \mathrm{mg} / \mathrm{kg}(-57 \%)$ without any observed overt depressive effects.

The mixed kappa and sigma agonists, pentazocine and cyclazocine each dose-dependently decreased haloperidol-induced CMA-SS although cyclazocine was more potent. Pentazocine at doses from 20 to $80 \mathrm{mg} / \mathrm{kg}$ decreased CMA-SS from $29 \%$ to $63 \%$ (Table 22 ) while cyclazocine attenuated CMA-SS at doses from 1.25 to $5 \mathrm{mg} / \mathrm{kg}$ by $32 \%$ to $55 \%$ (Table 23). The prototype sigma agonist, SKF 10,047 also effectively reduced haloperidol-induced CMA-SS by $39 \%$ to $75 \%$ at doses between 5 and 40 $\mathrm{mg} / \mathrm{kg}$ (Table 24).

The effects of chronic (5-day) haloperidol (1.25 mg/kg) administration on apomorphine-induced locomotor activity. Although there was a slight increase $(15 \%)$ in apomorphine $(0.4 \mathrm{mg} / \mathrm{kg})$-induced locomotor activity during the first hour of testing following chronic haloperidol treatment, this effect was not statistically significant (Table 25, Fig. 15). 
The effects of chronic (5-day) simultaneous administration of opiate agents and haloperidol 72 hours prior to apomorphine at $0.4 \mathrm{mg} / \mathrm{kg} \mathrm{sc}$ on stereotyped behavior. Chronic treatment of haloperidol at 1.25 $\mathrm{mg} / \mathrm{kg}$ per day for five days resulted in approximately twice the amount of stereotyped behavior following apomorphine at $0.4 \mathrm{mg} / \mathrm{kg}$, compared to vehicle-treated controls (Tables 26-30, Figs. 16-20). Chronic morphine at $10 \mathrm{mg} / \mathrm{kg}$ per day for five days also produced a significantly enhanced stereotyped response $(+117 \%$ compared to control) to apomorphine (Table 26, Fig. 16). However, when morphine was simultaneously administered with haloperidol, the enhanced effect $(+117 \%)$ was not additive and was essentially the same as the chronic haloperidol group $(+144 \%)$ and the chronic morphine-haloperidol group (+150\%, Table 25). When naltrexone at $40 \mathrm{mg} / \mathrm{kg}$ was chronically administered, it had no effect on apomorphine stereotypy compared to vehicle controls (Table 27, Fig. 17). Also, naltrexone did not attenuate haloperidol-induced enhancement of apomorphine stereotypy (Table 27, Fig. 17). Likewise, chronic EKC at $20 \mathrm{mg} / \mathrm{kg}$ either alone or in combination with haloperidol had no effect in this paradigm (Table 28, Fig. 18).

On the other hand, both chronic cyclazocine and SKF 10,047 effectively attenuated haloperidol-induced supersensitivity in the stereotypy model. Apomorphine $(0.4 \mathrm{mg} / \mathrm{kg})$-induced stereotypy was enhanced by $137 \%$ in the chronic haloperidol group and only enhanced by $58 \%$ in the cyclazocine $(2.5 \mathrm{mg} / \mathrm{kg})$-haloperidol group when compared to the vehicle control group (Table 29, Fig. 19). In comparing the mean stereotypy scores $(\bar{x}$ of veh.-haloperidol $=5.63 ; \bar{x}$ of cyclazocine- 
haloperidol $=3.75)$, there was a $33 \%$ reduction in supersensitivity which was statistically significant (Table 29). The combination of chronic SKF 10,047 at $40 \mathrm{mg} / \mathrm{kg}$ and haloperidol was most effective in significantly reducing haloperidol-induced supersensitivity by $61 \%$ to control levels (Table 30, Fig. 20).

The effects of chronic (5-day) simultaneous administration of opiate agents and haloperidol 72 hours prior to apomorphine at $0.4 \mathrm{mg} / \mathrm{kg} \mathrm{sc}$ in the climbing mouse assay. Chronic morphine at doses from 2.5 to 10 $\mathrm{mg} / \mathrm{kg}$ resulted in an enhanced responsiveness (53\% to $76 \%$ ) to apomorphine in the climbing assay although this effect was not significant (Table 31). However, when morphine was simultaneously administered with haloperidol, there was no further enhancement of apomorphine-induced climbing seen after haloperidol alone (Table 31). The concurrent administration of chronic naloxone (5 to $40 \mathrm{mg} / \mathrm{kg}$ ) and haloperidol had no effect on haloperidol-induced CMA-SS (Table 32). However, chronic naltrexone at doses from 2.5 to $40 \mathrm{mg} / \mathrm{kg}$ slightly decreased ( $11 \%$ to $46 \%$ ) haloperidol-induced CMA-SS although this effect was not statistically significant (Table 33 ).

The chronic simultaneous administration of EKC at 5 to $20 \mathrm{mg} / \mathrm{kg}$ and haloperidol resulted in a consistent (although non-significant) suppression $(40 \%$ to $49 \%$ ) in the enhanced climbing response to apomorphine seen after haloperidol alone (Table 34). Five-day administration of EKC alone had variable effects on the climbing behavior (Table 34). The mixed agonist-antagonist, pentazocine (10 to $80 \mathrm{mg} / \mathrm{kg}$ ) had no effect on haloperidol-induced CMA-SS (Table 35) while chronic cyclazocine at doses from 0.38 to $3 \mathrm{mg} / \mathrm{kg}$ significantly 
reduced (by $38 \%$ to $49 \%$ ) the enhanced responsiveness of apomorphine following chronic haloperidol to control levels (Table 36). On the other hand, chronic cyclazocine and vehicle had no effect in this paradigm (Table 36). The sigma agonist, SKF 10,047 dose-dependently attenuated haloperidol-induced CMA-SS (Table 37). At doses from 5 to $40 \mathrm{mg} / \mathrm{kg}$, haloperidol-induced CMA-SS was decreased from $33 \%$ to $76 \%$ while chronic SKF 10,047 alone had no effect on apomorphine-induced climbing behavior in this paradigm.

Acute interaction effects of apomorphine $(0.4 \mathrm{mg} / \mathrm{kg})$ and either naloxone, EKC or SKF 10,047 on climbing behavior in mice. Naloxone alone at 1,3 and $10 \mathrm{mg} / \mathrm{kg}$ did not induce climbing behavior in mice (Table 38). However, when naloxone at 3 and $10 \mathrm{mg} / \mathrm{kg}$ ip was simultaneously administered with apomorphine at $0.4 \mathrm{mg} / \mathrm{kg} \mathrm{sc}$, there was a slight potentiation in climbing from $25 \% \mathrm{climbing}$ in the apomorphine group to $46 \%$ climbing in the apomorphine-plus-naloxone group (Table 38). EKC alone at 3 and $10 \mathrm{mg} / \mathrm{kg} 180$ minutes after administration, produced hyperactivity after an initial depression unlike the prolonged stereotyped climbing seen after apomorphine (Table 39). This hyperactivity was not similar to either amphetamine or morphine hyperactivity in that the mice did not limit their locomotion to circling on the bottom of the cage as with amphetamine or exhibit the "running fit" of persistant circling accompanied by Straub tail as observed with morphine (unpublished observations). EKC-induced hyperactivity was characterized by quick, sporadic running up and down vertically in the cage and episodes of stereotypic rearing and sniffing. The combination of EKC and apomorphine resulted in a slight 
increase in climbing behavior compared to apomorphine controls (27\% climbing compared to $33 \%$ to $42 \%$ ). SKF 10,047 at $10 \mathrm{mg} / \mathrm{kg}$ induced a climbing response $(+33 \%)$ at 90 minutes resembling the deliberate and sustained stereotypic climbing seen after apomorphine alone (Table 40). Mice were initially ataxic for the first 30 minutes after administration, then followed stereotyped behavior characterized by vocalization, excessive grooming and sniffing, then rearing and finally climbing approximately 75 to 90 minutes post administration. The combination of SKF 10,047 ( 1 to $10 \mathrm{mg} / \mathrm{kg}$ ) and apomorphine produced an approximate additive climbing response compared to apomorphine controls (Table 40).

Ethylketocyclazocine-induced hyperactivity in mice. Since EKC administration produced hyperactivity after an initial decrease in locomotor activity, a time response was run over six hours to determine the duration of locomotor activity in the wire mesh stick cages. EKC was administered at $5 \mathrm{mg} / \mathrm{kg} \mathrm{sc}$ in mice. Onset of hyperactivity occurred at 120 to 150 minutes with peak activity (47\%) at 180 to 210 minutes, followed by a gradual decrease in activity to six hours (Table 41). Then EKC was administered at doses from 1.25 to $10 \mathrm{mg} / \mathrm{kg}$ and the ED50 for hyperactivity measured 180 minutes after administration was equal to $7.1 \mathrm{mg} / \mathrm{kg}$ sc (Table 42 ).

Effects of various blocking agents on EKC-induced hyperactivity. The following agents had no effect on EKC-induced hyperactivity at $5 \mathrm{mg} / \mathrm{kg}$ sc: naloxone, bicuculline, yohimbine, clonidine, propranolol, PCPA, methysergide and atropine although PCPA at $300 \mathrm{mg} / \mathrm{kg}$ antagonized the hyperactivity by $46 \%$, it was not statistically significant (Table 43 ). 
The following catecholaminergic blockers and depleters significantly an-tagonized EKC-induced hyperactivity (Table 43): haloperidol at 1 $\mathrm{mg} / \mathrm{kg}(-54 \%)$, apomorphine at $0.1 \mathrm{mg} / \mathrm{kg}(-65 \%)$, muscimol at $1 \mathrm{mg} / \mathrm{kg}$ ($63 \%)$, alpha-methyl-para-tyrosine at $300 \mathrm{mg} / \mathrm{kg}(-81 \%)$, phentolamine at $10 \mathrm{mg} / \mathrm{kg}(-47 \%)$, prazosin at $2.5 \mathrm{mg} / \mathrm{kg}(-97 \%)$, reserpine at $5 \mathrm{mg} / \mathrm{kg}(-$ $74 \%)$ and tetrabenazine at 5 and $40 \mathrm{mg} / \mathrm{kg} \quad(-81 \%$ and $-90 \%$, respectively).

SKF 10,047-induced climbing behavior in mice. As previously described, SKF 10,047-induced a climbing response similar to that of apomorphine-induced climbing. SKF 10,047 was administered at $40 \mathrm{mg} / \mathrm{kg}$ sc and climbing was measured from 30 to 180 minutes after dosing (Table 44). Onset of climbing began at 30 minutes with peak effect at 90 minutes (72\%) and then the climbing gradually waned. Then SKF 10,047 was administered at doses from 3 to $30 \mathrm{mg} / \mathrm{kg}$ and the $\mathrm{ED}_{50}$ for climbing determined 90 minutes after administration was equal to 14.6 $\mathrm{mg} / \mathrm{kg} \mathrm{sc}($ Table 45 ).

Effects of various blocking agents on SKF 10,047-induced climbing behavior. The following agents had no effect on SKF 10,047-induced climbing behavior: naloxone, bicuculline, yohimbine, clonidine, propranolol, PCPA, atropine and reserpine (Table 46). The following blockers significantly antagonized SKF 10,047-induced climbing activity (Table 46): haloperidol at $1 \mathrm{mg} / \mathrm{kg}(-73 \%)$, apomorphine at 0.1 $\mathrm{mg} / \mathrm{kg}(-64 \%)$, muscimol at $1 \mathrm{mg} / \mathrm{kg}(-89 \%)$, alpha-methyl-para-tyrosine at $300 \mathrm{mg} / \mathrm{kg}(-97 \%)$, phentolamine $(-37 \%)$ and prazosin at $2.5 \mathrm{mg} / \mathrm{kg}$ $(-90 \%)$, methysergide at $10 \mathrm{mg} / \mathrm{kg}(-66 \%)$ and tetrabenazine at 5 and 40 $\mathrm{mg} / \mathrm{kg}(-75 \%$ and $-97 \%$, respectively). 


\section{DISCUSSION}

Just as dopaminergic supersensitivity (DA-SS) is a wellestablished behavioral and biochemical phenomenon following dopamine receptor blockade by neuroleptics, the fact that endorphinergic agents such as morphine and endorphin are capable of inducing DA-SS (Puri and Lal, 1973; Gianutsos et al., 1974; Cox et al., 1976; Carlson and Almasi, 1978; Baume et al., 1979; Bhargava, 1981; Martin and Takemori, 1986 ) is an intriguing consequence of how disruption of endorphinergic homeostasis can effect dopamine-dependent behaviors. This dissertation dealt with how the various exogenous opiate receptor subtype agents, namely mu $(\mu)$, kappa $(\kappa)$ and sigma $(\sigma)$ agonists, influenced dopaminergic systems, specifically in the development of haloperidolinduced dopamine receptor supersensitivity.

It has also become apparent that there are two major dopamine receptor subtypes: $0-1$ receptors involved in the stimulation of adenylate cyclase activity and D-2 receptors which act independently of the enzyme and which, in some tissues, inhibit adenylate cyclase activity (Kebabian and Calne, 1979; Sibley et al., 1982; Creese, 1985). Clinically, effective neuroleptics such as haloperidol, possess a nanomolar potency for displacement of tritiated ligand at $\mathrm{D}-2$ receptor sites and a micromolar potency at D-1 receptor sites (Creese et al., 1982). Neuroleptics also antagonize apomorphine-induced behavioral effects which primarily reflect activation of $\mathrm{D}-2$ receptor sites (Randrup and Munkvad, 1974; Creese et al., 1983). However, recent evidence suggests that dopaminergic behaviors may be mediated through 0-1 receptors or be expressed by complex functional interactions 
between $D-1$ and $D-2$ receptors in the brain (Mailman et al., 1984; Molloy and Waddington, 1984, 1985; Pugh et al., 1985; Barone et al., 1986; Saller and Salama, 1986).

Therefore, since apomorphine is a direct dopamine-receptor agonist (Ernst, 1967), it served as a pharmacological tool for gauging dopamine receptor ( $D-2$ ) sensitivity in the behavioral paradigms predictive of mesolimbic and striatal dopamine activity, i.e., locomotion, stereotypy and climbing behavior (Pijnenberg and Van Rossum, 1973; Costall and Naylor, 1975; Kelley et al., 1975; Pijenberg et al., 1976; Protais et al., 1976; Costall et al., 1979, 1980). Apomorphine's effects on these behaviors were verified in these procedures and produced especially reliable and robust effects in stereotypy (ED50 = $0.80 \mathrm{mg} / \mathrm{kg} \mathrm{sc}$; Table 2) and climbing (ED50 $=0.58 \mathrm{mg} / \mathrm{kg}$ sc; Table 3), while only producing slight enhancement of locomotion (Table 1; Fig. 6). However, the reason for only slight increases in locomotion is due to the fact that the stereotypic components of apomorphine's effects (even at relatively low postsynaptic doses) interferes with horizontal locomotor activity, i.e., stereotyped behavior was observed between $0.3-3.0 \mathrm{mg} / \mathrm{kg}$ (Table 2) whereas slight increases in locomotor activity occur at 1.5 and $5.0 \mathrm{mg} / \mathrm{kg}$ (Table 1 ).

It was of interest to determine whether the opiates were capable of blocking dopaminergic effects by antagonizing apomorphine-induced climbing and stereotyped behavior. Biochemical studies showed neuroleptics act at opiate sites (Creese et al., 1976) but opiates do not interact at neuroleptic sites (Creese et al., 1976; Puri et al., 1978). Generally, this was the case in the climbing and stereotypy 
experiments. Morphine, naloxone, naltrexone, pentazocine and cyclazocine had no effect on apomorphine $(1.5 \mathrm{mg} / \mathrm{kg})$-induced climbing behavior (Table 12). Although, ethylketocyclazocine (EKC) at $20 \mathrm{mg} / \mathrm{kg}$ and SKF 10,047 at $40 \mathrm{mg} / \mathrm{kg}$ significantly decreased $\mathrm{climbing}$ by $52 \%$ and 25\%, respectively (Table 12), this may have been due to the initial depressive effects of EKC and the ataxia produced by SKF 10,047 which rendered the mice unable to climb. In fact, lower doses of these compounds had no effect on climbing (Table 12). Likewise, only EKC $(20 \mathrm{mg} / \mathrm{kg})$ was active in antagonizing apomorphine-induced stereotypy (Table 13), further evidence that the side effects of EKC, namely, general overt depression and flaccidity were responsible for the blockade of these behaviors, not dopamine-receptor blockade. Also, SKF $10,047(40 \mathrm{mg} / \mathrm{kg})$ did not antagonize apomorphine-induced stereotypy which showed that although ataxia interfered with climbing, it had no effect on stereotypy. Furthermore, in both the acute (Tables 17, 21 and 24) and chronic (Tables 28, 30, 34 and 37) supersensitivity paradigms, neither EKC nor SKF 10,047 were capable of inducing DA-SS. Therefore, the opiate receptor subtype agents do not appear to act as dopamine receptor antagonists in the two behavioral assays which are predictive for antipsychotic agents, i.e., apomorphine-induced climbing and stereotypy.

On the other hand, might these opiates act either directly or indirectly as dopaminergic agents? Inasmuch as dopamine agonists and releasers are known to, induce locomotor activity in rodents (Costall and Naylor, 1977), it was important to investigate the locomotor effects of the opiate subtypes. 
In the locomotor activity experiments, morphine, EKC, pentazocine, cyclazocine and SKF 10,047 all increased locomotion at some time during the six hours of testing while the pure antagonists, naloxone and naltrexone, had no effect. Opioid-induced hyperactivity has previously been implicated to be mediated by dopaminergic transmission (Buxbaum et a1., 1973; Holtzman and Jewett, 1972, 1973; Kuschinsky and Hornykiewicz, 1974; Iwamoto, 1981). Morphine $(\mu), \operatorname{SKF} 10,047(\sigma)$, pentazocine and cyclazocine $(\kappa, \sigma)$ each produced immediate increases in locomotion which generally lasted from one to three hours (Tables $4,9,10$ and 11; Figures $7,11,12$ and 13).

Morphine induction of hyperactivity or "morphine mania", as well as pentazocine-, cyclazocine- and SKF 10,047-induced hyperactivity have been well documented (Rethy et al., 1971; Holtzman and Jewett, 1972, 1973; Iwamoto, 1981). However, initial experiments in rats and mice (Tepper and Woods, 1978; Iwamoto, 1981) failed to show EKCinduced hyperactivity because these experiments lasted for one to two hours and hyperactivity was not evident until three hours postadministration (Table 8, Fig. 10). The results in this dissertation, along with a recent study (Gwynn and Domino, 1984) where locomotion was monitored for 6 hours showed that EKC induced a biphasic locomotor effect where an initial decrease in activity was followed at approximately 180 minutes by a significant increase in locomotion (Table 8, Fig. 10).

EKC hyperactivity was further investigated for peak effect and mechanism of action by utilizing the wire-mesh stick cages. Peak activity at $5 \mathrm{mg} / \mathrm{kg} \mathrm{SC}$ was determined to be between 180 to 210 minutes 
(Table 41). Various blocking agents at appropriate pretreats were combined with EKC at $5 \mathrm{mg} / \mathrm{kg} \mathrm{sC}$ and hyperactivity was measured at 180 to 210 minutes (Table 43). EKC hyperactivity was clearly distinguishable from the morphine-induced "running fit" or "morphine mania" in mice. EKC hyperactivity was relatively insensitive to naloxone (Table 43) and EKC induced a sporadic running and episodes of stereotyped rearing and sniffing whereas morphine induced a "running fit" characterized by persistant circling which was antagonized by naloxone (Rethy et al., 1971). EKC hyperactivity was dependent upon catecholamine transmission since the synthesis inhibitor $\alpha-M P T$ (Spector et al., 1965) and the depleters reserpine (Iverson et al., 1965 ) and tetrabenazine (Quinn et al., 1959; Pletscher et al., 1962) blocked EKC-induced hyperactivity. Furthermore, the postsynaptic dopamine receptor blocker haloperidol, and a presynaptic autoreceptor dose of apomorphine $(0.1 \mathrm{mg} / \mathrm{kg})$ effectively antagonized the increased activity produced by EKC. Also, the GABA agonist muscimol (Beaumont et a1., 1978) suppressed the EKC-induced hyperactivity suggesting GABAergic inhibition of this activity, possibly through the mediation of the dopaminergic system. In addition to dopamine mediation of EKCinduced hyperactivity, norepinephrine transmission at the alpha-1 receptor (but not alpha-2) appeared important since phentolamine and prazosin (but not yohimbine) effectively antagonized EKC-induced locomotor activity. However, there was only limited serotonergic mediation of this behavior and no cholinergic involvement (Table 43). Therefore, the kappa agonist EKC may be acting through the mesolimbic 
and/or striatal system by increasing synthesis and release of catecholamines.

These experiments also revealed that the sigma agonist SKF 10,047 (Martin et al., 1976; Pasternak et a1., 1981) induced a stereotypic behavior in mice which eventually culminated into a climbing response similar to that of apomorphine (Dunn et al., 1984). Following SKF 10,047 (40 mg/kg sc) administration, mice were initially ataxic for the first 30 minutes, then exhibited stereotyped behavior characterized by vocalization, excessive grooming and sniffing, then rearing and finally climbing approximately 75 to 90 minutes postadministration (Table 44) with an ED50 for climbing equal to $14.6 \mathrm{mg} / \mathrm{kg}$ sc (Table 45).

In addition, SKF 10,047 induced an increase in locomotor activity beginning at 15 minutes postadministration and lasting for up to five hours (Table 11; Fig. 13). This increase in locomotion was previously observed in rats (Iwamoto, 1981) and was at least partially attributed to dopaminergic activity since this activity was attenuated by spiperone (a postsynaptic dopamine receptor antagonist) and apomorphine (a presynaptic dopamine inhibitor at $0.1 \mathrm{mg} / \mathrm{kg}$ ). On the other hand, the mu antagonist naltrexone, had no effect on SKF 10,047induced locomotion except at very high doses (Iwamoto, 1981). These results were confirmed in mice in the six-hour locomotion paradigm in that haloperidol but not naltrexone effectively antagonized SKF 10,047-induced locomotion (unpublished observations).

To further elucidate the mechanism of action responsible for SKF 10,047 induction of locomotor activity, stereotypy and climbing, 
interaction experiments were conducted utilizing the climbing mouse paradigm since climbing behavior is mediated by both mesolimbic (locomotion) and striatal (stereotypy) systems (Protais et al., 1976; Costall et al., 1979). SKF 10,047 was administered at $40 \mathrm{mg} / \mathrm{kg} \mathrm{SC}$ and combined with the various blocking agents (at appropriate pretreats) and $\mathrm{climbing}$ behavior was scored for 30 minutes, 90 minutes post-SKF 10,047 administration (Table 46). SKF 10,047-induced climbing behavior was not mediated by the opiate system since it was not antagonized by naloxone. SKF 10,047-induced climbing behavior was dependent upon catecholamine transmission and a direct serotonin receptor interaction. Blockade of catecholamine synthesis by a-MPT completely antagonized (-97\%) SKF 10,047-induced climbing while autoinhibition of dopamine systems by apomorphine, GABAergic inhibition by muscimol and dopamine-receptor blockade by haloperidol also attenuated this behavior. Furthermore, noradrenergic receptor blockade by phentolamine, specifically alpha-1 receptor antagonism by prazosin and serotonin receptor blockade by methysergide significantly antagonized SKF 10,047 climbing behavior. However, this behavior was independent of serotonin synthesis and release since PCPA had no effect on SKF 10,047-induced climbing. Interestingly, tetrabenazine but not reserpine blocked this behavior probably due to the dopamine receptor blocking properties of tetrabenazine (Reches et al., 1983) and not because of neurotransmitter depletion.

These results suggest that SKF 10,047-induced climbing is the result of an activation of catecholamine transmission and of a serotonin receptor interaction. The effect of a serotonin mediation 
of this behavior is somewhat unclear since serotonin and specifically the serotonergic raphe projection to the substantia nigra and striatum are predominately inhibitory (Grabowska, 1974; Miller et al., 1975; Dray et al., 1976), although an excitatory role of serotonin based on some selective neuronal excitation cannot be excluded (Oray et al., 1976). Furthermore, serotonin inhibits dopamine mediated hyperactivity and stereotypy (Weiner et al., 1975; Pycock et al., 1978). However, SKF 10,047 effects may be similar to the 5-HT agonist, quipazine, which has been found to potentiate apomorphine-induced stereotypy (Pycock et al., 1978), possibly through inhibition of dopamine reuptake (Ponzio et a1., 1981). Therefore, SKF 10,047induced climbing behavior may result from a dopamine reuptake inhibition similar to quipazine, a selective serotonergic excitatory effect on mesolimbic and/or striatal dopaminergic neurons, as well as a direct and/or indirect effect on catecholamine synthesis and transmission.

Although both EKC and SKF 10,047 appear to have some effects on dopaminergic systems, might these agents be working indirectly to potentiate dopaminergic transmission? In order to ascertain indirect effects, these compounds were combined with a low dose of apomorphine $(0.4 \mathrm{mg} / \mathrm{kg})$ and observed in the climbing mouse paradigm. In each case, EKC and SKF 10,047 at doses from 1 to $10 \mathrm{mg} / \mathrm{kg}$ potentiated apomorphine-induced climbing from 23 to $67 \%$ (Tables 39 and 40 ) in an approximately additive fashion because each of these compounds alone at 3 and $10 \mathrm{mg} / \mathrm{kg}$ showed either hyperactivity (EKC) or climbing (SKF $10,047)$. 
Since each of these compounds have in common mu antagonist properties, might this characteristic be at least partially responsible for the potentiation of dopaminergic effects? As previously reported, naloxone has augmented several dopamine-dependent behaviors (Namba et a1., 1980; Quock and Welsh, 1981; Adams et a1., 1981; Quock and Lucas, 1981, 1983; Quock et al., 1983; Balsara et al., 1984). Naloxone at 1 to $10 \mathrm{mg} / \mathrm{kg}$ was shown to potentiate apomorphine climbing from 17 to 83\% (Table 38) while having no effect alone on either climbing or hyperactivity. These results further substantiate the hypothes is that an opiate receptor antagonist may potentiate dopaminergic effects through the blockade of opiate receptors on nigrostriatal and mesolimbic dopamine neurons, thereby releasing these neurons from the tonic inhibition of endogenous opiate production (Celsen and Kushinsky, 1974; Loh et al., 1976; Balsara et a1., 1984). In addition, recent evidence has shown that newly synthesized dopamine and norepinephrine and an alpha-1 receptor interaction influence naloxone potentiation of apomorphine-induced climbing (Quock et al., 1984). Therefore, although EKC and SKF 10,047 alone induce hyperactivity and climbing, respectively, part of the potentiation of apomorphine's effect may be due to the blockade of these opiate receptors as well as either direct and/or indirect effects of these agents on dopaminergic systems.

Because of the following results suggesting dopaminergic effects: mu, kappa, sigma and kappa, sigma agonists induced locomotor activity; sigma agonist-induced stereotypy and climbing; and mu antagonists as well as kappa and sigma agonists potentiation of apomorphine effects; 
all of these protypical opiate agents were tested in the acute DA-SS climbing paradigm. All of these compounds except morphine effectively attenuated acute haloperidol-induced DA-SS (Tables 18-24). It was not surprising that compounds which either directly or indirectly augment dopaminergic transmission (in the above acute models) would prevent the development of haloperidol-induced DA-SS in an acute paradigm, since it was previously reported that L-DOPA or apomorphine in combination with haloperidol blocked the development of DA-SS (Friedhoff et a1., 1977; Ezrin-Waters and Seeman, 1978; Christensen and Nielsen, 1979; List and Seeman, 1979; Seeger et al., 1981).

Morphine's lack of effect in attenuating DA-SS may be due to the fact that it, unlike all of the other opiates tested, was devoid of mu antagonist properties. Quite possibly, at least in the acute model, opiate receptor blockade was the initial factor in down regulating the development of DA-SS following haloperidol administration. The importance of opiate receptor antagonism was further substantiated since naloxone and naltrexone, which lack overt dopaminergic effects, i.e., locomotion, stereotypy, climbing etc., were active in attenuating haloperidol-induced DA-SS. Blockade of opiate receptors located presynaptically on dopamine neurons or on opiate neurons synaptically connecting with dopamine neurons in the mesolimbic and striatal areas (Pollard et al., 1977a, b; 1978; Murrin et al., 1980) may be sufficient to antagonize endorphinergic and enkephalinergic inhibition of dopamine release (Celsen and Kushinsky, 1974; Subramanian et al., 1977; Loh et al., 1976). In other words, more endogenous dopamine would be released as a result of occupation of opiate receptors by mu 
antagonists. The fact that the sigma and/or kappa agonist components of SKF 10,047, EKC, cyclazocine and pentazocine may be either directly or indirectly facilitating the release of dopamine may be of secondary importance to the opiate-receptor blocking properties of these compounds (and naloxone and naltrexone) in attenuating the development of haloperidol-induced DA-SS. Therefore, would these agents when administered chronically with haloperidol, prevent the development of DA-SS?

The consequences of chronic simultaneous administration of the opiate agents with haloperidol were assessed in the climbing mouse paradigm as well as the stereotypy model since chronic haloperidol treatment produced DA-SS in this model (Tables 26-30) although acute administration did not induce DA-SS (Table 15). In both models, chronic five-day morphine administration resulted in an enhanced response to apomorphine (Tables 26 and 31) while having no effect on haloperidol-induced DA-SS. These results were similar to earlier studies where morphine induced DA-SS in various paradigms (Puri and Lal, 1973; Gianutsos et al., 1974; Cox et al., 1976; Carlson and Almasi, 1978; Baume et al., 1979; Bhargava, 1980; Martin and Takemori, 1985). Since morphine does not antagonize dopamine receptors (Creese et al., 1976; Puri et al., 1978), morphine-induced DA-SS apparently results from an inhibition of dopamine release mediated by the opiate system (Celsen and Kuschinsky, 1974; Loh et al., 1976; Subramanian et a1., 1977). Therefore, chronic inhibition of dopamine release would have the same effect as receptor blockade, i.e., a decrease in postsynaptic dopaminergic activation. 
The opiate antagonists, naloxone and naltrexone, when chronically administered alone or with haloperidol, had no effect in either paradigm (Tables 27,32 and 33 ). These results showed that while opiate receptor blockade alone was sufficient to down regulate the hypersensitivity which developed following acute haloperidol administration in the climbing paradigm, it did not effectively attenuate chronic haloperidol-induced DA-SS in either the climbing or stereotypy models. It should be noted that naltrexone showed some slight attenuation of haloperidol-induced DA-SS in the climbing assay (Table 33). This may have been due to the longer duration of antagonist activity of naltrexone compared to naloxone (Verebey et al., 1976). The kappa agonist, mu antagonist EKC, produced similar results in these models. Although chronic EKC had no effect on the development of DA-SS in the stereotypy paradigm (Table 28), it provided a consistent suppression of haloperidol-induced DA-SS in the climbing model (Table 34). It is possible that the mesolimbic system (climbing-mesolimbic and striatal mediation) was more sensitive than the striatal system (stereotypystriatal mediation) to these long-acting agents, i.e., naltrexone as an antagonist and EKC as an antagonist and a locomotor stimulant after three hours. Although the locomotor effects of EKC appeared to be primarily due to dopaminergic activity (Table 43), the dopaminergic effects were not as robust as SKF 10,047 .

The sigma agonist, mu antagonist SKF 10,047 produced the most consistent suppression of haloperidol-induced DA-SS in both chronic stereotypy and climbing models (Tables 30 and 37 ). Not only was this suppression statistically significant but in each case, the combina- 
tion of SKF 10,047 and haloperidol effectively reduced the development of DA-SS to vehicle control levels. The dopaminergic activity of SKF 10,047 i.e., locomotor effects, stereotypy and climbing, apparently was sufficient to down regulate the dopamine-receptor blocking effects of haloperidol which lead to the development of DA-SS, similar to LDOPA's effect in this paradigm.

Likewise, the sigma, kappa agonist, mu antagonist cyclazocine also effectively suppressed the development $c$ : haloperidol-induced DA-SS in both the chronic stereotypy and climbing models (Tables 29 and 36). However, the kappa, sigma agonist, mu antagonist pentazocine, had no effect on haloperidol-induced DA-SS in the chronic climbing paradigm (Table 35 ). This may be a result of the fact that cyclazocine has a much greater affinity than pentazocine for the sigma receptor (Zukin and Zukin, 1981b). Also, in drug discrimination testing, cyclazocine but not pentazocine generalized to SKF 10,047 trained rats (Shearman and Herz, 1982). These results suggested that cyclazocine had a high affinity for and high intrinsic activity at the sigma receptor while pentazocine had a much lower affinity for the sigma receptor. Therefore, in the chronic DA-SS paradigms, cyclazocine had similar effects to SKF 10,047, whereas pentazocine did not.

These results would suggest that agents with strong sigma effects, as well as mu antagonist effects, were able to suppress the development of DA-SS in both acute and chronic behavioral paradigms. Kappa agents and opiate antagonists were effective in attenuating the development of DA-SS in the acute climbing model while showing little or no effects in the chronic stereotypy and climbing models. Other 
than the fact that the attenuation of DA-SS by sigma agonists in particular may be due to dopaminergic effects as manifest behaviorally by increased locomotion, stereotypy and climbing, there are other aspects of opioid pharmacology, some of which remain controversial, which might explain some of the results in this dissertation, especially opiate influence on dopaminergic systems.

First and foremost, it was crucial to establish the existence in the central nervous system (CNS) of these various opiate receptor subtypes, namely, mu, kappa and sigma (and even delta and epilsilon for enkephalins and endorphins, respectively) so that the behavioral effects could be linked to the brain. Furthermore, any drug which attenuates DA-SS must exhibit activity in the mesolimbic and/or striatal dopaminergic systems.

Since Martin's (1976) pioneer study in dogs where he classified opiates based on neurophysiological and behavioral evidence as either mu, kappa or sigma, some controversy has surrounded the existence of these receptors in the CNS. The existence of different mu (morphine) and delta (enkephalin) binding sites in the CNS was well established (Pert and Snyder, 1973; Snyder, 1978). Autoradiographic techniques revealed a high concentration of mu receptors in the striatum and high levels of delta receptors in the striatum, nucleus accumbens and olfactory tubercle (Goodman et al., 1980). The highest concentrations of endorphins and enkephalins were located in the striatum (LlorensCortes et al., 1977). Furthermore, approximately one-third of striatal opiate or enkephalin receptors are located on dopaminergic neurons while one-half to two-thirds are located on neurons intrinsic 
to or emanating from the striatum (Hong et al., 1977; Pollard et a)., 1977b, 1978; Murrin et al., 1980). An even larger percentage (50-70\%) of opiate receptors were located presynaptically on dopaminergic neurons in the mesolimbic area (Pollard et al., 1977a).

The discovery of sigma and kappa receptors in the CNS has been somewhat controversial. SKF 10,047 is the protoype sigma agonist (with mu antagonist properties) which produces psychotomimetic effects in man (Keats and Teford, 1964). Biochemical and autoradiographic studies have identified sigma receptors in mouse, rat and guinea pig brains. Since the intial report of a commonality of the sigma opiate/phencyclidine (PCP) receptor (Zukin and Zukin, 1981b), much debate has taken place in defense of these receptors being identified (Zukin, 1982; Mendelsohn et al., 1985; Sircar et al., 1986) and to the contrary, that these receptors are distinct (Su, 1982; Tam, 1983, 1985; Martin et a1., 1984; Gundlach, 1985; Downes et al., 1986). The distinction between these two binding sites was based on several observations: $\left({ }^{3} H\right)$ PCP binding is decreased in the presence of sodium ions but $(+)-\left({ }^{3} H\right)$ SKF 10,047 binding is not; the two binding sites have different drug selectivity; the PCP binding sites show low affinity and little stereoselectivity towards SKF 10,047, EKC, cyclazocine and pentazocine whereas these drugs are highly stereoselective towards the $(+)-\left({ }^{3} H\right)$ SKF 10,047 binding sites; and the regional distribution in the CNS of the sigma binding sites differs from the PCP binding sites. Moreover, biochemical and autoradiographic techniques have shown that $(+)-\left({ }^{3} H\right)$ SKF 10,047 labels two sites, a high affinity site corresponding to the sigma receptor and a 
low affinity site representing the $P C P$ receptor (Gundlach et al., 1985; Downes et al., 1986). Therefore, the sigma and PCP receptors are probably different receptors which share some similar properties.

Until recently, the proof of the existence of a central kappa receptor site was difficult since kappa drugs interacted with a number of receptor sites, i.e., mu $(\mu)$, sigma $(\sigma)$, enkephalin $(\delta)$ and kappa (k) sites (Kosterlitz and Paterson, 1980; Pasternak, 1980; Snyder and Goodman, 1980; Chang et a1., 1981; Garzon et a1., 1984). Biochemical and autoradiographic studies showed distinct kappa opiate receptors were present in the CNS of the guinea pig (Kosterlitz et al.., 1981; Wood and Charleson, 1982), mouse (Garzon et al., 1984) and human brain (Pfeiffer et al., 1982; Maurer et al., 1983). Furthermore, $\kappa, \sigma, \mu$, and $\delta$ receptors have all been established in the striatum, midbrain and frontal cortex (Wolozin et al., 1982).

Since enkephalin-containing neurons and various opiate receptors are present in high concentrations in the basal ganglia and mesolimbic system, areas also rich in dopamine (Snyder, 1978), what effects would endogenous and exogenous opiates have on dopaminergic transmission? In vitro evidence from superfused striatal slices showed that morphine (Celsen and Kuschinsky, 1974), enkephalin (Subramanian et al., 1977) and $\beta$-endorphin (Loh et al., 1976) inhibited $K^{+}$stimulated release of $\left({ }^{3} H\right)-D A$. However, in vivo evidence appears to show a species difference between rats and mice. Both mu and delta agonists elevated striatal DA synthesis but not release in the rat striatum (Wood et al., 1980; Wood and Richard, 1982), while in the mouse, there was an increase in DA synthesis and release (Wood et a1., 1980; Wood and 
Richard, 1982). In the rat, this initial depression of dopaminergic transmission following morphine administration was followed by a feedback activation which was probably responsible for an increased firing rate in the substantia nigra (Iwatsubo and Clovet, 1977). Also, direct injection of opiates and opioid peptides into the substantia nigra activated dopamine neurons projecting to the caudate nucleus (Iwamoto and Way, 1977). Opiate injection into the ventral tegmental region induced hyperactivity in the rat due to a release of dopamine in the nucleus accumbens (Kelley et al., 1980). Therefore, opiates activate both mesolimbic and striatal dopamine neurons. However, this appeared to be an indirect effect since iontophoretically applied morphine at the substantia nigra has no effect on dopaminergic neuron activity (Pert et al., 1979).

Morphine-induced hyperactivity appears to be mediated by both opiate and catecholamine systems since morphine-induced locomotor activity was blocked by naloxone (Rethy et al., 1971; Parker, 1974), $\alpha$-MPT or reserpine (Buxbaum et al., 1973) and presynaptic (autoinhibiting) doses of apomorphine (Strombom and Svensson, 1978). Further evidence for two independent systems which mediate locomotor activity was provided by Pert and Sivit (1977) who showed that intraaccumbens morphine-induced locomotor activity was antagonized by naloxone but not haloperidol and intraccumbens apomorphine-induced locomotor activity was antagonized by haloperidol but not naloxone. Also, other regions besides the mesolimbic system appear to be involved in morphine-induced hyperactivity since lesions of the nucleus accumbens and ventral tegmental area attenuated and delayed, 
but did not completely abolish morphine-induced locomotor activity (Bunney et a1., 1984).

It is unlikely that presynaptic opiate receptors are located on dopaminergic neurons in mice since lesion of the nigrostriatal pathway in mice did not result in decreased opiate binding in the striatum whereas this lesion resulted in decreased opiate binding in the rat (Wood and Richard, 1982). Because intranigral morphine induced increases in DA metabolites similar to parenteral injection in mice, it was suggested that opiate receptors on dopaminergic cell bodies and/or afferent nerve fibers innervating these neurons regulate nigrostriatal activity (Wood and Richard, 1982).

In the mouse, the initial increase in DA turnover in the striatum following morphine administration (Baume et al., 1979; Wood and Richard, 1982) lasting for six to 12 hours (Kuschinsky, 1974; Baume et al., 1979) was followed at 24 hours by a significant decrease in HVA levels following either a single dose of morphine or for several days following chronic morphine administration (Baume et al., 1979). In fact, either a single dose of morphine or chronic morphine resulted in an enhanced apomorphine-induced climbing response for days following treatment similar to haloperidol (Baume et al., 1979; Martin and Takemori, 1985, 1986) as well as DA-SS in other models (Puri and Lal, 1973; Gianutsos et a1., 1974; Cox et al., 1976; Carlson and Almasi, 1978). The diminished activity of DA neurons reflected an increased activity of the feedback loop when the postsynaptic receptors became hypersensitive to dopamine (Matres et al., 1977). Chronic morphine resulted in tolerance to the increase in DA turnover from morphine and 
cross tolerance to the increase in DA turnover following haloperidol administration (Baume et a1., 1979). Morphine-induced DA-SS could not be attributed to an increase in dopamine receptors similar to that seen following haloperidol administration (Burt et al., 1977) since chronic morphine either decreased (Puri et al., 1978), slightly increased (Baume et a1., 1979; Martin and Takemori, 1986) or had no

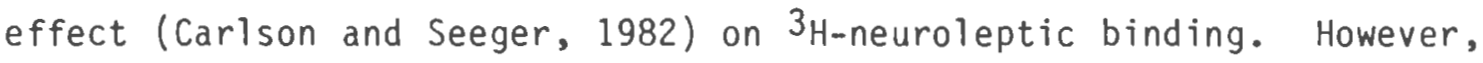
there may be an increase in affinity, although fewer binding sites (Puri et al., 1978).

The effects of kappa and/or sigma agonists on dopaminergic transmission remains somewhat unclear and in need of more thorough investigations. Pentazocine has been reported to have either no effect on catecholamine turnover (Holtzman and Jewett, 1972) or increased the turnover of dopamine in whole brain (Sugre, 1974) and striatum (Sugre, 1974; Wood et al., 1980). Likewise, cyclazocine slightly lowered brain catecholamine levels (Holtzmann and Jewett, 1973) while increasing striatal dopamine turnover (Wood et al., 1980; Gavend et al., 1981; Snell et al., 1984) and norepinephrine and serotonin turnover in the cortex, hypothalamus, midbrain, pons and medulla (Gavend et al., 1981). Cyclazocine also inhibited stimulated acetylcholine release from striatal slices (Johnson and Snell, 1985).

The kappa agonists, EKC and ketazocine, showed a slight increase in striatal DA metabolite levels and turnover (Wood et al., 1980; Snell et al., 1984). However, animals were sacrificed 60 minutes following drug administration while stimulant activity of EKC was not apparent until three hours postadministration. If turnover studies 
were run at this time point, it might be possible that there would be higher levels of DA turnover. Furthermore, EKC potently inhibited acetylcholine (ACh) release in superfused striatal slices and this effect was reversed by haloperidol (Leventer and Johnson, 1984). Since ACh release is known to be inhibited by $D A$, it was suggested that EKC-induced inhibition of ACh was mediated via dopaminergic neurons (Leventer and Johnson, 1984).

The sigma agonist, SKF 10,047 produced small increases in striatal DOPAC and DA that were resistant to naloxone challenge (Wood et al., 1980). It must be noted that tissue samples were analyzed at 60 minutes postadministration and quite possibly more dramatic effects may have been seen at 90 minutes after SKF 10,047. In an in vitro assay, SKF 10,047 and EKC slightly enhanced the basal efflux of $\left({ }^{3} \mathrm{H}\right)$ DA from striatal slices (Snell et al., 1984). In addition, SKF 10,047 inhibited the reuptake of DA while EKC and cyclazocine were extremely weak uptake inhibitors (Johnson and Snell, 1985). Similar to EKC, SKF 10,047 inhibited ACh release (Leventer and Johnson, 1984; Johnson and Sne11, 1985), with this effect being reversed by haloperidol (Leventer and Johnson, 1984).

In addition to biochemical evidence linking sigma activity to the dopamine system, behavioral studies have also shown a sigma-dopamine interaction. Since the original observation by Martin et al. (1976) that some of the activity of the dopamine agonist apomorphine showed certain similarities to those of SKF 10,047 , recent behavioral evidence has supported a dopaminergic mediation of sigma-induced behavior. In rats, SKF 10,047 and cyclazocine induced dose-related 
increases in locomotion, sniffing, repetitive head movements, rearing and some ataxia (Iwamoto, 1980, 1981; French and Vantini, 1984; Contreras et al., 1986; Greenberg and Segal, 1986). SKF 10,047induced hyperactivity was attenuated by presynaptic autoinhibition of dopamine and norepinephrine by apomorphine $(0.1 \mathrm{mg} / \mathrm{kg})$ and clonidine $(0.1 \mathrm{mg} / \mathrm{kg})$, respectively, and by postsynaptic dopamine blockade by spiperone $(0.15 \mathrm{mg} / \mathrm{kg}$ ) (Iwamoto, 1980, 1981). Further indication of SKF 10,047-induced dopaminergic activity in the midbrain was shown when SKF 10,047-induced hyperactivity was prevented by 6-hydroxydopamine (6-OHOA) lesions of both the nucleus accumbens (French and Vantini, 1984) and the A-10 region of the ventral tegmental area (French, 1986). Also, in the rat circling model (unilateral 6-OHDA lesion of the substantia nigra), SKF 10,047 causes ipsilateral turning like amphetamine, suggesting indirect activation of the intact dopaminergic pathway possibly by inhibition of dopamine reuptake, by releasing dopamine or by indirect stimulation of neostriatal pathways at the level of the cell body (Iwamoto, 1980). Further support for SKF 10,047 indirectly activating dopamine neurons was provided by electrophysiological (single-unit recording) evidence which showed that intravenously administered SKF 10,047 increased the firing rate of dopamine neurons in the ventral tegmental area (A-10) and the substantia nigra (A-9) while iontophoretically applied SKF 10,047 had no effect on these neurons (Freeman and Bunney, 1984).

Both biochemically and behaviorally, the sigma opiates may indirectly affect dopamine turnover and/or uptake. It is intriguing that antipsychotic agents such as haloperidol and other phenothiazines 
have been shown to inhibit striatal and whole brain binding of $\left({ }^{3} \mathrm{H}\right)$ SKF 10,047 in vitro in rat and guinea pigs (Su, 1981, 1982; Tam and Cook, 1984; Tam, 1985). Also, an in vivo binding assay in mouse brain found haloperidol to be the most potent compound to inhibit specific $(+)-\left({ }^{3} \mathrm{H}\right)$ SKF 10,047 binding with an ID50 of $0.75 \mathrm{mg} / \mathrm{kg} i . p$. , followed by thioridazine $(8.9 \mathrm{mg} / \mathrm{kg}$ ) and chlorpromazine $(19.2 \mathrm{mg} / \mathrm{kg}$ ) (Ferris et al., 1985, 1986). Therefore, in both in vivo and in vitro sigma binding assays, haloperidol was the most potent displacer of $\left({ }^{3} H\right)$ SKF 10,047 followed by the phenothiazines. However, the sigma and dopamine binding sites were found to be different for several reasons: Dopamine and dopamine agonists did not bind to the SKF 10,047 binding site; there was reversed stereoselectivity for butaclamol binding to the sigma and dopamine sites; and there was no direct relationship between the affinity of antipsychotic drugs for the sigma site and for the $\left({ }^{3} H\right)$ spiperone binding site (Tam, 1983; Tam and Cook, 1984). However, an intricate relationship between haloperidol and SKF 10,047 was shown in whole guinea pig brain in binding assays when the order of drug potency for opiates and antipschotics in displacing these $\left({ }^{3} \mathrm{H}\right)$ ligands was similar (Tam and Cook, 1984).

$\left({ }^{3} \mathrm{H}\right)$ Haloperidol bound to two distinct receptors, namely a dopamine D-2 binding site and the sigma site. Therefore, it was proposed that some antipsychotic agents may act therapeutically by antagonizing both dopamine and sigma receptors. Furthermore, an endogenous ligand referred to as "sigmaphin" has been identified to directly interact with sigma receptors (Su et al., 1986). It was proposed that the ideal antipsychotic drug might be a specific sigma 
antagonist, devoid of dopamine receptor antagonism and, therefore, more likely not to cause the undesirable extrapyramidal side effects or tardive dyskinesias. Likewise, since there appears to be a dynamic interrelationship between the sigma and dopamine systems, it is not surprising that an agent with sigma properties could interact in some way to either down regulate or compensate for the development of dopaminergic supersensitivity following haloperidol administration.

In light of what has previously been reported as well as the results of this dissertation, it would appear that the sigma agonist, SKF 10,047 has at least indirect dopamine agonist properties in the mesolimbic and striatal areas. This, in combination with its mu antagonist property which also potentiates dopamine-dependent behaviors, would appear to sufficiently stimulate release and augment dopaminergic transmission in the mesolimbic and striatal systems to compensate for and down regulate the development of DA-SS following haloperidol treatment. Cyclazocine, which is more of a sigma rather than kappa agonist (Zukin and Zukin, 1981b), also has dopaminergic effects capable of attenuating haloperidol-induced DA-SS. Kappa effects on dopaminergic transmission are somewhat unclear at this time but following an initial period of sedation, dopaminergic activity is enhanced, but not to the extent of a sigma agonist. Enhancement of dopaminergic transmission by these opiate agents was partially responsible for the attenuation of haloperidol-induced DA-SS but it is also important to note recent results concerning haloperidol's effect on endorphinergic transmission and how this effect may mediate the development of DA-SS. 
Although this dissertation did not directly study endogenous opiates, enkephalins and endorphins seem to play a role in the modulation of neuroleptic effects and the eventual development of DA-SS. Chronic administration of haloperidol has been shown to increase enkephalin content in the striatum (Hong et a 1., 1978; Tang et al., 1983; Chou et al., 1984; Blanc et al., 1985) and the nucleus accumbens (Hong et al., 1978) due to an increase in peptide synthesis (Hong et al., 1979). Recently, it was found that haloperidol increased the biosynthes is of the mRNA for preproenkephalin which led to an increase in enkephalin synthesis (Tang et a1., 1983; Blanc et al., 1985) and possibly release (Tang et al., 1980; Blanc et al., 1985). The effects of enkephal in on dopaminergic activity remain controversial. Enkephalin has been reported to have either no effect on striatal dopamine release (Loh et al., 1976), or inhibit both striatal (Subramanian et al., 1977) and retinal (Dubocovich and Weiner, 1983) dopamine release. The inhibition of dopamine release was naloxone reversible (Subramanian et al., 1977; Dubocovich and Weiner, 1983) since naloxone blocked the binding of enkephalins to endogenous opiate receptors (Pert and Snyder, 1973). Naloxone alone either had no effect on dopamine release (Loh et al., 1976; Subramanian et al., 1977; Dubocovich and Weiner, 1983) or has caused increases in striatal dopamine concentration (Costa et al., 1978).

Acute and chronic haloperidol administration also resulted in an increased release of immunoreactive $\beta$-endorphin ( $\beta$-endorphin is the predominant peptide) in the blood and in the striatum (Holt and Bergmann, 1982). However, unlike the tolerance to striatal dopamine 
turnover which occurs rapidly following haloperidol administration (Lerner et al., 1977), there was no tolerance to the increase in $\beta$ endorphin following haloperidol treatments (Holt and Bergmann, 1982). Although, Arbilla and Langer (1978) reported that $\beta$-endorphin had no effect on dopamine release in the striatum, others have found $\beta$ endorphin inhibited striatal dopamine release (Celsen and Kuschinsky, 1974; Loh et al., 1976) and increased dopamine reuptake (George and Van Loon, 1982) in the striatum. These effects were naloxone reversible. Interestingly, $\beta$-endorphin secretion can be inhibited by dopamine and dopamine receptor agonists (Vale et al., 1979). Therefore, $\beta$-endorphin-induced decrease of striatal dopamine release and increased reuptake decreased dopaminergic transmission. Hence, it was not surprising that behaviorally, B-endorphin-induced DA-SS (Bhargava, 1981) and chronic stress which increases the concentration of endogenous opiates (Amir et al., 1980) produced DA-SS as measured by enhanced apomorphine-induced climbing (Cabib et al., 1984). Furthermore, stress-induced DA-SS was prevented by chronic treatment with the opiate antagonist naltrexone (Cabib et al., 1984). It has become increasingly evident that the development of dopaminergic supersensitivity is a consequence of dopamine receptor blockade as well as an endorphinergic imbalance which further effects dopamine systems.

The results of this dissertation and some of the recent results of other groups has led to intriguing possibilities concerning opiate modulation of dopaminergic supersensitivity. Under normal physiological conditions, the effects of both endogenous opiates and opiate 
antagonists on the inhibition of dopamine release and disinhibition of dopamine release, respectively, is small and difficult to detect. However, enhanced dopaminergic responsiveness during DA-SS, resulting from either chronic antipsychotic treatment or from chronic endogenous or exogenous opiate agonists, magnifies the effects of enkephalins, endorphins and mu antagonists on dopaminergic transmission. Therefore, chronic haloperidol administration not only blocks dopamine receptors rendering them supersensitive but also may modulate or augment DA-SS through continual increased endorphin and enkephalin synthesis and release which inhibits dopamine release and increases reuptake. Concomitant administration of opiate antagonists may disinhibit endogenous opiate influence on dopaminergic transmission by increasing dopamine release and blocking reuptake, thereby increasing the amount of synaptic dopamine. However, this antagonism alone may be insufficient to compensate for or overcome dopamine receptor blockade to attenuate DA-SS during chronic neuroleptic therapy. Furthermore, if dopaminergic transmission is stimulated and opiate receptors blocked, DA-SS can be attenuated.

L-Dopa and other dopamine agonists have been shown to attenuate haloperidol-induced DA-SS (Friedhoff et al., 1977; Christensen and Nielsen, 1979; List and Seeman, 1979; Allen et al., 1980; Seeger et al., 1981; Reches et al., 1982). These dopamine agonists, by increasing the amount of dopamine at the receptor and increasing dopamine receptor stimulation, compensate for the haloperidol receptor blockade (Friedhoff et al., 1977; Christensen and Nielsen, 1979; List and Seeman, 1979; Allen et al., 1980; Seeger et al., 1981; Reches et 
a1., 1982). But also, dopamine and dopamine agonists inhibit $B-$ endorphin secretion (Vale et al., 1979), thus releasing dopaminergic neurons from endorphinergic inhibition. Therefore, at least theoretically, greater or more effective attenuation of haloperidol-induced DA-SS can be achieved by not only increasing dopamine release during receptor blockade but by antagonizing opiate receptors thereby thoroughly negating any endogenous opiate inhibition of dopaminergic transmission. Since there is no tolerance to the increased secretion of endogenous opiates during haloperidol treatment (Holt and Bergman, 1982), it is important to block the opiate receptor and thus dopamine modulation by endogenous opiates. SKF 10,047 and cyclazocine effectively attenuate haloperidol-induced DA-SS through an apparent increase in dopaminergic transmission as well as opiate receptor blockade. However, the psychotomimetic effects of sigma agonists in normal patients (Keats and Telford, 1964) may prevent the use of these drugs in schizophrenics unless there was a paradoxical effect in psychotic patients (similar to the paradoxical effect of amphetamine in hyperactive children).

The possibility of opiate agents modulating the development of dopaminergic supersensitivity is intriguing. Human studies in schizophrenic patients who received neuroleptics have shown increased $B-$ endorphin levels in plasma (Emrich et al., 1980) and in cerebrospinal fluid (Terrenius et al., 1976; Domschke et al., 1979; Lindstrom et al., 1980). This coupled with the fact that naloxone had no deleterious effect and may possibly improve some symptoms of schizophrenia (Verebey et a1., 1978; Watson et a1., 1978; Pickar et al., 1982; Lo et 
al., 1983; Blum et al., 1984) adds strength to the hypothes is that schizophrenia may be due to an imbalance in endorphinergic as well as dopaminergic homeostasis. The results of this dissertation add to the intriguing possibility that opiate agents may help to fine-tune dopaminergic imbalance in the treatment of schizophrenics. Hopefully, additional preclinical and clinical research in this area will lead to a better understanding of schizophrenia and a better prognosis for a schizophrenic to lead a more normal and satisfying 1 ife. 
CONCLUSIONS

Hypothes is 1.

Opiates are not dopamine receptor antagonists and therefore, will not attenuate apomorphine-induced climbing and stereotyped behavor in nice.

Ethylketocyclazocine (EKC) and SKF 10,047 inhibited apomorphineinduced climbing because of motor deficits, sedation and ataxia, respectively. Only EKC inhibited apomorphine-induced stereotypy due to initial motor deficits and sedation. Therefore, these compounds were not dopamine antagonists, insofar as apomorphine-induced behaviors were only antagonized at debilitating doses which incapacitated mice. In addition, the mixed kappa, sigma agonists, pentazocine and cyclazocine, as well as morphine, naloxone and naltrexone did not antagonize these behaviors.

\section{Hypothesis 2.}

Opiates which stimulate catecholamine neuronal activity will cause either increased locomotor activity (indicative of mesolimbic activity), stereotypy (indicative of striatal activity) or climbing behavior (indicative of mesolimbic and/or striatal activity) in mice.

Morphine, SKF 10,047, pentazocine and cyclazocine produced increases in locomotor activity suggesting increased dopaminergic activity, while naloxone and naltrexone had no effect on locomotion. EKC induced a biphasic effect of sedation followed by an increase in 
locomotor activity at three hours postadministration. SKF 10,047 not only increased locomotor activity but also induced stereotypy and climbing behavior. Kappa-induced EKC hyperactivity was dependent upon catecholamine synthesis and transmission since $\alpha$-MPT, reserpine, tetrabenazine, haloperidol, apomorphine (at $0.1 \mathrm{mg} / \mathrm{kg}$, a presynaptic autoreceptor dose), muscimol and prazosin blocked EKC-induced locomotor activity. Sigma-induced SKF 10,047 climbing was dependent on catecholamine transmission and a direct serotonin receptor interaction since $\alpha$-MPT, tetrabenazine, haloperidol, apomorphine $(0.1$ $\mathrm{mg} / \mathrm{kg}$ ), muscimol, prazosin and methysergide antagonized this behavior. Both EKC-induced hyperactivity and SKF 10,047-induced climbing were not antagonized by naloxone. In addition, EKC, SKF 10,047 and naloxone potentiated apomorphine-induced climbing behavior.

\section{Hypothes is 3.}

The acute and/or chronic simultaneous administration of the opiate receptor subtype agents and haloperidol will attenuate the development of dopaminergic supersensitivity as measured by apomorphine-induced climbing and stereotyped behavior in mice.

Enhanced responsiveness to apomorphine following the acute administration of haloperidol 72 hours prior to testing was only observed in the apomorphine-induced climbing mouse assay. In the acute climbing paradigm, haloperidol-induced dopaminergic supersensitivity (DA-SS) was dose-dependently attenuated by SKF 10,047, EKC, cyclazocine, pentazocine, naloxone and naltrexone, all of these compounds possessing mu antagonistic properties, with morphine 
inactive. Chronic five-day administration of haloperidol-induced DA-SS was observed in the apomorphine-induced climbing and stereotypy paradigms, but not in the locomotor activity model. In the chronic climbing and stereotypy models, only the concomitant administration of the sigma agents, either SKF 10,047 or cyclazocine and haloperidol attenuated the development of DA-SS, while morphine alone produced DASS. These results suggest differential modulation of DA-SS in the acute vs. chronic paradigms. Furthermore, sigma agonists were most effective in attenuating haloperidol-induced DA-SS. 


\section{Figure Legends}

Fig. 1 Dopaminergic structures in the nigrostriatal and mesolimbic systems in the mouse brain.

Fig. 2 Agonist and antagonist interaction of prototypical opiate agents at mu, kappa and sigma receptor sites.

Fig. 3 Chemical structures of morphine, naloxone and naltrexone.

Fig. 4 Chemical structures of the benzomorphans cyclazocine, pentazocine, SKF 10,047 and ethylketocyclazocine.

Fig. 5 Antinociceptive and locomotor activity of the prototypical opiate agents.

Fig. 6 The effects of apomorphine at $0.5,1,5$ and $5.0 \mathrm{mg} / \mathrm{kg} \mathrm{sc}$ on locomotor activity over two hours in mice. Locomotor activity units for each group based on four pairs of mice which were acclimated for one hour prior to dosing.

Fig. 7 The effects of morphine at 2.5, 5 and $10 \mathrm{mg} / \mathrm{kg} \mathrm{sc}$ on locomotor activity over six hours in mice. Locomotor activity units for each group based on four pairs of mice which were acclimated for one hour prior to dosing.

Fig. 8 The effects of naloxone at 10,20 and $40 \mathrm{mg} / \mathrm{kg} \mathrm{sc}$ on locomotor activity over six hours in mice. Locomotor activity units for each group based on four pairs of mice which were acclimated for one hour prior to dosing.

Fig. 9 The effects of naltrexone at 10,20 and $40 \mathrm{mg} / \mathrm{kg} \mathrm{sc}$ on locomotor activity over six hours in mice. Locomotor activity units for each group based on four pairs of mice which were acclimated for one hour prior to dosing. 
Fig. 10 The effects of ethylketocyclazocine at 5,10 and $20 \mathrm{mg} / \mathrm{kg}$ sc on locomotor activity over six hours in mice. Locomotor activity units for each group based on four pairs of mice which were acclimated for one hour prior to dosing.

Fig. 11 The effects of pentazocine at 20,40 and $80 \mathrm{mg} / \mathrm{kg} \mathrm{sc}$ on locomotor activity over six hours in mice. Locomotor activity units for each group based on four pairs of mice which were acclimated for one hour prior to dosing.

Fig. 12 The effects of cyclazocine at $2.5,5$ and $10 \mathrm{mg} / \mathrm{kg} \mathrm{sc}$ on locomotor activity over six hours in mice. Locomotor activity units for each group based on four pairs of mice which were acclimated for one hour prior to dosing.

Fig. 13 The effects of SKF 10,047 at 10,20 and $40 \mathrm{mg} / \mathrm{kg} \mathrm{sc}$ on locomotor activity over six hours in mice. Locomotor activity units for each group based on four pairs of mice which were acclimated for one hour prior to dosing.

Fig. 14 The effects of acute administration of haloperidor at 1.25 $\mathrm{mg} / \mathrm{kg}$ ip 72 hours prior to apomorphine at $0.4 \mathrm{mg} / \mathrm{kg} \mathrm{sc}$ on locomotor activity over two hours in mice. Locomotor activity units for each group based on eight pairs of mice which were acclimated for one hour prior to dosing.

Fig. 15 The effects of chronic (5-days) administration of haloperidol at $1.25 \mathrm{mg} / \mathrm{kg}$ ip 72 hours prior to apomorphine at $0.4 \mathrm{mg} / \mathrm{kg} \mathrm{sc}$ on locomotor activity over two hours in mice. Locomotor activity units for each group based on 
eight pairs of mice which were acclimated for one hour prior to dosing.

Fig. 16 The effects of chronic (5-days) simultaneous administration of morphine at $10 \mathrm{mg} / \mathrm{kg} \mathrm{sc}$ and/or haloperidol at $1.25 \mathrm{mg} / \mathrm{kg}$ ip, 72 hours prior to apomorphine at $0.4 \mathrm{mg} / \mathrm{kg} \mathrm{sc}$ on stereotyped behavior in mice. Stereotypy scores for each group based on eight mice (maximum score for each mouse $=6$ ) which were acclimated for one hour prior to dosing.

Fig. 17 The effects of chronic (5-days) simultaneous administration of naltrexone at $40 \mathrm{mg} / \mathrm{kg} \mathrm{sc}$ and/or haloperidol at $1.25 \mathrm{mg} / \mathrm{kg}$ ip, 72 hours prior to apomorphine at $0.4 \mathrm{mg} / \mathrm{kg} \mathrm{sc}$ on stereotyped behavior in mice. Stereotypy scores for each group based on eight mice (maximum score for each mouse $=6$ ) which were acclimated for one hour prior to dosing.

Fig. 18 The effects of chronic (5-days) simultaneous administration of ethylketocyclazocine (EKC) at $20 \mathrm{mg} / \mathrm{kg}$ Sc and/or haloperidol at $1.25 \mathrm{mg} / \mathrm{kg}$ ip, 72 hours prior to apomorphine at $0.4 \mathrm{mg} / \mathrm{kg} \mathrm{sc}$ on stereotyped behavior in mice. Stereotypy scores for each group based on eight mice (maximum score for each mouse $=6$ ) which were acclimated for one hour prior to dosing.

Fig. 19 The effects of chronic (5-days) simultaneous administration of cyclazocine at $2.5 \mathrm{mg} / \mathrm{kg} \mathrm{sc}$ and/or haloperidol at $1.25 \mathrm{mg} / \mathrm{kg}$ ip, 72 hours prior to 
apomorphine at $0.4 \mathrm{mg} / \mathrm{kg}$ SC on stereotyped behavior in mice. Stereotypy scores for each group based on eight mice (maximum score for each mouse $=6$ ) which were acclimated for one hour prior to dosing.

Fig. 20 The effects of chronic (5-days) simultaneous administration of SKF 10,047 at $40 \mathrm{mg} / \mathrm{kg} \mathrm{sC}$ and/or haloperidol at $1.25 \mathrm{mg} / \mathrm{kg}$ ip, 72 hours prior to apomorphine at $0.4 \mathrm{mg} / \mathrm{kg}$ sc on stereotyped behavior in mice. Stereotypy scores for each group based on eight mice (maximum score for each mouse $=6$ ) which were acclimated for one hour prior to dosing. 
Figure 1

NIGROSTRIATAL SYSTEM

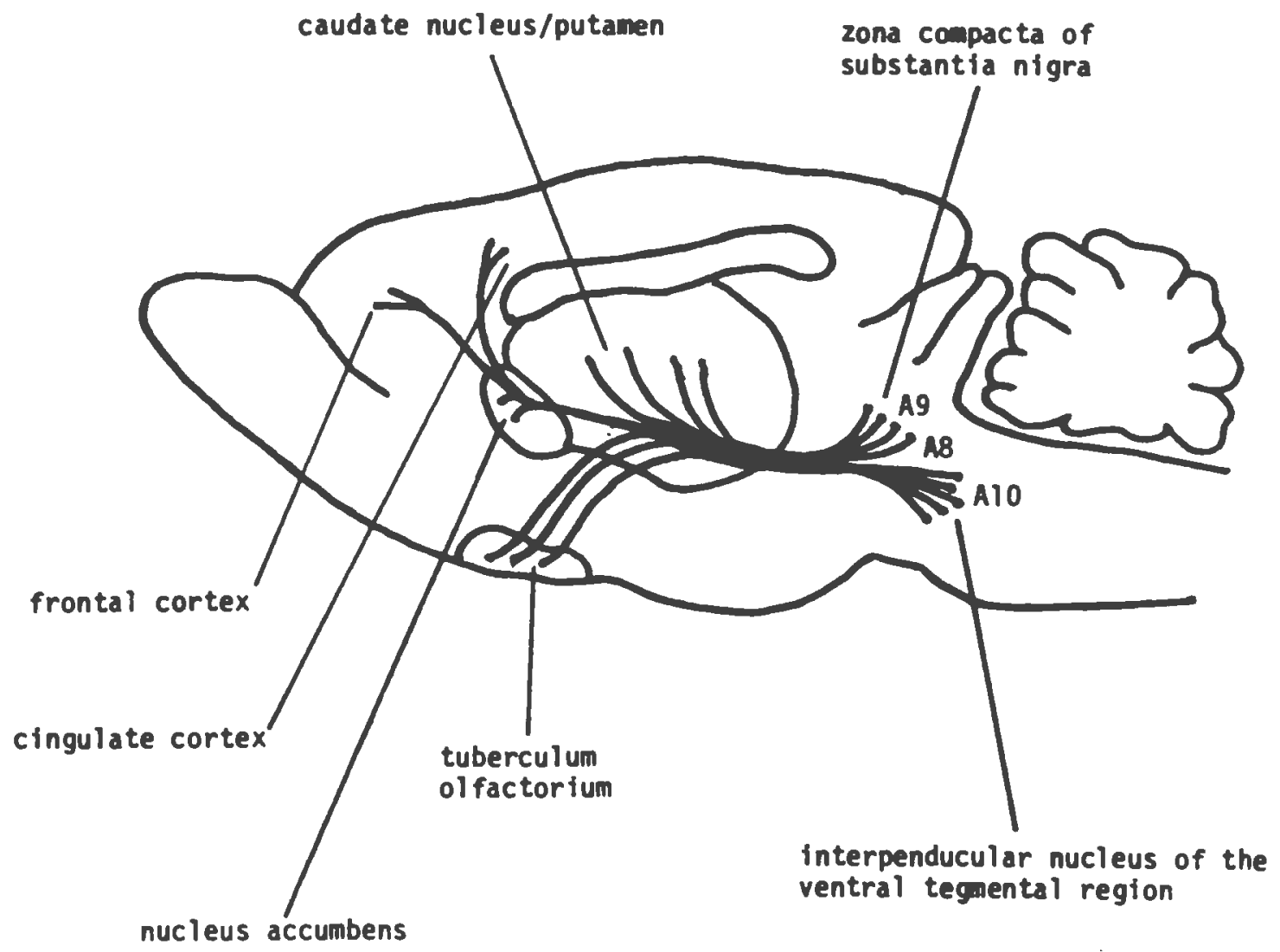

MESOLIMBIC SYSTEM 


\section{Figure 2}

\section{Opiate Receptor Subtypes}

Prototypical Agonists, Antagonists and Mixed Agonist-Antagonists

$\begin{array}{llcc}\text { Compound } & \underline{\kappa} & \underline{-} & - \\ \text { Morphine } & \text { Ag. } 1 & - & - \\ \text { Naloxone, Naltrexone } & \text { Ant. } & \text { Ant. } & \text { Ant. } \\ \text { Ketocyclazocine, Ethylketocyclazocine } & \text { Ant. } & \mathrm{Ag} . & - \\ \text { Pentazocine } & \text { Ant. } & \mathrm{Ag} . & \mathrm{Ag} . \\ \text { Cyclazocine } & \text { Ant. } & \mathrm{Ag} . & \mathrm{Ag} . \\ \mathrm{N} \text {-allyl-normetazocine (SKF 10,047) } & \text { Ant. } & - & \mathrm{Ag} . \\ & & & \\ 1_{\text {Ag. }}=\text { agonist, Ant. = antagonist, = no activity } & & \end{array}$


Figure 3

Morphine

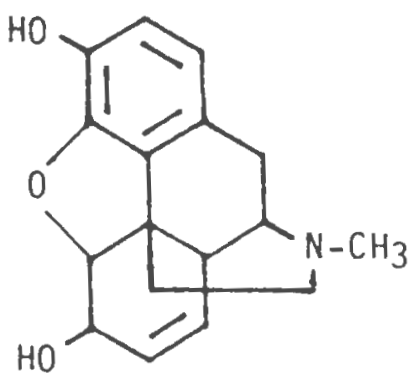

Naloxone

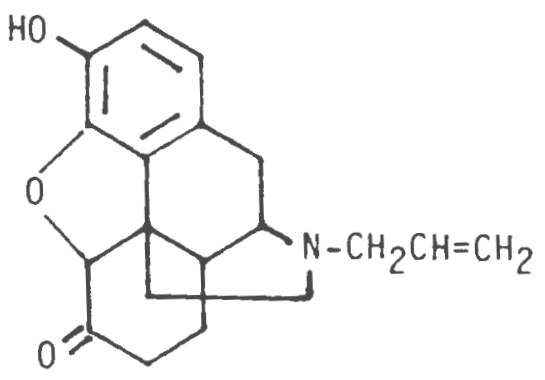

Naltrexone

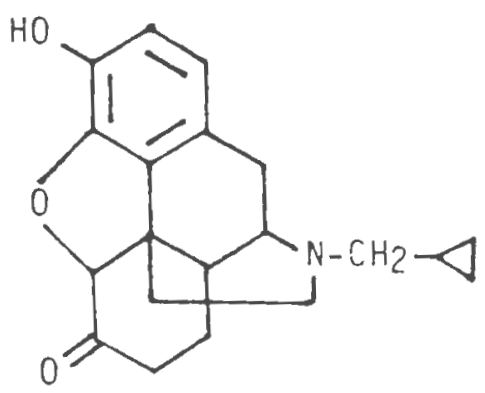


Figure 4

Chemical Structures of Benzomorphans

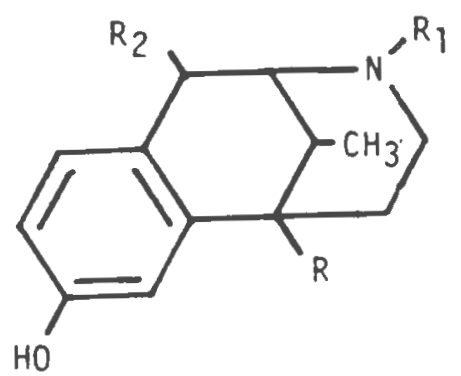

\begin{tabular}{|c|c|c|c|}
\hline & Type & $\underline{R}$ & $\underline{R_{3}}$ \\
\hline Cyclazocine & $(k, 0)$ & $\mathrm{CH}_{3}$ & $\mathrm{CH}_{2} \longrightarrow$ \\
\hline Pentazocine & $(k, 0)$ & $\mathrm{CH}_{3}$ & $\mathrm{CH}_{2} \mathrm{CH}=\mathrm{C}\left(\mathrm{CH}_{3}\right)_{2}$ \\
\hline SKF 10,047 & $(0)$ & $\mathrm{CH}_{3}$ & $\mathrm{CH}_{2} \mathrm{CH}=\mathrm{CH}_{2}$ \\
\hline Ethylketocyclazocine & $(k)$ & $\mathrm{CH}_{3} \mathrm{CH}_{2}$ & $\mathrm{CH}_{2} \longrightarrow$ \\
\hline
\end{tabular}




\section{Figure 5}

Opiate Receptor Subtypes

Antinociceptive Activity - Behavioral Excitation Activity in Mice

\begin{tabular}{|c|c|c|}
\hline Compound (receptor subtype) & $\begin{array}{l}\text { Ant inociceptive } \\
\text { Activity }\end{array}$ & $\begin{array}{l}\text { Behavioral } \\
\text { Excitation } \\
\text { Activity }\end{array}$ \\
\hline Morphine ( $\mu$ agonist) & +++1 & + \\
\hline Naloxone, naltrexone $(\mu, k, \sigma$ antagonist $)$ & - & $-(+)$ \\
\hline $\begin{array}{l}\text { Ketocyclazocine, ethylketocyclazocine } \\
(x \text { agonist, } \mu \text { ant agonist })\end{array}$ & +++ & $+^{2} ; 4$ \\
\hline Pentazocine ( $\kappa, \sigma$ agonist; $\mu$ antagonist) & ++ & 4 \\
\hline Cyclazocine ( $k, 0$ agonist; $\mu$ antagonist) & + & + \\
\hline $\begin{array}{l}N \text {-allyl-normetazocine (o agonist, } \\
\text { } \text { antagonist) }\end{array}$ & - & $\uparrow$ \\
\hline
\end{tabular}




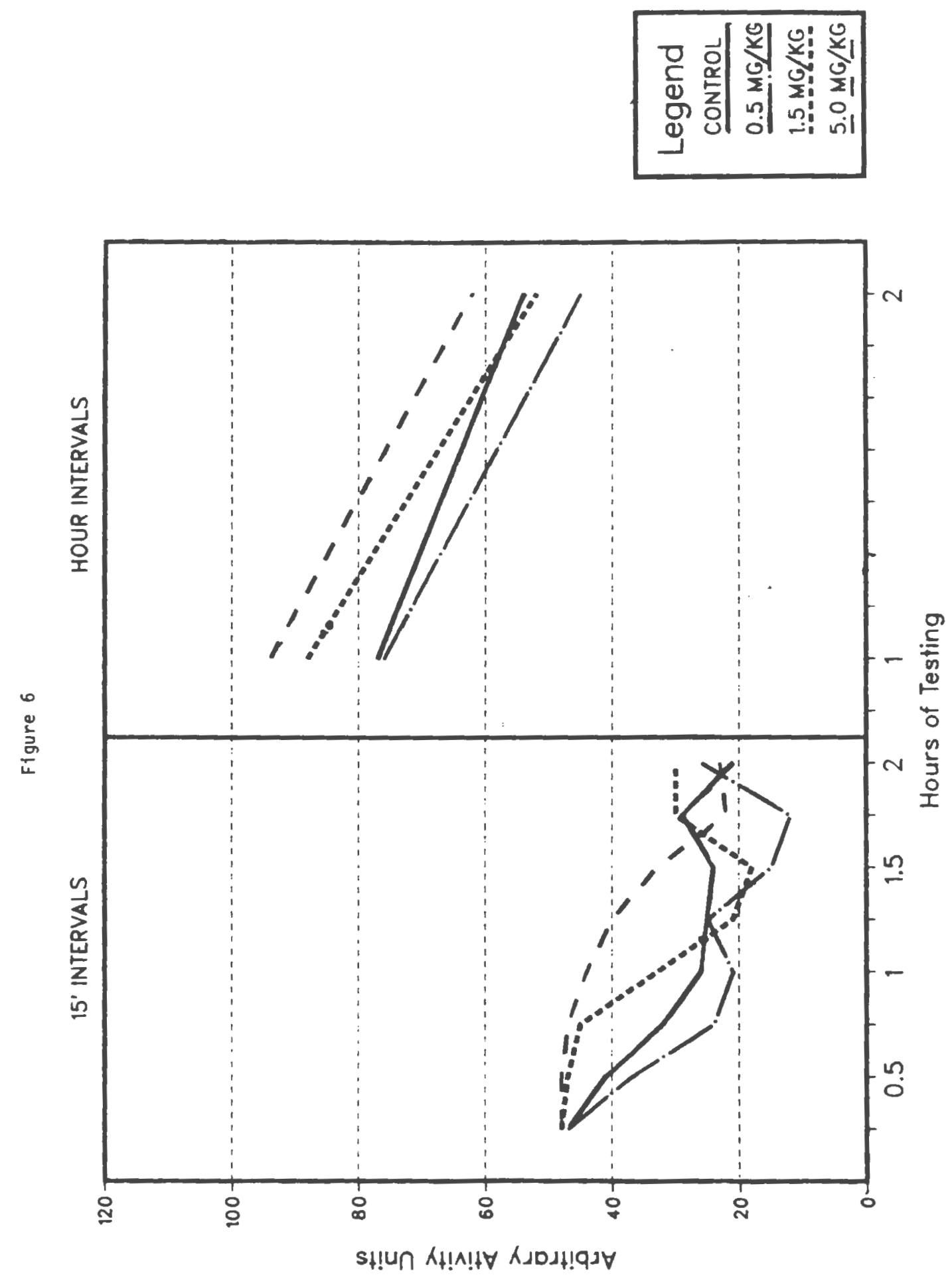


Figure 7

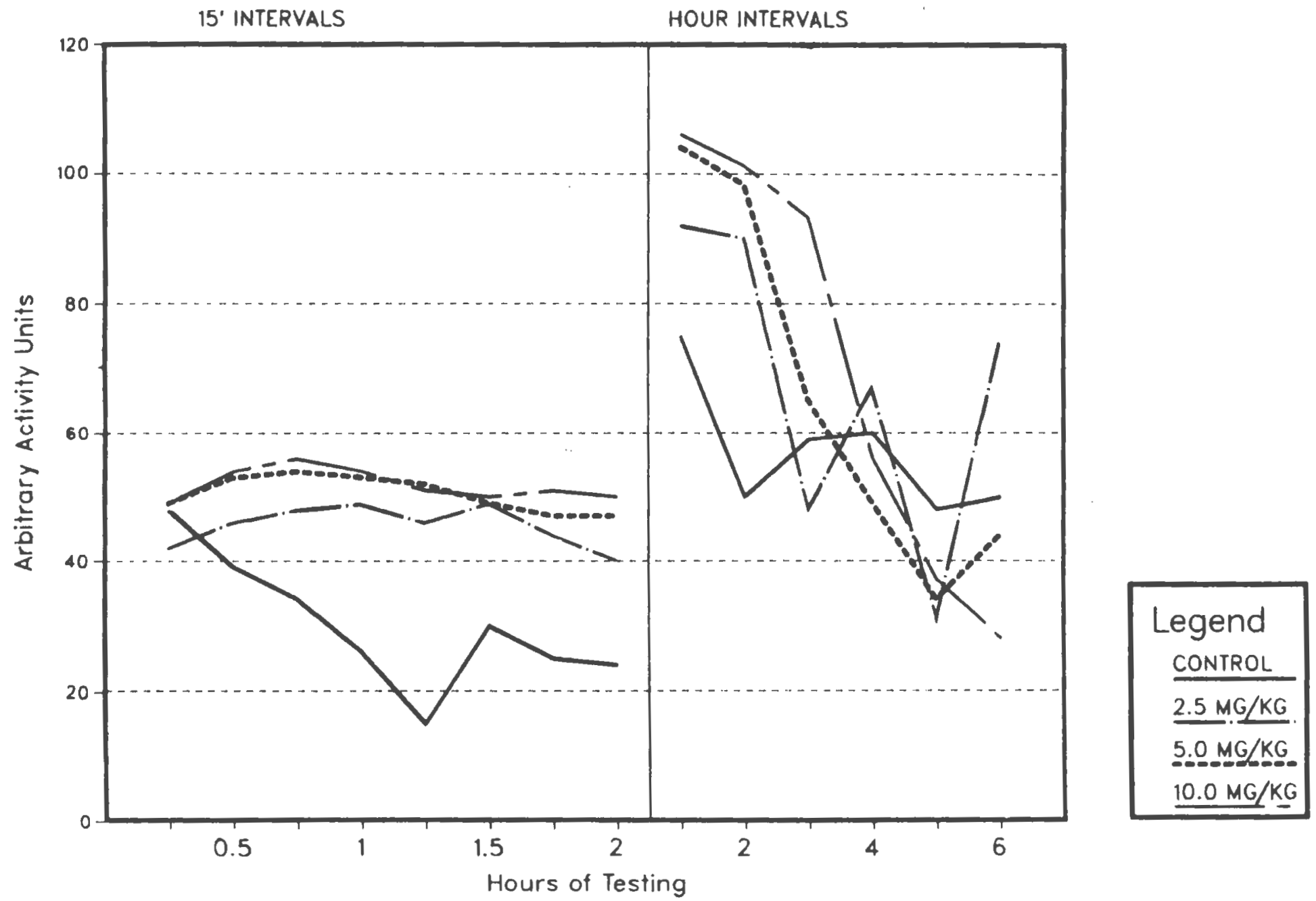


Figure 8

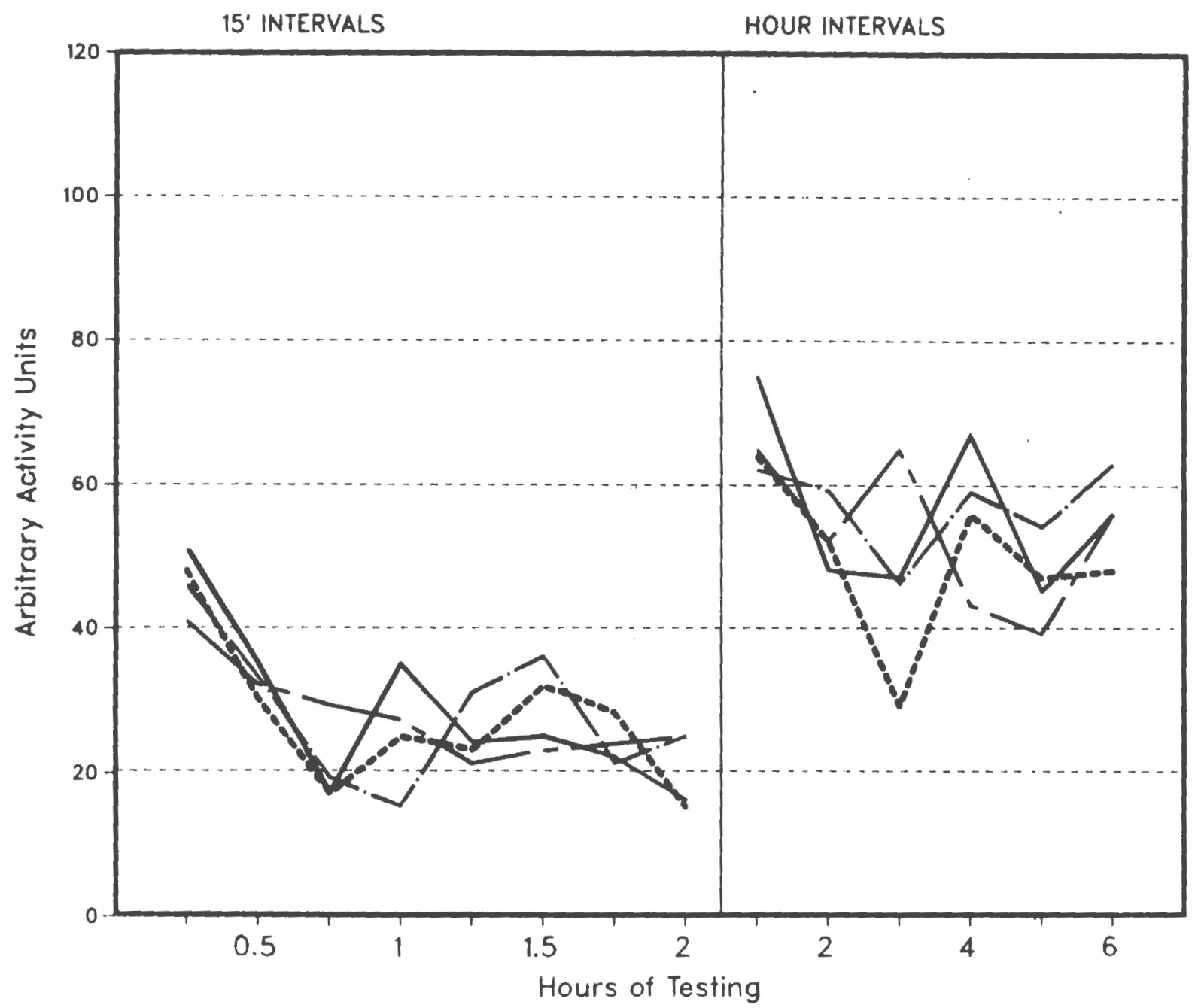
Legend CONTROL $10.0 \mathrm{MG} / \mathrm{KG}$ $20.0 \mathrm{MG} / \mathrm{KG}$ $40.0 \mathrm{MG} / \mathrm{KG}$

Hours of Testing 
Figure 9

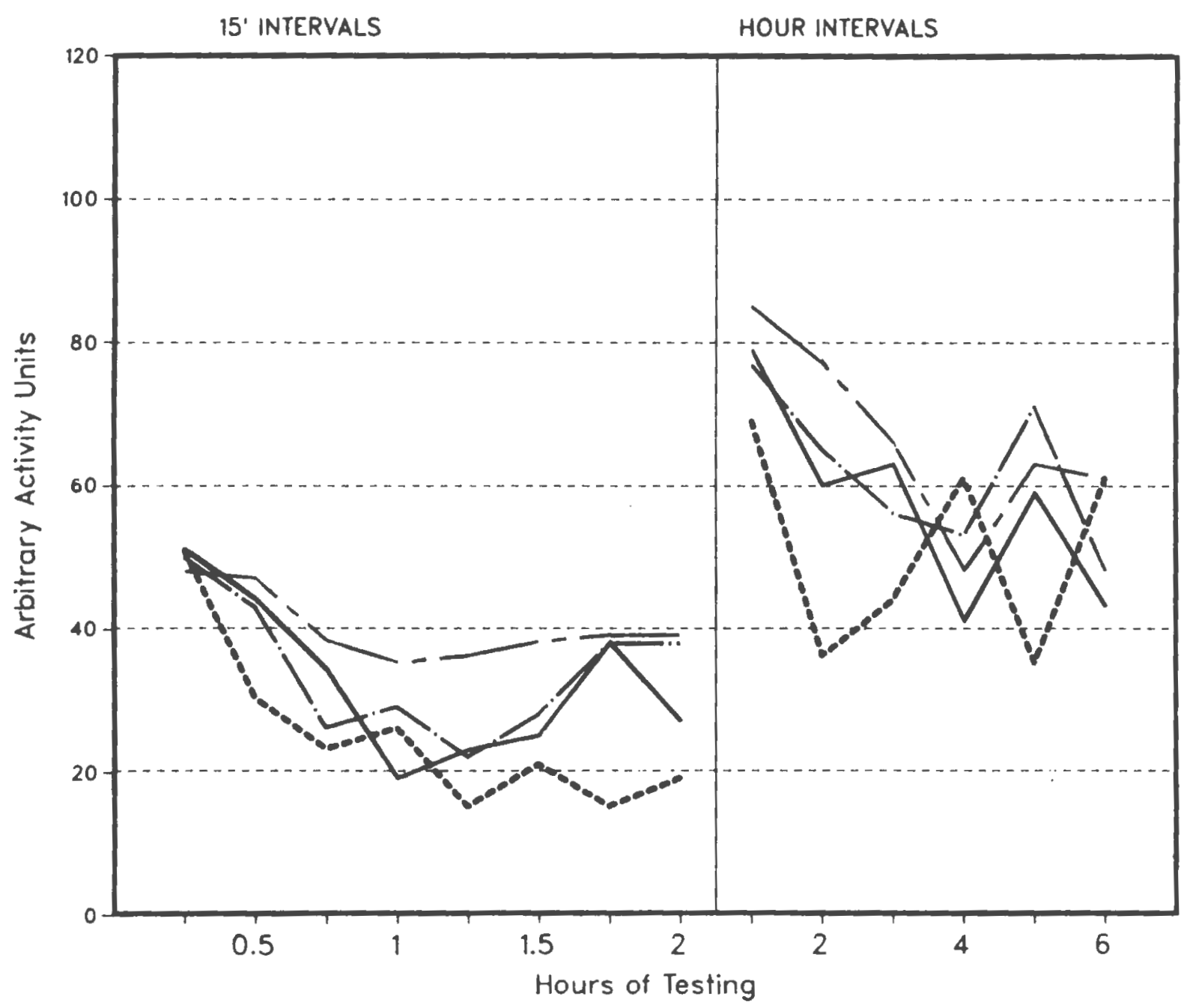


Figure 10

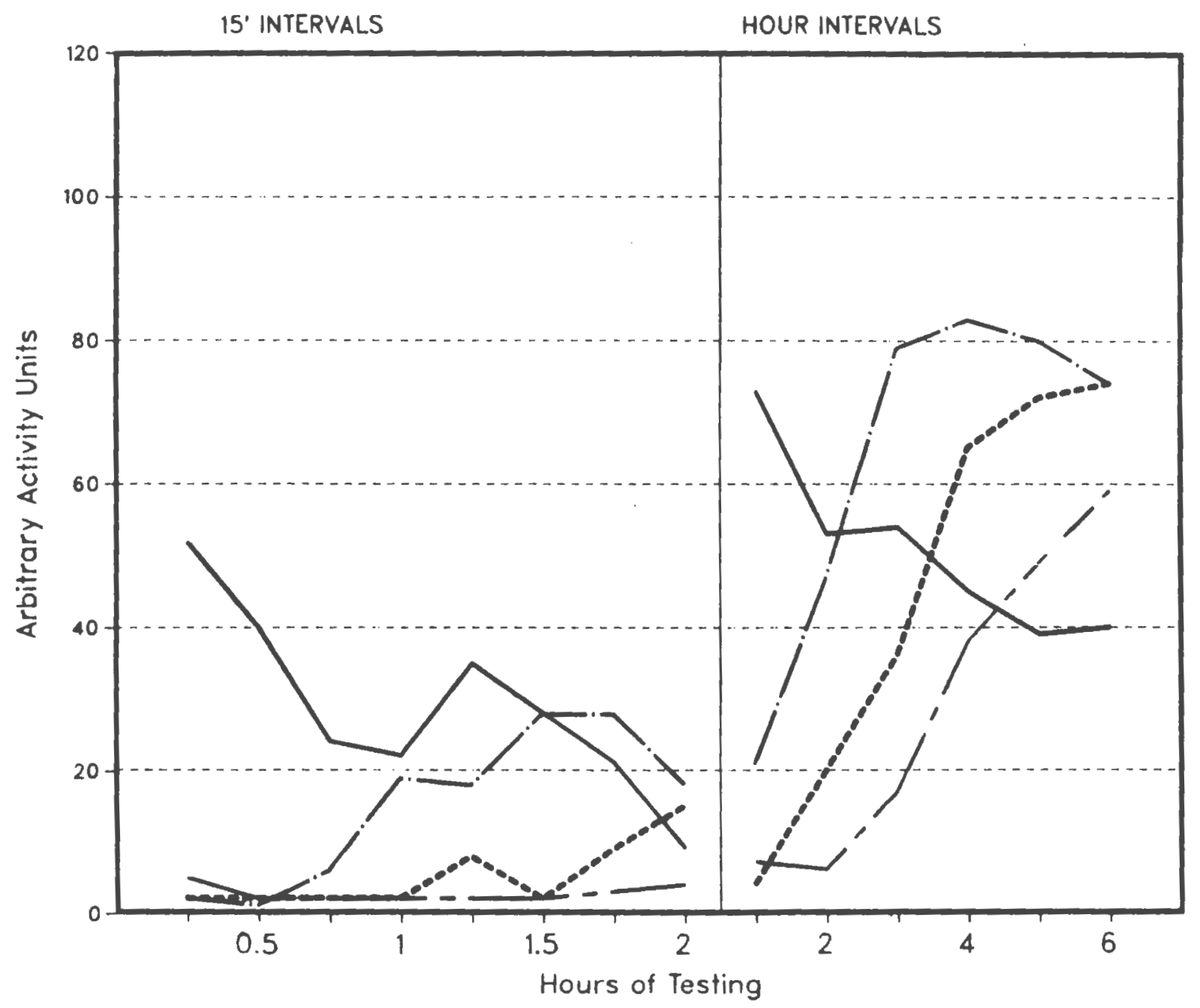

\begin{tabular}{l}
$\begin{array}{l}\text { Legend } \\
\text { CONTROL }\end{array}$ \\
\hline $5.0 \mathrm{MG} / \mathrm{KG}$ \\
$10.0 \mathrm{MG} / \mathrm{KG}$ \\
$20.0 \mathrm{MG} / \mathrm{KG}$
\end{tabular}


Figure 11

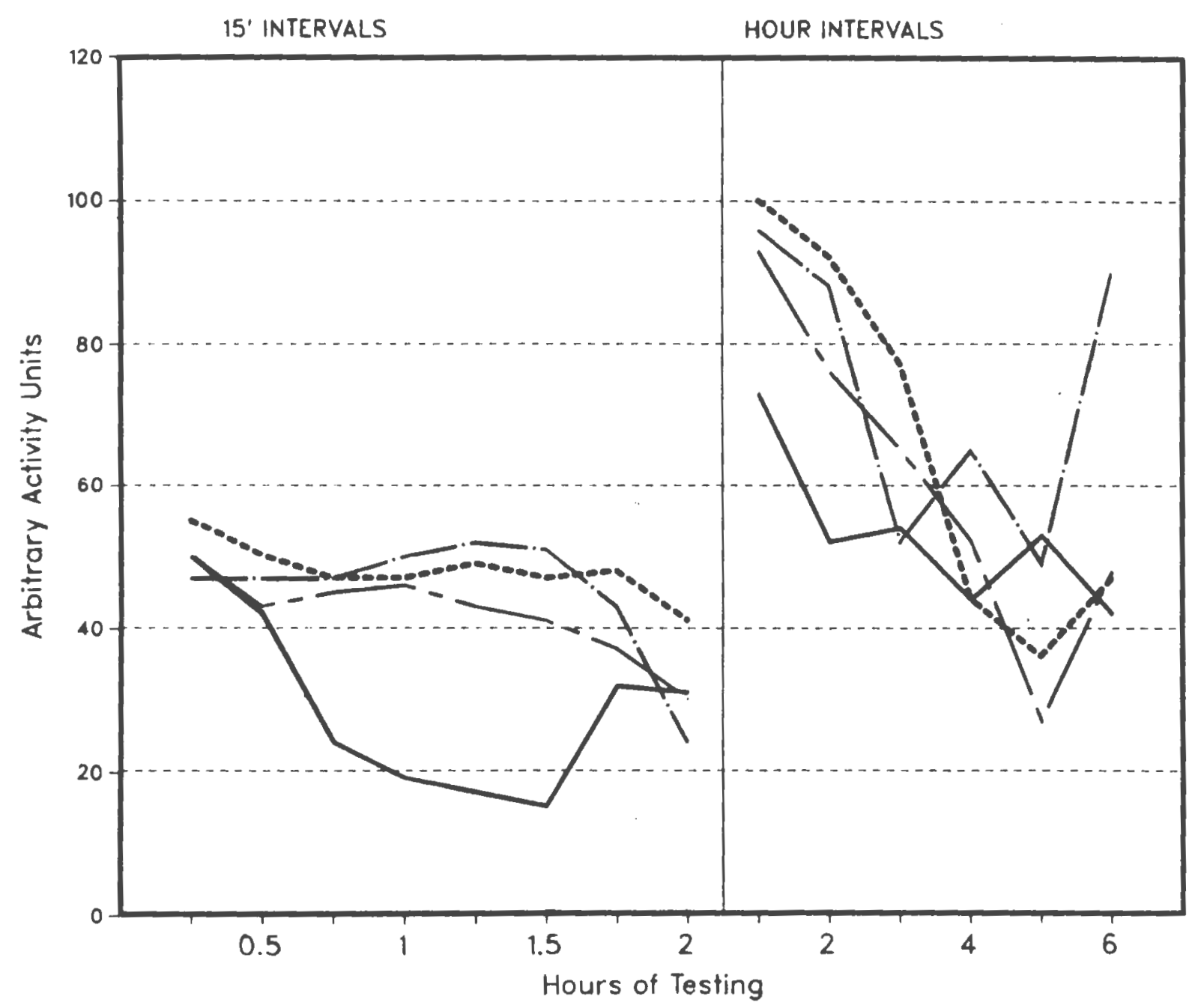

Legend

CONTROL

$20.0 \mathrm{MG} / \mathrm{KG}$

$40.0 \mathrm{MG} / \mathrm{KG}$

$80.0 \mathrm{MG} / \mathrm{KG}$ 
Figure 12

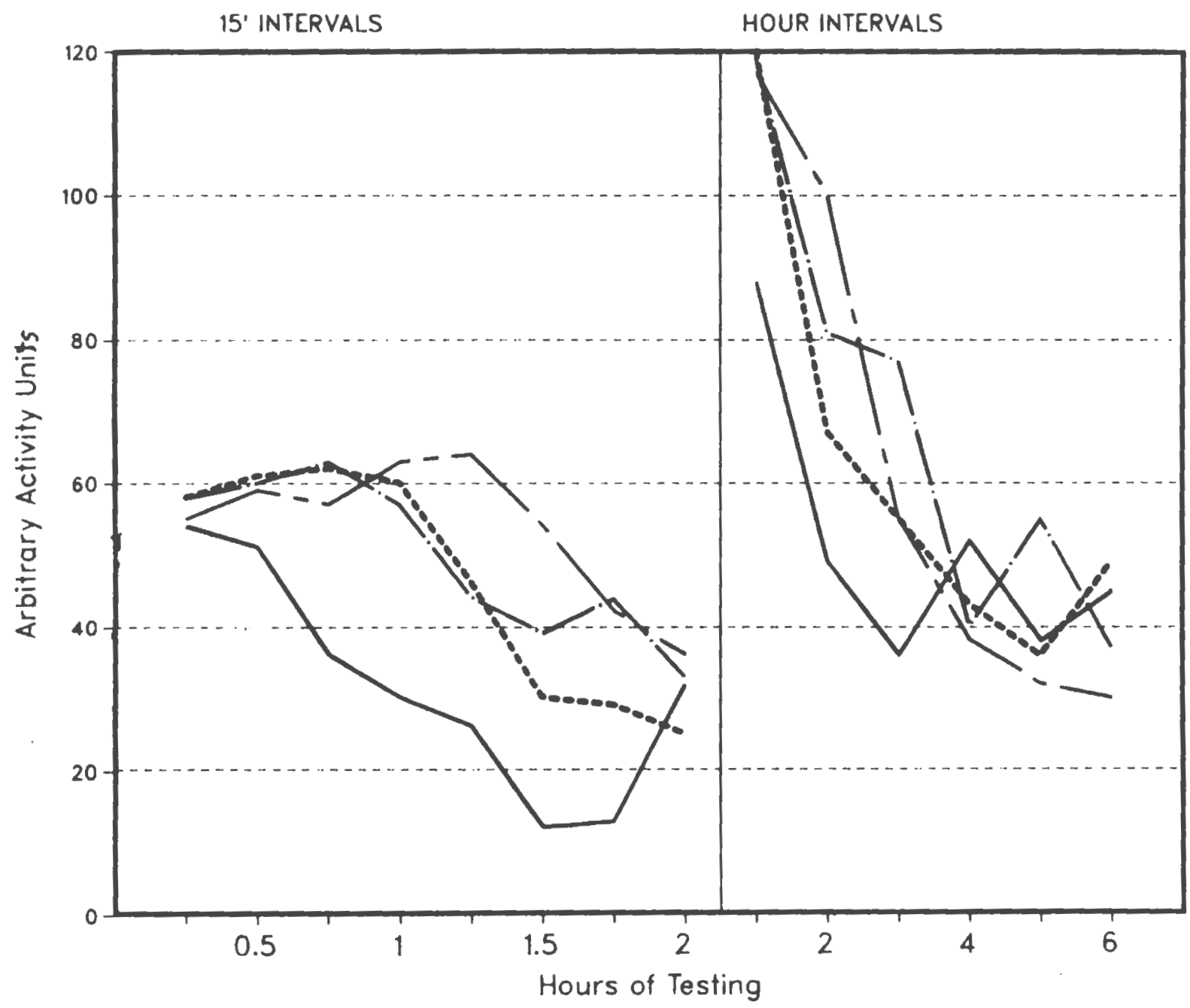




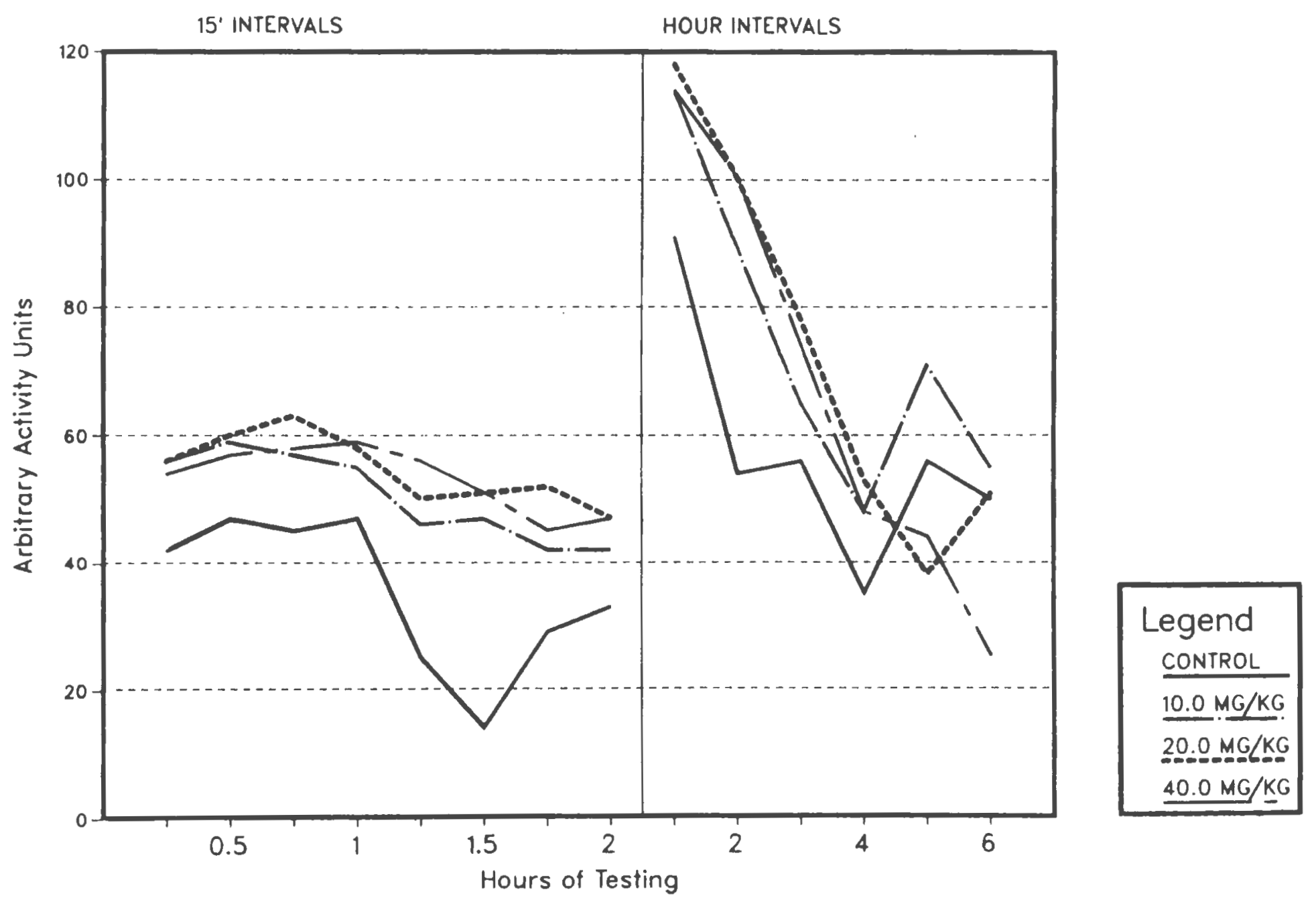




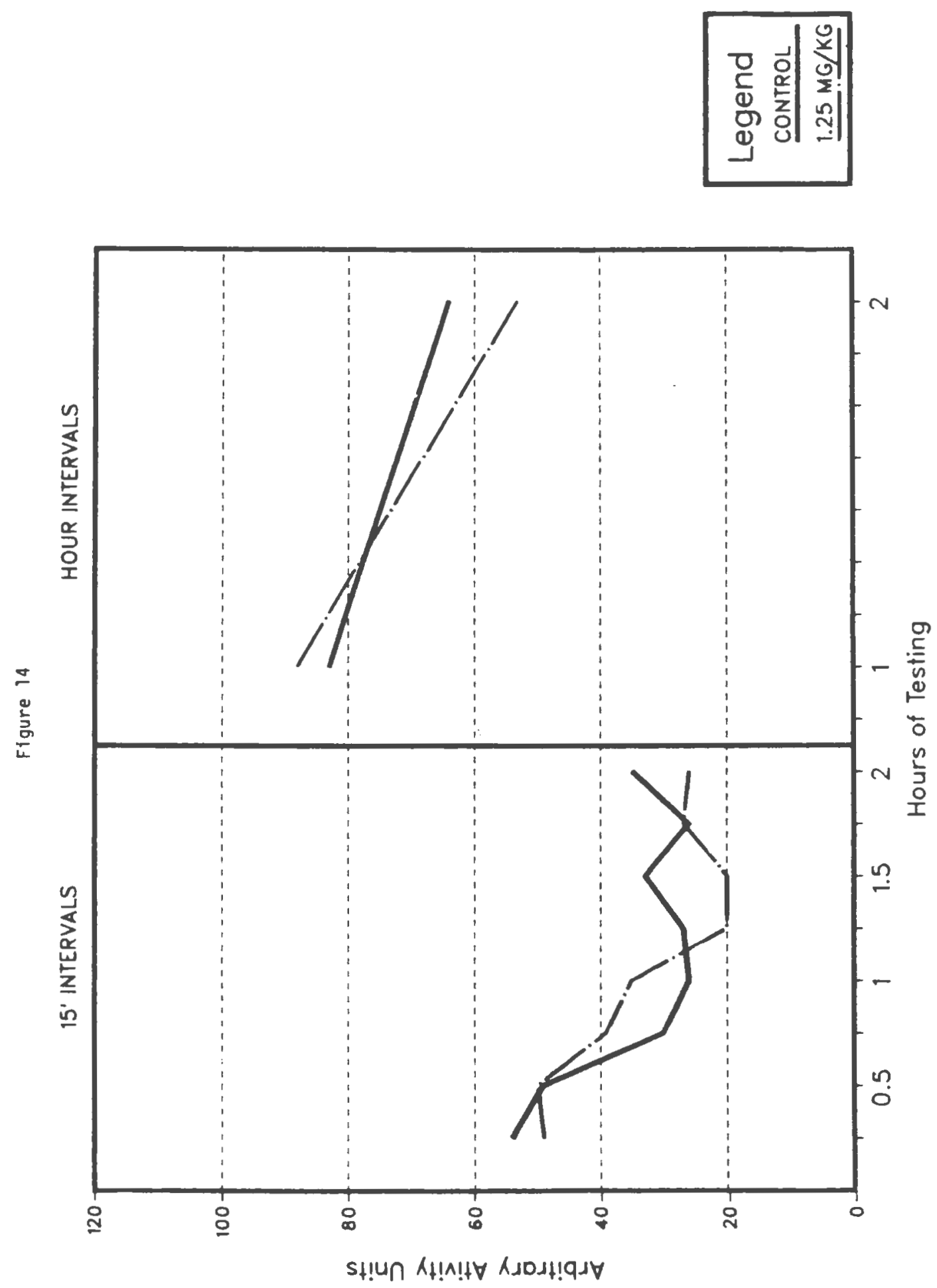


Figure 15

15' INTERVALS

HOUR INTERVALS

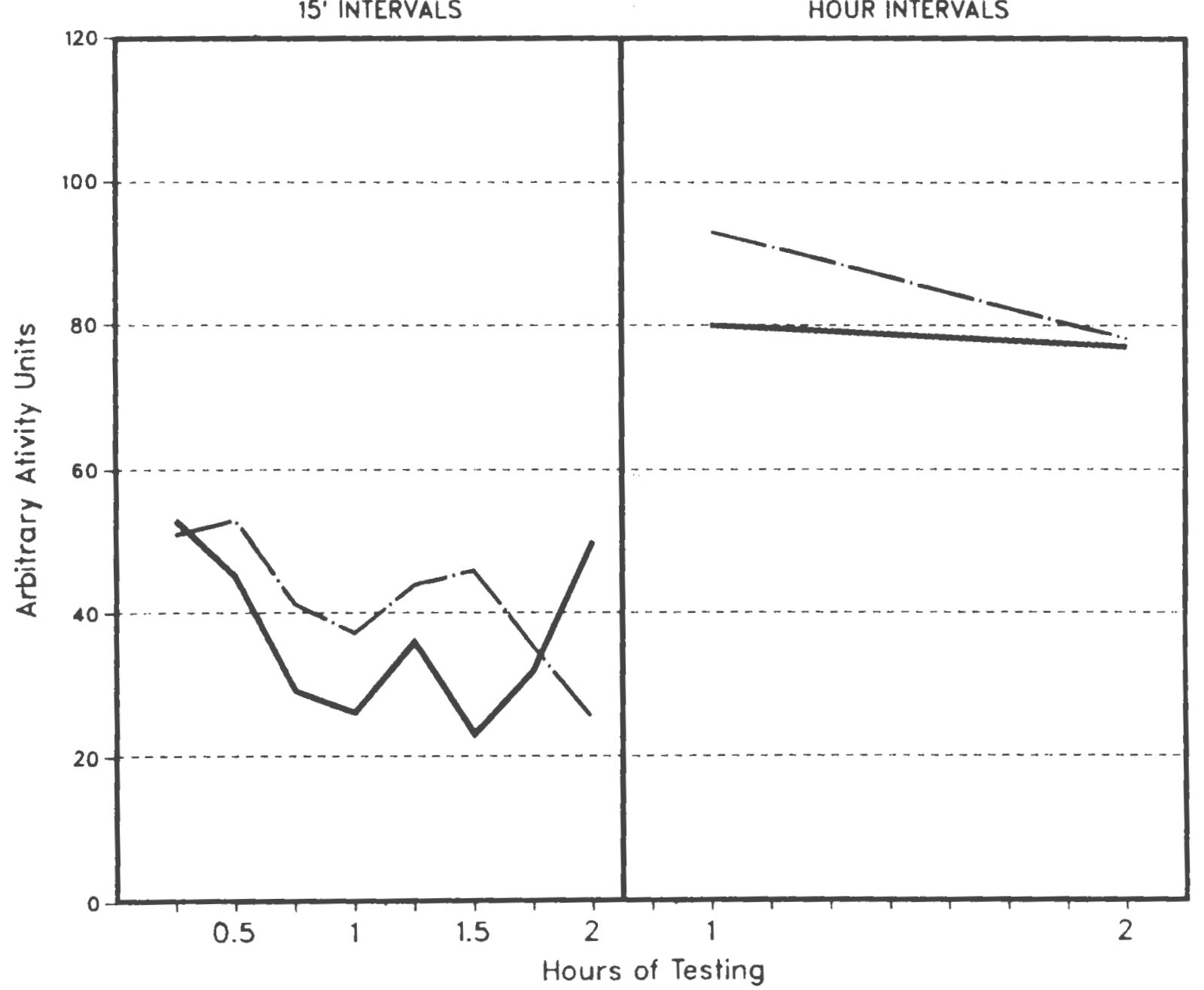




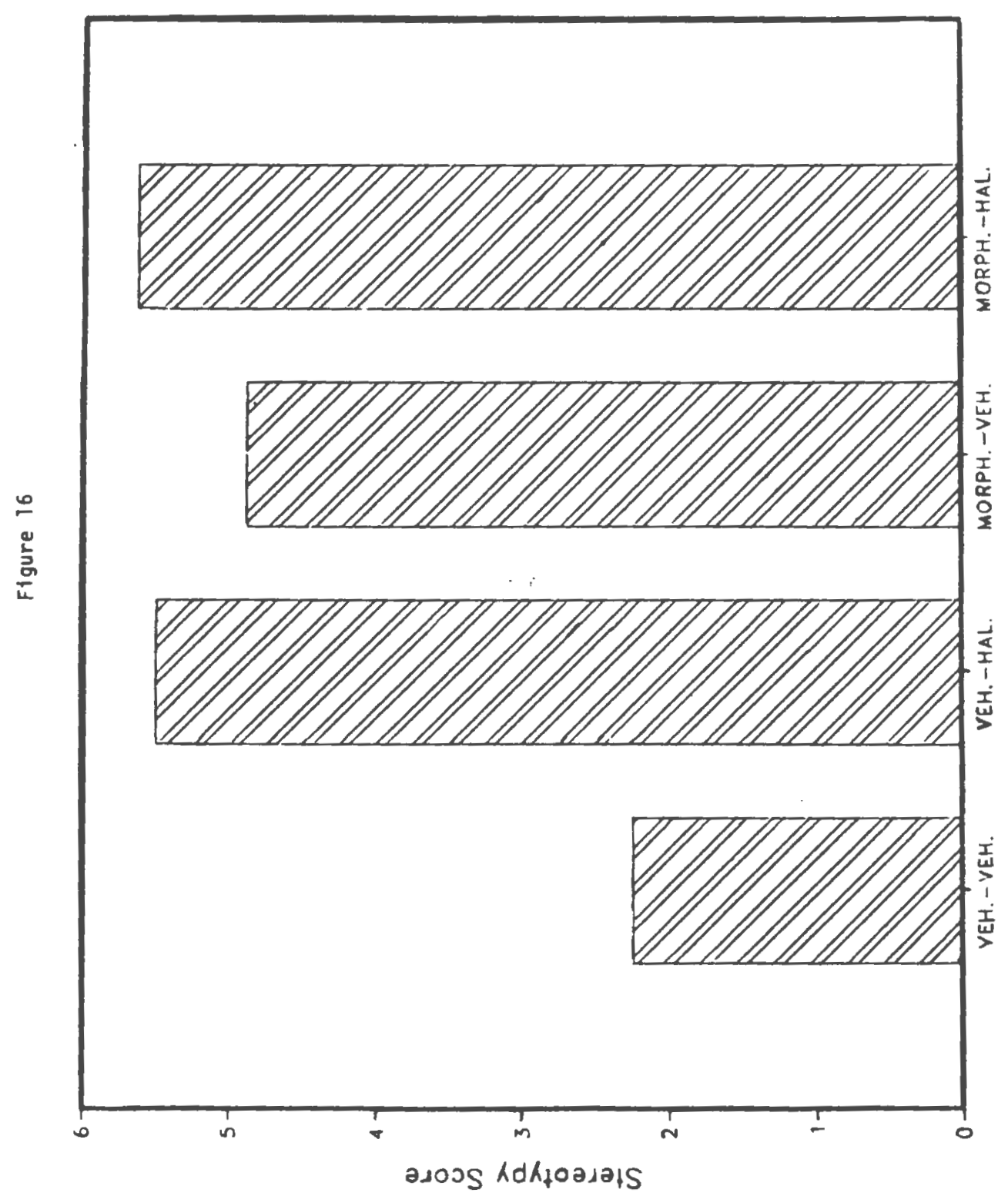


100

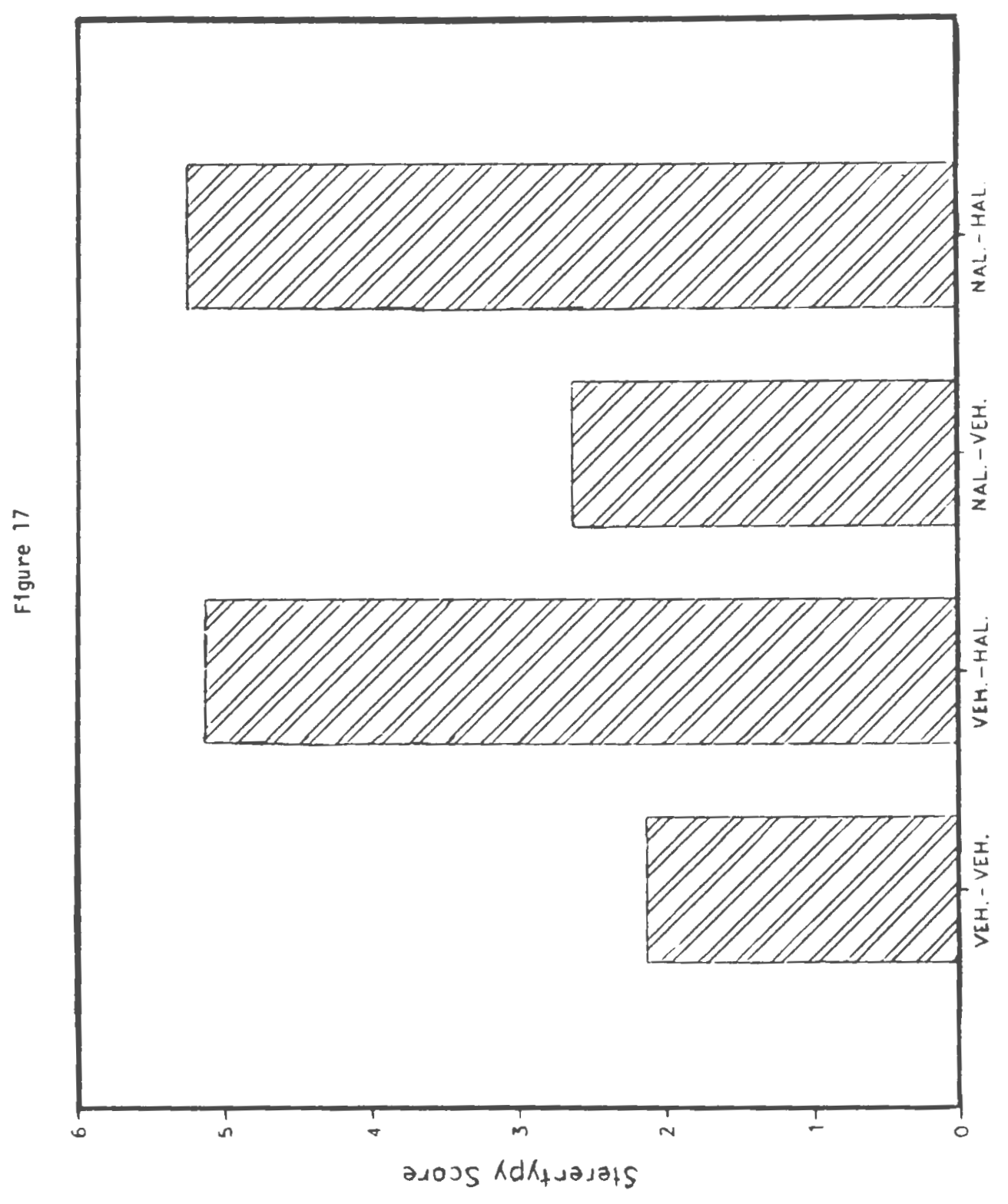




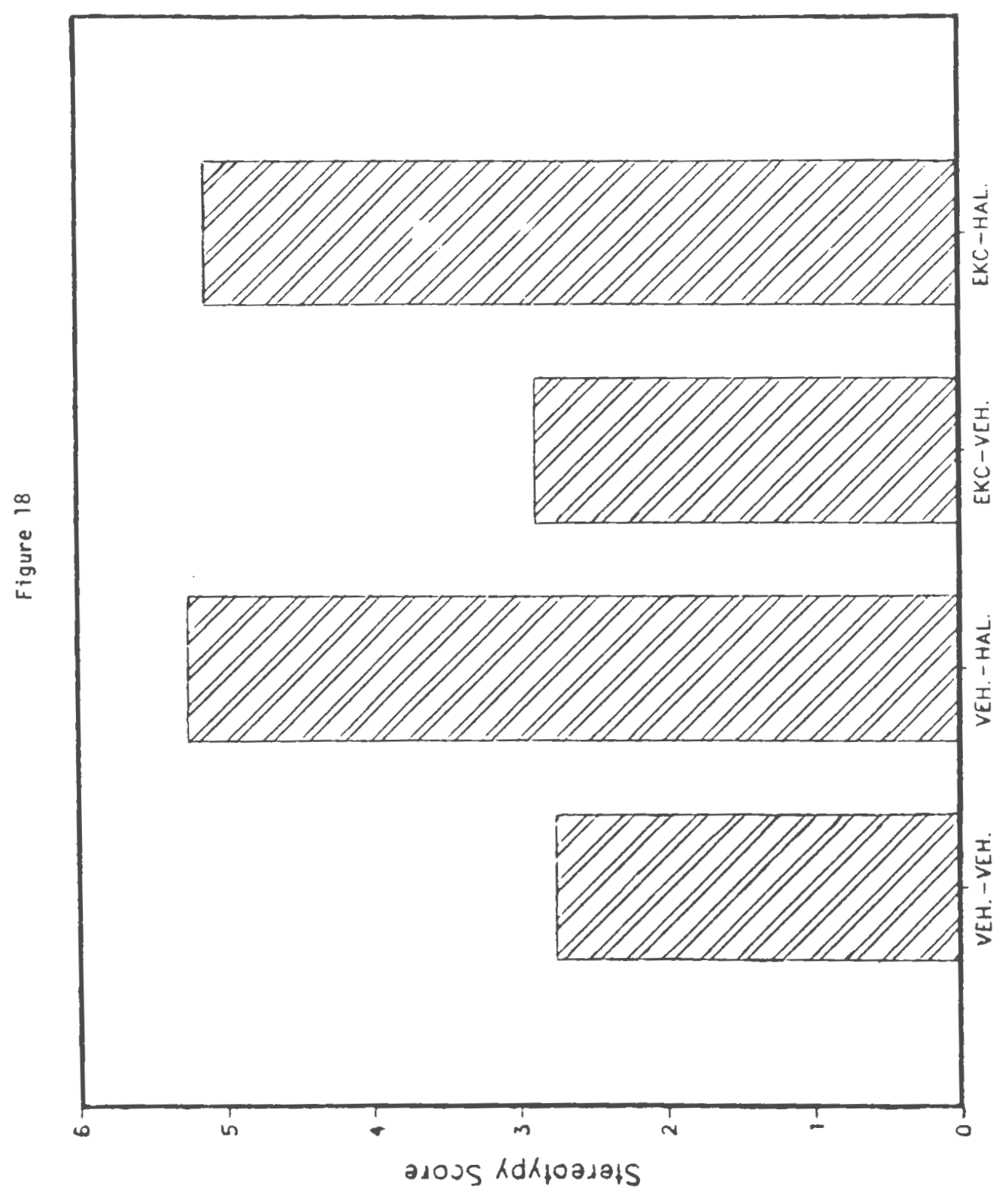




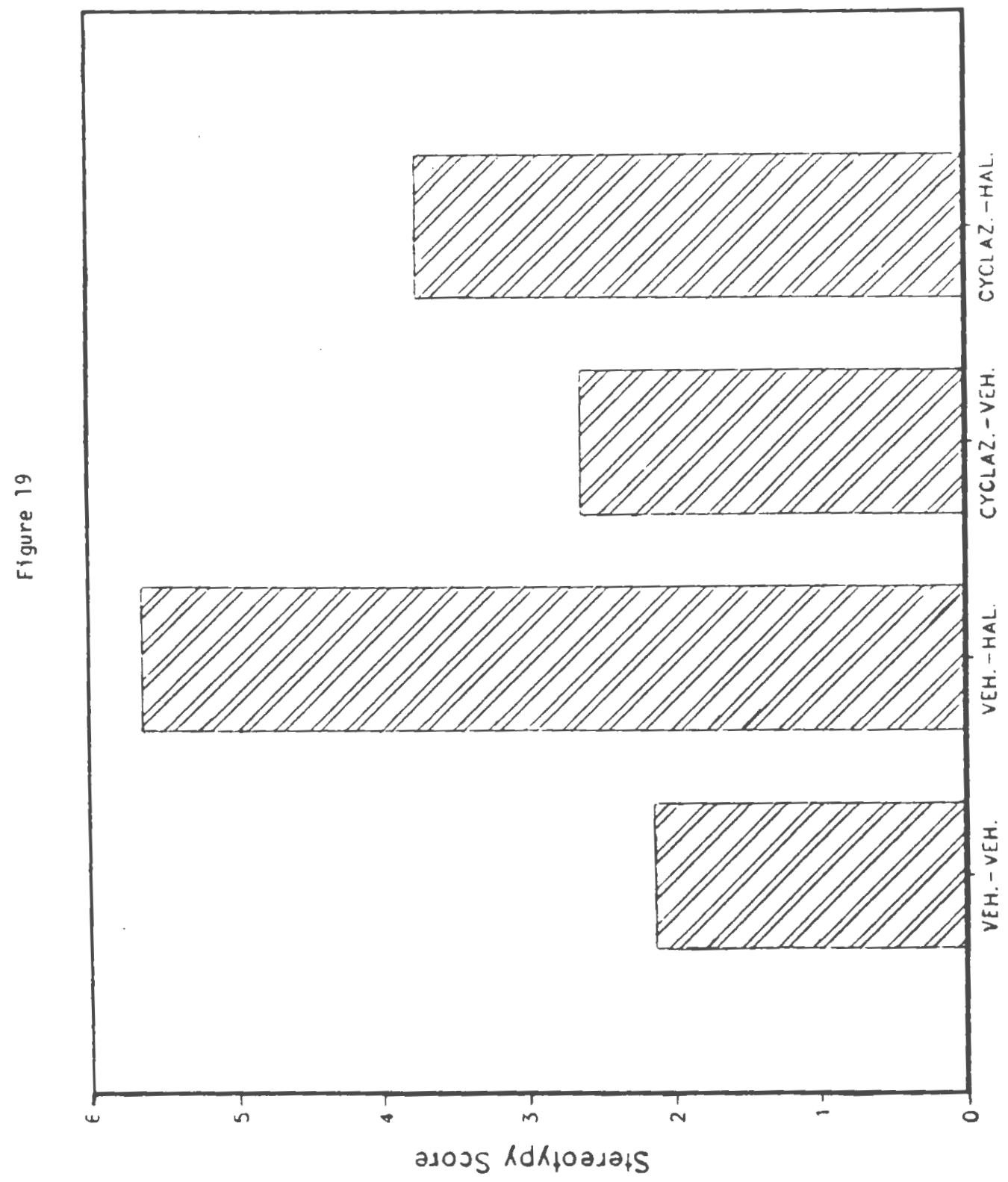




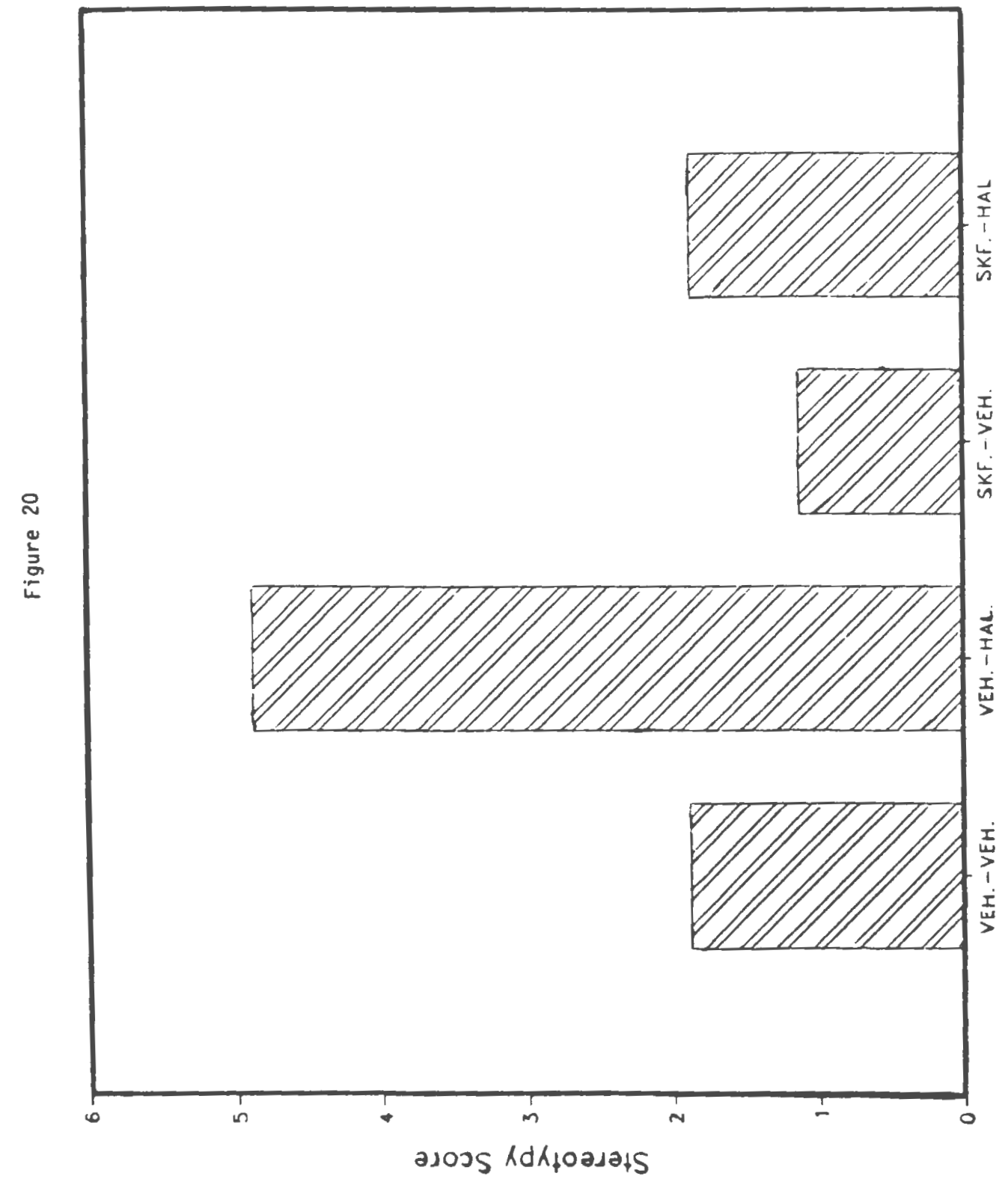


TABLE 1

Effects of Apomorphine on Locomotor Activity

Mean Activity Counts \pm S.E.a

1. $15^{\prime}$ Intervals over 2 Hours

$\begin{array}{ccccccccc}\begin{array}{c}\text { Dose } \\ \text { (mg/kg sc) }\end{array} & \underline{0-15^{\prime}} & \underline{15^{\prime}-30^{\prime}} & \underline{30^{\prime}-45^{\prime}} & \underline{45^{\prime}-60^{\prime}} & \underline{60^{\prime}-75^{\prime}} & \underline{75^{\prime}-90^{\prime}} & \frac{90^{\prime}-105^{\prime}}{105^{\prime}-120^{\prime}} \\ \text { Control } & 46.5 \pm 1.4 & 40.5 \pm 4.0 & 32.4 \pm 6.0 & 25.8 \pm 6.9 & 24.6 \pm 7.0 & 24.4 \pm 4.3 & 29.4 \pm 3.7 & 21.0 \pm 5.1 \\ 0.5 & 46.9 \pm 0.9 & 37.1 \pm 3.0 & 24.4 \pm 3.1 & 21.3 \pm 3.1 & 24.6 \pm 3.2 & 14.9 \pm 3.2 & 12.0 \pm 4.0 & 25.5 \pm 4.4 \\ 1.5 & 48.0 \pm 0.5 & 47.1 \pm 0.7 & 45.1 \pm 1.2 & 33.1 \pm 2.7 & 21.1 \pm 3.1 & 17.8 \pm 3.3 & 30.0 \pm 3.5 & 29.6 \pm 3.6 \\ 5.0 & 48.1 \pm 1.5 & 47.6 \pm 2.1 & 46.8 \pm 2.6 & 44.0 \pm 2.3 & 39.9 \pm 2.8 & 32.8 \pm 4.6 & 22.3 \pm 4.8 & 23.0 \pm 4.0\end{array}$

2. $60^{\prime}$ Intervals over 2 Hours

$\begin{array}{ccc}\begin{array}{c}\text { Dose } \\ \text { (mg/kg sc) }\end{array} & \underline{60} & \underline{120^{\prime}} \\ \text { Control } & 77.0 \pm 6.8 & 53.5 \pm 7.4 \\ 0.5 & 75.7 \pm 2.9 & 44.5 \pm 2.6 \\ 1.5 & 87.8 \pm 1.7 & 52.3 \pm 4.3 \\ 5.0 & 93.5 \pm 4.1 & 62.0 \pm 6.7\end{array}$

a Mean and standard error of the square root of the activity counts of 16 pairs of mice.

\#p <0.05; One-way ANOVA, Dunnet's multiple comparison 
TABLE la

Effects of Apomorphine on Locomotor Activity

Mean Activity Counts \pm S.E.a

1. 15 $^{\prime}$ Intervals over 2 Hours

\begin{tabular}{|c|c|c|c|c|c|c|c|c|}
\hline $\begin{array}{c}\text { Dose } \\
(\mathrm{mg} / \mathrm{kg} \mathrm{sc})\end{array}$ & $0-15^{\circ}$ & $15^{\prime}-30^{\prime}$ & $30^{\prime}-45^{\prime}$ & $45^{\prime}-60^{\prime}$ & $60^{\prime}-75^{\prime}$ & $75^{\prime}-90^{\prime}$ & $90^{\prime}-105^{\prime}$ & $105^{\prime}-120^{\prime}$ \\
\hline Control & $2170 \pm 133$ & $1751 \pm 261$ & $1289 \pm 331$ & $1001 \pm 324$ & $944 \pm 352$ & $732 \pm 214$ & $961 \pm 222$ & $624 \pm 245$ \\
\hline 0.5 & $2195 \pm 79$ & $1427 \pm 197$ & $670 \pm 149$ & $514 \pm 158$ & $688 \pm 143$ & $298 \pm 89$ & $261 \pm 135$ & $797 \pm 214$ \\
\hline 1.5 & $2308 \pm 45$ & $2242 \pm 66$ & $1797 \pm 178$ & $1148 \pm 192$ & $507 \pm 127$ & $383 \pm 151$ & $988 \pm 203$ & $975 \pm 198$ \\
\hline 5.0 & $2345 \pm 144$ & $2297 \pm 205$ & $2244 \pm 262$ & $1966 \pm 212$ & $1655 \pm 225$ & $1225 \pm 272$ & $660 \pm 252$ & $636+198$ \\
\hline
\end{tabular}

2. $60^{\prime}$ Intervals over 2 Hours

\begin{tabular}{ccc}
$\begin{array}{c}\text { Dose } \\
(\mathrm{mg} / \mathrm{kg} s c)\end{array}$ & $\underline{60^{\prime}}$ & $\underline{120^{\circ}}$ \\
\hline Control & $6211 \pm 999$ & $3261 \pm 791$ \\
0.5 & $4805 \pm 367$ & $2043 \pm 228$ \\
1.5 & $7732 \pm 301$ & $2863 \pm 446$ \\
5.0 & $8851 \pm 800$ & $4176 \pm 868$
\end{tabular}

aMean and standard error of the activity counts of 16 pairs of mice. 
TABLE 2

Apomorphine-Induced Stereotyped Behavior in Mice

\begin{tabular}{|c|c|c|c|c|}
\hline $\begin{array}{c}\text { Apomorphine } \\
\text { Dose } \\
(\mathrm{mg} / \mathrm{kg} \mathrm{sc})\end{array}$ & $\underline{n}$ & $\begin{array}{c}\text { Stereotypy Score } \\
\bar{x} \pm \text { SE }\end{array}$ & \% of Stereotypya & $\begin{array}{c}E D_{50} \\
\text { (95\% confidence limits) }\end{array}$ \\
\hline 0 & 8 & $0.00 \pm 0.00$ & - & \multirow{4}{*}{$0.80(0.76-0.84)$} \\
\hline 0.3 & 8 & $1.38 \pm 0.26$ & 23 & \\
\hline 1.0 & 8 & $3.25 \pm 0.16$ & 54 & \\
\hline 3.0 & 8 & $5.38 \pm 0.18$ & 90 & \\
\hline
\end{tabular}

a $\%$ of stereotypy based on maximum score $=6$

* stereotypy $=\frac{\bar{x} \text { of Dose Group }}{\text { Max. score }} \times 100$ 
TABLE 3

Apomorphine-Induced $\mathrm{Cl}$ imbing Behavior in Mice

\begin{tabular}{|c|c|c|c|c|}
\hline $\begin{array}{c}\text { Apomorphine } \\
\text { Dose } \\
(\mathrm{mg} / \mathrm{kg} \mathrm{sc})\end{array}$ & $\underline{n}$ & $\begin{array}{c}\text { Climbing Score } \\
\bar{x} \pm S E \\
\end{array}$ & \& of climbing & $\begin{array}{c}E D_{50} \\
\text { (95\% confidence limits) }\end{array}$ \\
\hline 0 & 8 & $0.13 \pm 0.13$ & - & \multirow{4}{*}{$0.58(0.55-0.61)$} \\
\hline 0.3 & 8 & $0.75 \pm 0.41$ & 11 & \\
\hline 1.0 & 8 & $5.25 \pm 0.37$ & 87 & \\
\hline 3.0 & 8 & $5.75 \pm 0.16$ & 96 & \\
\hline
\end{tabular}

a \% of climbing based on maximum score $=6$

\% climbing $=\frac{(\bar{x} \text { of Dose Group })-(\bar{x} \text { of Control })}{(\text { Max. score })-(\bar{x} \text { of Control })} \times 100$ 
TABLE 4

Effects of Morphine on Locomotor Activity

Mean Activity Counts \pm S.E. a

1. 15' Intervals over 2 Hours

\begin{tabular}{|c|c|c|c|c|c|c|c|c|}
\hline $\begin{array}{l}\text { Dose } \\
\mathrm{mg} / \mathrm{kg} \mathrm{sc})\end{array}$ & $0-15^{\prime}$ & $15^{\prime}-30^{\prime}$ & $30^{\prime}-45^{\prime}$ & $45^{\prime}-60^{\prime}$ & $60^{\prime}-75^{\prime}$ & $75^{\prime}-90^{\prime}$ & $90^{\prime}-105^{\prime}$ & $105^{\prime}-120^{\prime}$ \\
\hline Control & $48.1 \pm 10.4$ & $39.0 \pm 15.8$ & $33.6 \pm 9.6$ & $25.7 \pm 7.1$ & $14.9 \pm 7.3$ & $30.2 \pm 13.9$ & $24.6 \pm 4.0$ & $24.3 \pm 2.8$ \\
\hline 2.5 & $41.5 \pm 4.8$ & $46.0 \pm 17.9$ & $48.2 \pm 4.6$ & $48.6 \pm 4.9 *$ & $45.6 \pm 5.7^{\star}$ & $48.8 \pm 4.0$ & $43.6 \pm 1.9 \star$ & $40.1 \pm 4.8^{*}$ \\
\hline 5 & $48.7 \pm 1.8$ & $52.6 \pm 0.4$ & $53.7 \pm 1.3$ & $52.8 \pm 0.4^{\star}$ & $51.8 \pm 0.8$ & $49.4 \pm 2.0$ & $47.2 \pm 5.5^{\star}$ & $47.4 \pm 5.0^{*}$ \\
\hline 10 & $48.7 \pm 3.8$ & $54.2 \pm 3.6$ & $55.9 \pm 0.6$ * & $53.5 \pm 0.7$ * & $51.1 \pm 0.1 \star$ & $49.8 \pm 0.3$ & $50.6 \pm 0.1 *$ & $50.0 \pm 0.7 \star$ \\
\hline
\end{tabular}

2. 60 ' Intervals over 6 Hours

\begin{tabular}{|c|c|c|c|c|c|c|}
\hline $\begin{array}{c}\text { Dose } \\
(\mathrm{mg} / \mathrm{kg} \mathrm{sc})\end{array}$ & $\underline{60^{\prime}}$ & $\underline{120^{\prime}}$ & $\underline{180^{\prime}}$ & $240^{\circ}$ & $300^{\circ}$ & $\underline{360^{\prime}}$ \\
\hline Control & $75.3 \pm 21.5$ & $50.0 \pm 9.9$ & $58.9 \pm 26.7$ & $60.4 \pm 9.7$ & $47.6 \pm 1.8$ & $49.7 \pm 21.4$ \\
\hline 2.5 & $92.3 \pm 9.5$ & $89.5 \pm 6.3^{\star}$ & $48.1 \pm 1.9$ & $66.5 \pm 8.5$ & $31.2 \pm 6.8$ & $73.9 \pm 4.5$ \\
\hline 5 & $104.0 \pm 2.0$ & $98.1 \pm 6.5^{\star}$ & $64.7 \pm 6.3$ & $49.0 \pm 14.2$ & $34.4 \pm 21.7$ & $44.3 \pm 7.2$ \\
\hline 10 & $106.3 \pm 4.2$ & $100.7 \pm 0.5^{*}$ & $92.6 \pm 7.1$ & $55.8 \pm 9.1$ & $37.2 \pm 5.8$ & $28.2 \pm 0.8$ \\
\hline
\end{tabular}

aMean and standard error of the square root of the activity counts of 4 pairs of mice.

\#P<0.05; One-way ANOVA, Dunnet's multiple comparison 


\section{TABLE $4 a$}

Effects of Morphine on Locomotor Activity

Mean Activity Counts \pm S.E.a

1. 15' Intervais over 2 Hours

$\begin{array}{ccccccccc}\begin{array}{c}\text { Dose } \\ \text { (mg/kg sc) }\end{array} & \underline{0-15^{\prime}} & \underline{15^{\prime}-30^{\prime}} & \underline{30^{\prime}-45^{\prime}} & \underline{45^{\prime}-60^{\prime}} & \underline{60^{\prime}-75^{\prime}} & \frac{75^{\prime}-90^{\prime}}{90^{\prime}-105^{\prime}} & \frac{105^{\prime}-120^{\prime}}{5} \\ \text { Control } & 2426 \pm 1002 & 1772 \pm 1229 & 1223 \pm 648 & 708 \pm 362 & 275 \pm 216 & 1105 \pm 838 & 622 \pm 198 & 599 \pm 136 \\ 2.5 & 1746 \pm 401 & 2139 \pm 427 & 2347 \pm 442 & 2385 \pm 478 & 2112 \pm 523 & 2401 \pm 386 & 1900 \pm 168 & 1634 \pm 388 \\ 5 & 2379 \pm 176 & 2772 \pm 45 & 2889 \pm 140 & 2790 \pm 44 & 2689 \pm 83 & 2440 \pm 199 & 2260 \pm 519 & 2270 \pm 476 \\ 10 & 2386 \pm 369 & 2954 \pm 384 & 3121 \pm 61 & 2865 \pm 79 & 2615 \pm 4 & 2477 \pm 30 & 2558 \pm 2 & 2501 \pm 68\end{array}$

2. $60^{\prime}$ Intervals over 6 Hours

\begin{tabular}{|c|c|c|c|c|c|c|}
\hline $\begin{array}{c}\text { Dose } \\
(\mathrm{mg} / \mathrm{kg} \mathrm{sc})\end{array}$ & $\underline{60}$ & $\underline{120^{\prime}}$ & $180^{\prime}$ & $\underline{240^{\prime}}$ & $300^{\prime}$ & $360^{\prime}$ \\
\hline Control & $6128 \pm 3242$ & $2601 \pm 992$ & $4186 \pm 3146$ & $3744 \pm 1175$ & $2265 \pm 167$ & $2923 \pm 2122$ \\
\hline 2.5 & $8616 \pm 1748$ & $8047 \pm 1129$ & $2318 \pm 178$ & $4487 \pm 1124$ & $1022 \pm 426$ & $5481 \pm 668$ \\
\hline 5 & $10829 \pm 406$ & $9658 \pm 1278$ & $4225 \pm 819$ & $2605 \pm 1395$ & $1653 \pm 1491$ & $2018 \pm 634$ \\
\hline 10 & $11324 \pm 895$ & $10150 \pm 96$ & $8629 \pm 1308$ & $3197 \pm 1020$ & $1414 \pm 430$ & $796 \pm 46$ \\
\hline
\end{tabular}

aptean and standard error of the activity counts of 4 pairs of mice. 
TABLE 5

Effects of Morphine on Locomotor Activity

Mean Activity Counts \pm S.E.a

1. 15' Intervals over 2 Hours

\begin{tabular}{|c|c|c|c|c|c|c|c|c|}
\hline $\begin{array}{c}\text { Dose } \\
\text { (ing/kg sc) }\end{array}$ & $\underline{0-15^{\prime}}$ & $15^{\prime}-30^{\prime}$ & $30^{\prime}-45^{\prime}$ & $45^{\prime}-60^{\prime}$ & $60^{\prime}-75^{\prime}$ & $75^{\prime}-90^{\prime}$ & $90^{\prime}-105^{\prime}$ & $105^{\circ}-120^{\circ}$ \\
\hline Control & $45.1 \pm 1.0$ & $33.4 \pm 5.1$ & $32.9 \pm 7.7$ & $8.0 \pm 2.0$ & $10.2 \pm 7.1$ & $10.5 \pm 0.3$ & $20.4 \pm 13.7$ & $23.4 \pm 13$. \\
\hline 10 & $52.7 \pm 0.2 *$ & $52.6 \pm 0.4^{*}$ & $52.3 \pm 1.7 *$ & $51.6 \pm 1.5 *$ & $51.7 \pm 1.3^{*}$ & $50.4 \pm 1.8$ & $55.0 \pm 4.3 *$ & $50.5 \pm 1.4$ \\
\hline 20 & $58.0 \pm 1.7^{\star}$ & $64.6 \pm 1.6^{\star}$ & $58.8 \pm 0.5^{\star}$ & $54.3 \pm 1.8^{\star}$ & $54.2 \pm 1.0^{\star}$ & $54.2 \pm 0.9^{\star}$ & $52.0 \pm 0.4^{\star}$ & $51.5 \pm 0.4$ \\
\hline 40 & $51.8 \pm 2.4^{*}$ & $57.2 \pm 1.2^{\star}$ & $53.0 \pm 0.5$ & $50.5 \pm 1.9 *$ & $50.9 \pm 3.1 *$ & $49.4 \pm 3.8^{*}$ & $49.1 \pm 4.0$ & $49.8 \pm 3.8$ \\
\hline
\end{tabular}

2. $60^{\prime}$ Intervals over 6 Hours

\begin{tabular}{|c|c|c|c|c|c|c|}
\hline $\begin{array}{c}\text { Dose } \\
(\mathrm{mg} / \mathrm{kg} \mathrm{sc})\end{array}$ & $60^{\prime}$ & $\underline{120^{\circ}}$ & $\underline{180^{\circ}}$ & $\underline{240^{\circ}}$ & $300^{\circ}$ & $360^{\circ}$ \\
\hline Contral & $60.2 \pm 0.4$ & $39.7 \pm 2.4$ & $46.2 \pm 10.8$ & $41.5 \pm 12.5$ & $35.0 \pm 2.1$ & $49.4 \pm 17.3$ \\
\hline 10 & $1094.7 \pm 1.6 *$ & $104.0 \pm 1.5 *$ & $99.1 \pm 5.0$ & $70.3 \pm 6.5$ & $47.7 \pm 5.2$ & $40.2 \pm 9.8$ \\
\hline 20 & $118.1 \pm 0.6 \star$ & $106.0 \pm 1.3 \star$ & $98.0 \pm 2.0$ & $34.6 \pm 5.0^{*}$ & $58.1 \pm 0.3$ & $42.1 \pm 6.1$ \\
\hline 40 & $106.4 \pm 1.7 \star$ & $99.7 \pm 7.3^{*}$ & $98.4 \pm 2.4^{\star}$ & $95.5 \pm 2.1$ & $49.8 \pm 14.2$ & $39.4 \pm 1.2$ \\
\hline
\end{tabular}

aMean and standard error of the square root of the activity counts of 4 pairs of mice.

$\star p<0.05$; One-way ANOVA, Dunnet's multiple comparison 
TABLE 5a

Effects of Morphine on Locomotor Activity

Mean Activity Counts \pm S.E.a

1. 15' Intervais over 2 Hours

\begin{tabular}{|c|c|c|c|c|c|c|c|c|}
\hline $\begin{array}{c}\text { Dose } \\
(\operatorname{lng} / \mathrm{kg} \mathrm{sc})\end{array}$ & $0-15^{\prime}$ & $15^{\prime}-30^{\prime}$ & $30^{\prime}-45^{\prime}$ & $45^{\prime}-60^{\prime}$ & $60^{\prime}-75^{\prime}$ & $75^{\prime}-90^{\prime}$ & $90^{\prime}-105^{\prime}$ & $105^{\prime}-120^{\prime}$ \\
\hline Control & $2030 \pm 87$ & $1139 \pm 337$ & $1142 \pm 506$ & $67 \pm 31$ & $154 \pm 144$ & $110 \pm 5.5$ & $603 \pm 558$ & $717 \pm 610$ \\
\hline 10 & $2778 \pm 18$ & $2769 \pm 38$ & $2742 \pm 173$ & $2673 \pm 150$ & $2679+129$ & $2551 \pm 177$ & $3039 \pm 473$ & $2551 \pm 142$ \\
\hline 20 & $3362 \pm 195$ & $4177 \pm 206$ & $3456 \pm 60$ & $2948 \pm 191$ & $2935 \pm 104$ & $2947 \pm 93$ & $2701 \pm 43$ & $2657 \pm 38$ \\
\hline 40 & $2690 \pm 246$ & $3273+138$ & $2809 \pm 55$ & $2553 \pm 187$ & $2600 \pm 312$ & $2456 \pm 371$ & $2430 \pm 391$ & $2499+377$ \\
\hline
\end{tabular}

2. $60^{\prime}$ Intervais over 6 Hours

$\begin{array}{cccccc}\begin{array}{c}\text { Dose } \\ (\mathrm{mg} / \mathrm{kg} \mathrm{scl}\end{array} & \underline{60^{\prime}} & \underline{120^{\prime}} & \underline{180^{\prime}} & \underline{240^{\prime}} & \underline{360^{\prime}} \\ & 4378 \pm 51 & 1583 \pm 190 & 2248 \pm 1000 & 1879 \pm 1038 & 1230 \pm 149 \\ 10 & 10960 \pm 343 & 10820 \pm 309 & 9845 \pm 987 & 4985 \pm 907 & 2299 \pm 493 \\ 20 & 13943 \pm 150 & 11240 \pm 278 & 9613 \pm 396 & 7189 \pm 843 & 3379 \pm 39 \\ 40 & 11324 \pm 350 & 9984 \pm 1452 & 9704 \pm 475 & 9131 \pm 547 & 2677 \pm 1413\end{array}$

aMean and standard error of the activity counts of 4 palrs af mice. 
TABLE 6

Effects of Naloxone on Locomotor Activity

Mean Activity Counts \pm S.E.a

1. 15' Intervals over 2 Hours

$\begin{array}{ccccccccc}\begin{array}{c}\text { Dose } \\ \text { (mg/kg sc) }\end{array} & \underline{0.15^{\prime}} & \underline{15^{\prime}-30^{\prime}} & \underline{30^{\prime}-45^{\prime}} & \underline{45^{\prime}-60^{\prime}} & \underline{60^{\prime}-75^{\prime}} & \underline{75^{\prime}-90^{\prime}} & \frac{90^{\prime}-105^{\prime}}{105^{\prime}-120^{\prime}} \\ \text { Control } & 51.2 \pm 5.2 & 35.3 \pm 1.8 & 17.3 \pm 7.2 & 35.0 \pm 17.2 & 24.4 \pm 20.4 & 24.5 \pm 4.4 & 21.9 \pm 4.1 & 16.0 \pm 9.3 \\ 10 & 45.9 \pm 0.6 & 32.9 \pm 1.7 & 18.7 \pm 4.4 & 15.4 \pm 3.2 & 30.8 \pm 5.3 & 36.4 \pm 1.8 & 21.4 \pm 1.9 & 24.6 \pm 14.9 \\ 20 & 47.9 \pm 2.9 & 30.1 \pm 8.4 & 17.4 \pm 3.3 & 24.5 \pm 6.9 & 23.1 \pm 9.5 & 31.8 \pm 4.5 & 28.3 \pm 16.4 & 15.0 \pm 0.4 \\ 40 & 40.9 \pm 3.2 & 32.0 \pm 5.1 & 28.6 \pm 2.7 & 26.5 \pm 0.7 & 20.7 \pm 5.7 & 23.4 \pm 11.7 & 24.4 \pm 12.6 & 25.1 \pm 11.8\end{array}$

2. $60^{\circ}$ Intervals over 6 Hours

\begin{tabular}{|c|c|c|c|c|c|c|}
\hline $\begin{array}{c}\text { Dose } \\
(\mathrm{mg} / \mathrm{kg} \mathrm{sc})\end{array}$ & $60^{\prime}$ & $\underline{120^{\circ}}$ & $180^{\circ}$ & $240^{\prime}$ & $300^{\prime}$ & $360^{\prime}$ \\
\hline Control & $74.6 \pm 14.1$ & $47.9 \pm 13.1$ & $47.0 \pm 18.7$ & $66.7 \pm 27.8$ & $44.6 \pm 3.9$ & $56.2 \pm 25.1$ \\
\hline 10 & $61.7 \pm 0.1$ & $59.2 \pm 9.4$ & $45.5 \pm 1.1$ & $59.4 \pm 5.7$ & $53.5 \pm 8.5$ & $63.1 \pm 8.7$ \\
\hline 20 & $64.4 \pm 9.6$ & $51.9 \pm 8.4$ & $28.6 \pm 7.0$ & $55.7 \pm 12.7$ & $47.3 \pm 12.3$ & $47.6 \pm 14.3$ \\
\hline 40 & $65.2 \pm 3.1$ & $51.5 \pm 4.1$ & $64.5 \pm 10.0$ & $42.7 \pm 4.3$ & $39.0 \pm 12.1$ & $55.8 \pm 2.4$ \\
\hline
\end{tabular}

aMean and standard error of the square root of the activity counts of 4 pairs of mice.

$\star p<0.05$; One-way ANOVA, Dunnet's multiple comparison 
TABLE 6a

Effects of Naloxone on Locomotor Activity

Mean Activity Counts \pm S.E.a

1. 15' Intervals over 2 Hours

\begin{tabular}{|c|c|c|c|c|c|c|c|c|}
\hline $\begin{array}{c}\text { Dose } \\
(\mathrm{mg} / \mathrm{kg} \mathrm{sc})\end{array}$ & $0-15^{\prime}$ & $\underline{15^{\circ}-30^{\prime}}$ & $30^{\prime}-45^{\prime}$ & $\underline{45^{\prime}-60^{\prime}}$ & $60^{\prime}-75^{\prime}$ & $75^{\prime}-90^{\prime}$ & $90^{\prime}-105^{\prime}$ & $105^{\prime}-120^{\prime}$ \\
\hline Control & $2653 \pm 533$ & $1249 \pm 127$ & $350 \pm 248$ & $1518 \pm 1199$ & $1008 \pm 992$ & $620 \pm 215$ & $496 \pm 178$ & $341 \pm 297$ \\
\hline 10 & $2105 \pm 53$ & $1088 \pm 114$ & $368 \pm 163$ & $247 \pm 99$ & $975 \pm 323$ & $1330 \pm 133$ & $460 \pm 79$ & $825 \pm 731$ \\
\hline 20 & $2303 \pm 274$ & $976 \pm 506$ & $315 \pm 115$ & $647 \pm 337$ & $624 \pm 438$ & $1034 \pm 285$ & $1066 \pm 925$ & $226 \pm 11$ \\
\hline 40 & $1682 \pm 259$ & $1051 \pm 329$ & $824 \pm 153$ & $703 \pm 36$ & $460 \pm 237$ & $685 \pm 547$ & $756 \pm 615$ & $770 \pm 591$ \\
\hline
\end{tabular}

2. $60^{\circ}$ Intervals over 6 Hours

\begin{tabular}{|c|c|c|c|c|c|c|}
\hline $\begin{array}{c}\text { Dose } \\
(\mathrm{mg} / \mathrm{kg} \mathrm{sC})\end{array}$ & $60^{\circ}$ & $\underline{120^{\circ}}$ & $180^{\circ}$ & $240^{\prime}$ & $300^{\prime}$ & $360^{\circ}$ \\
\hline Control & $5769 \pm 2107$ & $2465 \pm 1251$ & $2553 \pm 1754$ & $5218 \pm 3704$ & $2004 \pm 345$ & $3785 \pm 2816$ \\
\hline 10 & $3807 \pm 4$ & $3589 \pm 1108$ & $2070 \pm 103$ & $3564 \pm 678$ & $2930 \pm 910$ & $4060 \pm 1099$ \\
\hline 20 & $4243 \pm 1234$ & $2950 \pm 1659$ & $864 \pm 398$ & $3261 \pm 1418$ & $2394 \pm 1167$ & $2473 \pm 1362$ \\
\hline 40 & $4259 \pm 400$ & $2670 \pm 423$ & $4264 \pm 1287$ & $1846 \pm 367$ & $1663 \pm 942$ & $3115 \pm 268$ \\
\hline
\end{tabular}

a Mean and standard error of the activity counts of 4 pairs of mice. 


\section{TABLE 7}

Effects of Naltrexone on Locomotor Activity

Mean Activity Counts \pm S.E.a

1. 15' Intervals over 2 Hours

\begin{tabular}{|c|c|c|c|c|c|c|c|c|}
\hline $\begin{array}{c}\text { Dose } \\
\text { (ing/kg sc) }\end{array}$ & $0-15^{\prime}$ & $15^{\prime}-30^{\prime}$ & $30^{\prime}-45^{\prime}$ & $45^{\prime}-60^{\prime}$ & $60^{\circ}-75^{\circ}$ & $75^{\prime}-90^{\prime}$ & $90^{\prime}-105^{\prime}$ & $105^{\prime}-120^{\prime}$ \\
\hline Control & $51.1 \pm 7.7$ & $44.2 \pm 5.8$ & $34.8 \pm 6.0$ & $19.9 \pm 1.0$ & $23.9 \pm 1.9$ & $25.1 \pm 19.6$ & $38.3 \pm 7.8$ & $27.0 \pm 5.3$ \\
\hline 10 & $49.6 \pm 4.2$ & $43.2 \pm 6.7$ & $26.2 \pm 4.3$ & $29.1 \pm 0.2$ & $22.0 \pm 10.1$ & $27.8 \pm 5.1$ & $37.5 \pm 5.9$ & $37.7 \pm 4.9$ \\
\hline 20 & $51.2 \pm 3.1$ & $29.6 \pm 8.5$ & $22.8 \pm 0.6$ & $26.3 \pm 11.0$ & $14.7 \pm 1.4$ & $22.0 \pm 8.4$ & $15.2 \pm 6.0^{\star}$ & $19.0 \pm 9.8$ \\
\hline 40 & $47.9 \pm 0.7$ & $47.4 \pm 0.7$ & $38.4 \pm 2.8$ & $35.2 \pm 0.7$ & $36.3 \pm 1.7$ & $38.4 \pm 0.5$ & $39.2 \pm 1.5$ & $39.1 \pm 0.3$ \\
\hline
\end{tabular}

2. $60^{\prime}$ Intervals over 6 Hours

$\begin{array}{ccccccc}\begin{array}{c}\text { Dose } \\ \text { mg/kg sc) }\end{array} & \underline{60} & \underline{120^{\prime}} & \underline{180^{\prime}} & \underline{240^{\prime}} & \underline{300^{\prime}} & \underline{360^{\prime}} \\ \text { Control } & 78.7 \pm 10.7 & 60.0 \pm 16.3 & 63.1 \pm 7.7 & 40.7 \pm 13.3 & 58.5 \pm 2.1 & 42.6 \pm 1.7 \\ 10 & 76.6 \pm 8.0 & 65.4 \pm 0.7 & 56.3 \pm 0.9 & 53.5 \pm 7.6 & 70.9 \pm 2.4 & 48.4 \pm 3.8 \\ 20 & 69.3 \pm 10.3 & 36.3 \pm 13.2 & 44.1 \pm 26.8 & 60.9 \pm 7.6 & 35.3 \pm 7.7 & 60.5 \pm 14.4 \\ 40 & 85.2 \pm 1.6 & 76.5 \pm 1.4 & 66.4 \pm 3.7 & 48.0 \pm 1.8 & 62.8 \pm 21.0 & 61.4 \pm 5.0\end{array}$

amean and standard error of the square root of the activity counts of 4 pairs of mice.

$\star p<0.05$; One-way ANOVA, Dunnet's multiple comparison 
TABLE 7a

Effects of Naltrexone on Locomotor Activity

Mean Activity Counts \pm S.E.a

1. 15' Intervals over 2 Hours

\begin{tabular}{|c|c|c|c|c|c|c|c|c|}
\hline $\begin{array}{l}\text { Dose } \\
\text { (ing/kg sc) }\end{array}$ & $0-15^{\prime}$ & $15^{\prime}-30^{\prime}$ & $30^{\prime}-45^{\prime}$ & $45^{\prime}-60^{\prime}$ & $60^{\prime}-75^{\prime}$ & $75^{\prime}-90^{\prime}$ & $90^{\prime}-105^{\prime}$ & $105^{\prime}-120^{\prime}$ \\
\hline Control & $2669 \pm 786$ & $1988 \pm 514$ & $1247 \pm 414$ & $398 \pm 39$ & $573 \pm 92$ & $1011 \pm 980$ & $1526 \pm 595$ & $755 \pm 286$ \\
\hline 10 & $2480 \pm 419$ & $1908 \pm 576$ & $703 \pm 223$ & $845 \pm 10$ & $587 \pm 444$ & $798 \pm 283$ & $1441 \pm 439$ & $1447 \pm 371$ \\
\hline 20 & $2634 \pm 318$ & $950 \pm 505$ & $519 \pm 27$ & $812 \pm 576$ & $217 \pm 39$ & $553 \pm 367$ & $267 \pm 181$ & $455 \pm 370$ \\
\hline 40 & $2297 \pm 70$ & $2245 \pm 69$ & $1481 \pm 216$ & $1238 \pm 50$ & $1320 \pm 119$ & $1472 \pm 42$ & $1537+115$ & $1525+24$ \\
\hline
\end{tabular}

2. $60^{\circ}$ Intervals over 6 Hours

\begin{tabular}{|c|c|c|c|c|c|c|}
\hline $\begin{array}{c}\text { Dose } \\
(\mathrm{mg} / \mathrm{kg} \mathrm{sc})\end{array}$ & $60^{\circ}$ & $\underline{120^{\prime}}$ & $180^{\prime}$ & $240^{\circ}$ & $300^{\prime}$ & $360^{\prime}$ \\
\hline Control & $6302 \pm 1674$ & $3863 \pm 1955$ & $4041 \pm 973$ & $1831 \pm 1080$ & $3422 \pm 243$ & $1815 \pm 143$ \\
\hline 10 & $5936 \pm 1228$ & $4272 \pm 93$ & $3171 \pm 101$ & $2915 \pm 811$ & $5036 \pm 338$ & $2353 \pm 369$ \\
\hline 20 & $4914 \pm 1426$ & $1491 \pm 958$ & $2660 \pm 2360$ & $3761 \pm 924$ & $1302 \pm 542$ & $3865 \pm 1746$ \\
\hline 40 & $7260 \pm 266$ & $5853 \pm 217$ & $4429 \pm 489$ & $2304 \pm 173$ & $4386 \pm 2644$ & $3791 \pm 609$ \\
\hline
\end{tabular}

amean and standard error of the activity counts of 4 pairs of mice. 
TABLE 8

Effects of Ethylketocyclazocine on Locomotor Activity

Mean Activity Counts \pm S.E.a

1. 15' Intervals over 2 Hours

\begin{tabular}{|c|c|c|c|c|c|c|c|c|}
\hline $\begin{array}{c}\text { Dose } \\
(\mathrm{mg} / \mathrm{kg} \mathrm{sC})\end{array}$ & $0-15^{\prime}$ & $15^{\prime}-30^{\prime}$ & $30^{\prime}-45^{\prime}$ & $45^{\prime}-60^{\prime}$ & $60^{\prime}-75^{\prime}$ & $75^{\prime}-90^{\prime}$ & $90^{\prime}-105^{\prime}$ & $105^{\prime}-120^{\prime}$ \\
\hline Control & $52.1 \pm 4.4$ & $40.2 \pm 0.6$ & $24.0 \pm 1.5$ & $21.6 \pm 4.8$ & $34.9 \pm 9.6$ & $27.9 \pm 8.1$ & $20.6 \pm 14.3$ & $9.0 \pm 0.3$ \\
\hline 5 & $1.7 \pm 1.7 \star$ & $0.7 \pm 0.7$ & $6.4 \pm 1.0$ & $19.1 \pm 11.0$ & $18.2 \pm 2.3$ & $27.8 \pm 6.2$ & $28.2 \pm 4.4$ & $17.8 \pm 0.4$ \\
\hline 10 & $2.2 \pm 2.2$ & $1.8 \pm 1.8$ & $2.2 \pm 2.2$ & $2.3 \pm 2.3$ & $7.8 \pm 0.1$ & $2.3 \pm 0.9 *$ & $8.8 \pm 3.1$ & $14.6 \pm 7.6$ \\
\hline 20 & $4.7 \pm 1.5 *$ & $1.8 \pm 1.8$ & $2.2 \pm 2.2 \star$ & $2.3 \pm 2.2$ & $2.1 \pm 2.1 *$ & $1.5 \pm 1.5 \star$ & $2.7 \pm 2.7$ & $3.8 \pm 1.0$ \\
\hline
\end{tabular}

2. $60^{\circ}$ Intervals over 6 Hours

\begin{tabular}{|c|c|c|c|c|c|c|}
\hline $\begin{array}{c}\text { Dose } \\
(\mathrm{mg} / \mathrm{kg} \mathrm{sc})\end{array}$ & $60^{\circ}$ & $120^{\prime}$ & $180^{\circ}$ & $240^{\circ}$ & $300^{\prime}$ & $360^{\circ}$ \\
\hline Contral & $73.4 \pm 5.3$ & $53.4 \pm 3.6$ & $54.3 \pm 10.4$ & $44.6 \pm 10.9$ & $38.3 \pm 0.8$ & $40.5 \pm 2.0$ \\
\hline 5 & $20.5 \pm 10.7 \star$ & $47.2 \pm 7.0$ & $79.3 \pm 14.5$ & $82.6 \pm 1.7$ & $79.6 \pm 1.8 *$ & $73.6 \pm 3.8$ \\
\hline 10 & $4.2 \pm 4.2$ & $20.2 \pm 4.3 \star$ & $36.1 \pm 5.8$ & $64.5 \pm 8.3$ & $72.4 \pm 18.5$ & $73.6 \pm 13.9$ \\
\hline 20 & $1.0 \pm 0.8 *$ & $5.8 \pm 3.0 \star$ & $17.0 \pm 7.1$ & $37.6 \pm 18.2$ & $49.0 \pm 7.0$ & $58.7+10.2$ \\
\hline
\end{tabular}

a Mean and standard error of the square root of the activity counts of 4 pairs of mice.

$\star p<0.05$; One-way ANOVA, Dunnet's multiple comparison 
TABLE 8a

Effects of Ethylketocyclazocine on Locomotor Activity

Mean Activity Counts \pm S.E.a

1. 15' Intervals over 2 Hours

$\begin{array}{ccccccccc}\begin{array}{c}\text { Dose } \\ \text { (mg/kg sc) }\end{array} & \underline{0-15^{\prime}} & \underline{15^{\prime}-30^{\prime}} & \underline{30^{\prime}-45^{\prime}} & \underline{45^{\prime}-60^{\prime}} & \underline{60^{\prime}-75^{\prime}} & \underline{75^{\prime}-90^{\prime}} & \frac{90^{\prime}-105^{\prime}}{105^{\prime}-120^{\prime}} \\ \text { Control } & 2734 \pm 453 & 1615 \pm 44 & 577 \pm 69 & 487 \pm 205 & 1308 \pm 667 & 844 \pm 453 & 630 \pm 590 & 81 \pm 5 \\ 5 & 6 \pm 6 & 1 \pm 1 & 42 \pm 13 & 486 \pm 419 & 335 \pm 83 & 809 \pm 345 & 814 \pm 246 & 316 \pm 13 \\ 10 & 10 \pm 10 & 7 \pm 7 & 10 \pm 10 & 11 \pm 11 & 62 \pm 1 & 6 \pm 4 & 87 \pm 54 & 272 \pm 222 \\ 20 & 25 \pm 14 & 7 \pm 7 & 10 \pm 10 & 10 \pm 10 & 9 \pm 9 & 5 \pm 5 & 14 \pm 14 & 16 \pm 7\end{array}$

2. 60' Intervals over 6 Hours

\begin{tabular}{|c|c|c|c|c|c|c|}
\hline $\begin{array}{c}\text { Dose } \\
(\mathrm{mg} / \mathrm{kg} \mathrm{sc})\end{array}$ & $\underline{60^{\prime}}$ & $\underline{120^{\prime}}$ & $\underline{180^{\circ}}$ & $\underline{240^{\prime}}$ & $300^{\prime}$ & $360^{\circ}$ \\
\hline Control & $5412 \pm 722$ & $2863 \pm 381$ & $3058 \pm 1125$ & $2105 \pm 973$ & $1548 \pm 63$ & $1642 \pm 165$ \\
\hline 5 & $535 \pm 439$ & $2273 \pm 660$ & $6502 \pm 2302$ & $6830 \pm 281$ & $6344 \pm 279$ & $5434 \pm 564$ \\
\hline 10 & $36 \pm 36$ & $426 \pm 172$ & $1340 \pm 417$ & $4227 \pm 1066$ & $5588 \pm 2684$ & $5605 \pm 2043$ \\
\hline 20 & $50 \pm 11$ & $43 \pm 34$ & $339 \pm 241$ & $1747 \pm 1366$ & $2449 \pm 683$ & $3552 \pm 1193$ \\
\hline
\end{tabular}

aMean and standard error of the activity counts of 4 pairs of mice. 
TABLE 9

Effects of Pentazocine on Locomotor Activity

Mean Activity Counts \pm S.E.a

1. 15' Intervals over 2 Hours

$\begin{array}{ccccccccc}\begin{array}{c}\text { Dose } \\ \text { (mg/kg sc) }\end{array} & \underline{0.15^{\prime}} & \underline{15^{\prime}-30^{\prime}} & \underline{30^{\prime}-45^{\prime}} & \underline{45^{\prime}-60^{\prime}} & \underline{60^{\prime}-75^{\prime}} & \underline{75^{\prime}-90^{\prime}} & \underline{90^{\prime}-105^{\prime}} & \underline{105^{\prime}-120^{\prime}} \\ \text { Control } & 50.1 \pm 7.1 & 42.1 \pm 0.6 & 24.2 \pm 5.9 & 18.6 \pm 9.6 & 17.4 \pm 3.9 & 14.6 \pm 5.4 & 32.0 \pm 16.0 & 31.2 \pm 2.8 \\ 20 & 47.0 \pm 2.1 & 46.7 \pm 1.4 & 46.9 \pm 0.0^{*} & 49.9 \pm 9.3^{*} & 51.9 \pm 6.0^{*} & 50.5 \pm 9.9^{*} & 43.3 \pm 2.2 & 24.1 \pm 5.2 \\ 40 & 55.3 \pm 2.7 & 50.3 \pm 3.9 & 46.8 \pm 2.2^{*} & 47.3 \pm 4.1 & 48.5 \pm 2.9 * & 46.6 \pm 3.3^{*} & 47.7 \pm 1.0 & 41.4 \pm 1.5 \\ 80 & 49.6 \pm 4.2 & 43.3 \pm 7.0 & 45.3 \pm 2.9 * & 46.0 \pm 4.4 & 42.9 \pm 4.7 * & 40.9 \pm 7.3 & 36.7 \pm 8.2 & 30.3 \pm 7.2\end{array}$

2. $60^{\prime}$ Intervals over 6 Hours

\begin{tabular}{|c|c|c|c|c|c|c|}
\hline $\begin{array}{c}\text { Dose } \\
(\mathrm{mg} / \mathrm{kg} \mathrm{sc})\end{array}$ & $\underline{60^{\prime}}$ & $120^{\circ}$ & $\underline{180^{\prime}}$ & $\underline{240^{\circ}}$ & $300^{\prime}$ & $360^{\prime}$ \\
\hline Control & $73.2 \pm 5.0$ & $51.8 \pm 11.8$ & $54.4 \pm 19.0$ & $43.7 \pm 15.6$ & $53.1 \pm 2.1$ & $41.5 \pm 16.7$ \\
\hline 20 & $95.6 \pm 5.2^{\star}$ & $88.2 \pm 8.8$ & $52.2 \pm 1.7$ & $65.4 \pm 0.0$ & $48.5 \pm 3.1$ & $89.5 \pm 13.0$ \\
\hline 40 & $100.1 \pm 6.4 *$ & $92.3 \pm 3.1 *$ & $76.8 \pm 1.3$ & $43.6 \pm 10.3$ & $35.5 \pm 7.5 *$ & $46.6 \pm 8.2$ \\
\hline 80 & $92.7 \pm 1.9 *$ & $76.1 \pm 13.4$ & $64.5 \pm 9.6$ & $51.9 \pm 7.9$ & $26.6 \pm 0.3 *$ & $48.1 \pm 6.8$ \\
\hline
\end{tabular}

apean and standard error of the square root of the activity counts of 4 pairs of mice.

* $p<0.05$; One-way ANOVA, Dunnet's multiple comparison 
TABLE 9a

Effects of Pentazocine on Locomotor Activity

Mean Activity Counts \pm S.E. ${ }^{a}$

1. 15' Intervals over 2 Hours

\begin{tabular}{|c|c|c|c|c|c|c|c|c|}
\hline $\begin{array}{c}\text { Dose } \\
(\mathrm{mg} / \mathrm{kg} s \mathrm{~s})\end{array}$ & $0-15^{\prime}$ & $15^{\prime}-30^{\prime}$ & $30^{\prime}-45^{\prime}$ & $45^{\circ}-60^{\prime}$ & $60^{\prime}-75^{\prime}$ & $75^{\prime}-90^{\prime}$ & $90^{\prime}-105^{\prime}$ & $105^{\prime}-120^{\prime}$ \\
\hline Control & $2558 \pm 708$ & $1770 \pm 53$ & $619 \pm 284$ & $440 \pm 359$ & $319 \pm 137$ & $242 \pm 158$ & $1284 \pm 1027$ & $980 \pm 177$ \\
\hline 20 & $2214 \pm 195$ & $2182 \pm 129$ & $2200 \pm 0$ & $2577 \pm 931$ & $2732 \pm 622$ & $2646 \pm 1001$ & $1881 \pm 186$ & $607 \pm 250$ \\
\hline 40 & $3060 \pm 298$ & $2550 \pm 397$ & $2196 \pm 207$ & $2257 \pm 384$ & $2357 \pm 282$ & $2180 \pm 310$ & $2297 \pm 97$ & $1718 \pm 126$ \\
\hline 80 & $2476 \pm 415$ & $1922 \pm 608$ & $2057 \pm 26$ & $2133 \pm 401$ & $1860 \pm 402$ & $1727 \pm 596$ & $1415+599$ & $970 \pm 438$ \\
\hline
\end{tabular}

2. $60^{\prime}$ Intervals over 6 Hours

\begin{tabular}{|c|c|c|c|c|c|c|}
\hline $\begin{array}{c}\text { Dose } \\
(\mathrm{mg} / \mathrm{kg} \mathrm{sc})\end{array}$ & $60^{\prime}$ & $120^{\circ}$ & $\underline{180^{\circ}}$ & $240^{\prime}$ & $300^{\circ}$ & $360^{\prime}$ \\
\hline Control & $5387 \pm 729$ & $2824 \pm 1226$ & $3321 \pm 2070$ & $2155 \pm 1366$ & $2831 \pm 263$ & $1998 \pm 1386$ \\
\hline 20 & $9172 \pm 996$ & $7865 \pm 1560$ & $2723 \pm 178$ & $4278 \pm 2$ & $2366 \pm 305$ & $8178 \pm 2322$ \\
\hline 40 & $10062 \pm 1286$ & $8533 \pm 563$ & $5896 \pm 192$ & $2004 \pm 898$ & $1314 \pm 533$ & $2243 \pm 763$ \\
\hline 80 & $8587 \pm 355$ & $5971 \pm 2036$ & $4245+1234$ & $2754+821$ & $710 \pm 18$ & $2356 \pm 655$ \\
\hline
\end{tabular}

a Mean and standard error of the activity counts of 4 pairs of mice. 
TABLE 10

Effects of Cyclazocine on Locomotor Activity

Mean Activity Counts \pm S.E.a

1. 15' Intervals over 2 Hours

\begin{tabular}{|c|c|c|c|c|c|c|c|c|}
\hline $\begin{array}{c}\text { Dose } \\
\text { (ing/kg sc) }\end{array}$ & $0-15^{\circ}$ & $15^{\prime}-30^{\prime}$ & $30^{\prime}-45^{\prime}$ & $45^{\prime}-60^{\prime}$ & $60^{\prime}-75^{\prime}$ & $75^{\prime}-90^{\prime}$ & $90^{\prime}-105^{\prime}$ & $105^{\prime}-120^{\prime}$ \\
\hline Control & $53.9 \pm 9.5$ & $51.3 \pm 7.7$ & $36.1 \pm 10.0$ & $29.9 \pm 7.2$ & $26.2 \pm 16.3$ & $11.7 \pm 6.5$ & $13.4 \pm 6.1$ & $31.7 \pm 6.1$ \\
\hline 2.5 & $58.4 \pm 2.6$ & $59.8 \pm 1.0$ & $63.0 \pm 4.2$ & $56.5 \pm 3.9 *$ & $43.7 \pm 9.2$ & $38.9 \pm 10.5$ & $43.7 \pm 5.2^{\star}$ & $33.4 \pm 12$. \\
\hline 5 & $57.7 \pm 2.0$ & $60.7 \pm 2.2$ & $61.8 \pm 4.2$ & $60.2 \pm 0.3^{*}$ & $46.2 \pm 4.3$ & $29.6 \pm 5.2$ & $28.6 \pm 6.3$ & $24.6 \pm 2.5$ \\
\hline 10 & $55.4 \pm 0.1$ & $58.7 \pm 3.8$ & $57.2 \pm 1.9$ & $62.6 \pm 1.1^{\star}$ & $64.2 \pm 0.3^{\star}$ & $53.5 \pm 3.6$ & $42.4 \pm 3.1$ & $35.5 \pm 5.4$ \\
\hline
\end{tabular}

2. $60^{\prime}$ Intervals over 6 Hours

$\begin{array}{ccccccc}\begin{array}{c}\text { Dose } \\ (\mathrm{mg} / \mathrm{kg} \mathrm{sc})\end{array} & \underline{60^{\prime}} & \underline{120^{\prime}} & \underline{180^{\prime}} & \underline{240^{\prime}} & \underline{300^{\circ}} & \frac{360^{\prime}}{45.0 \pm 6.4} \\ \text { Control } & 88.1 \pm 16.8 & 48.7 \pm 4.7 & 36.3 \pm 4.7 & 52.1 \pm 11.2 & 37.5 \pm 2.6 & 36.5 \pm 11.9 \\ 2.5 & 119.0 \pm 5.8 & 80.6 \pm 18.1 & 77.1 \pm 3.7 * & 40.0 \pm 11.2 & 54.6 \pm 8.8 & 48.7 \pm 3.6 \\ 5 & 120.3 \pm 4.3 & 67.2 \pm 2.4 & 54.8 \pm 0.6 & 43.0 \pm 5.6 & 36.2 \pm 18.8 & 30.1 \pm 2.1\end{array}$

amean and standard error of the square root of the activity counts of 4 pairs of mice.

*p <0.05; One-way ANOVA, Dunnet's multiple comparison 


\section{TABLE 10a}

Effects of Cyclazocine on Locomotor Activity

Mean Activity Counts \pm S.E.d

1. 15' Intervals over 2 Hours

\begin{tabular}{|c|c|c|c|c|c|c|c|c|}
\hline $\begin{array}{c}\text { Dose } \\
\left(m g / \mathrm{kg} \mathrm{sc}^{2}\right)\end{array}$ & $0-15^{\prime}$ & $15^{\prime}-30^{\prime}$ & $30^{\prime}-45^{\prime}$ & $45^{\prime}-60^{\prime}$ & $60^{\prime}-75^{\prime}$ & $75^{\prime}-90^{\prime}$ & $90^{\prime}-105^{\prime}$ & $105^{\prime}-120^{\prime}$ \\
\hline Control & $2997 \pm 1021$ & $2694 \pm 794$ & $1402 \pm 720$ & $948 \pm 430$ & $954 \pm 854$ & $180 \pm 153$ & $216 \pm 163$ & $1042 \pm 386$ \\
\hline 2.5 & $3416 \pm 298$ & $3576 \pm 114$ & $3989 \pm 524$ & $3203 \pm 440$ & $1989 \pm 799$ & $1624 \pm 830$ & $1936 \pm 450$ & $1277 \pm 84$ \\
\hline 5 & $3333 \pm 226$ & $3690 \pm 268$ & $3830 \pm 513$ & $3626 \pm 34$ & $2154 \pm 392$ & $901 \pm 307$ & $860 \pm 362$ & $612 \pm 122$ \\
\hline 10 & $3073 \pm 16$ & $3462 \pm 449$ & $3280 \pm 211$ & $3915 \pm 136$ & $4120 \pm 42$ & $2870 \pm 385$ & $1806 \pm 262$ & $1290 \pm 382$ \\
\hline
\end{tabular}

2. $60^{\circ}$ Intervals over 6 Hours

$\begin{array}{ccccccc}\begin{array}{c}\text { Dose } \\ \text { (mg/kg sc) }\end{array} & \underline{60^{\prime}} & \underline{120^{\prime}} & \underline{180^{\prime}} & \underline{240^{\prime}} & \underline{300^{\prime}} & \frac{360^{\circ}}{2063 \pm 576} \\ \text { Control } & 8041 \pm 2965 & 2392 \pm 458 & 1342 \pm 339 & 2839 \pm 1161 & 1410 \pm 195 & 1470 \pm 865 \\ 2.5 & 14183 \pm 1376 & 6825 \pm 2914 & 5960 \pm 564 & 1723 \pm 894 & 3056 \pm 958 & 2385 \pm 349 \\ 5 & 14479 \pm 1042 & 4526 \pm 325 & 3005 \pm 65 & 1878 \pm 477 & 1666 \pm 1361 & 910 \pm 128 \\ 10 & 13729 \pm 781 & 10085 \pm 1072 & 3142 \pm 1252 & 1439 \pm 449 & 1157 \pm 720 & 910\end{array}$

a Meun and standard error of the activity counts of 4 pairs of mice. 
TABLE 11

Effects of SKF 10,047 on Locomotor Activity

Mean Activity Counts \pm S.E.a

1. 15' Intervals over 2 Hours

\begin{tabular}{|c|c|c|c|c|c|c|c|c|}
\hline $\begin{array}{l}\text { Dose } \\
\mathrm{mg} / \mathrm{kg} \mathrm{sc})\end{array}$ & $0-15^{\prime}$ & $15^{\prime}-30^{\prime}$ & $30^{\prime}-45^{\prime}$ & $45^{\prime}-60^{\prime}$ & $60^{\circ}-75^{\circ}$ & $75^{\circ}-90^{\prime}$ & $90^{\prime}-105^{\prime}$ & $105^{\prime}-120^{\prime}$ \\
\hline Control & $42.1 \pm 17.0$ & $47.3 \pm 10.3$ & $44.6 \pm 5.9$ & $46.9 \pm 10.8$ & $25.3 \pm 14.8$ & $13.8 \pm 1.9$ & $28.6 \pm 0.7$ & \\
\hline 10 & $56.2 \pm 0.9$ & $59.0 \pm 0.8$ & $56.8 \pm 1.6$ & $54.9 \pm 0.2$ & $45.8 \pm 4.9$ & $46.7 \pm 3.7 *$ & $41.7 \pm 4.7 *$ & $41.8 \pm 0.5$ \\
\hline 20 & $55.7 \pm 0.7$ & $59.8 \pm 0.6$ & $62.8 \pm 0.9$ & $58.2 \pm 1.8$ & $49.6 \pm 8.9$ & $50.5 \pm 6.3 *$ & $52.0 \pm 4.0$ & $47.3 \pm 6.6$ \\
\hline 40 & $53.7 \pm 0.7$ & $56.6 \pm 1.7$ & $58.4 \pm 3.0^{*}$ & $58.8 \pm 2.7$ & $56.2 \pm 3.9$ & $51.1 \pm 4.1 *$ & $45.3 \pm 0.6 *$ & $46.8 \pm 6.1$ \\
\hline
\end{tabular}

2. $60^{\prime}$ Intervals over 6 Hours

\begin{tabular}{|c|c|c|c|c|c|c|}
\hline $\begin{array}{c}\text { Dose } \\
\text { (ing } / \mathrm{kg} \mathrm{sc)}\end{array}$ & $\underline{60^{\prime}}$ & $\underline{120^{\prime}}$ & $180^{\circ}$ & $240^{\circ}$ & $300^{\prime}$ & $360^{\circ}$ \\
\hline Control & $91.0 \pm 21.6$ & $54.1 \pm 13.7$ & $55.9 \pm 19.3$ & $35.1 \pm 4.1$ & $55.8 \pm 13.3$ & $50.0 \pm 13.9$ \\
\hline 10 & $113.5 \pm 0.9$ & $88.5 \pm 1.9$ & $65.2 \pm 1.1$ & $47.9 \pm 21.3$ & $70.6 \pm 4.1$ & $54.6 \pm 9.5$ \\
\hline 20 & $118.4 \pm 1.1$ & $99.8 \pm 12.8$ & $77.9 \pm 15.1$ & $52.7 \pm 12.9$ & $38.1 \pm 19.1$ & $50.8 \pm 1.5$ \\
\hline 40 & $113.9 \pm 4.1$ & $100.4 \pm 1.1 *$ & $73.6 \pm 12.2$ & $47.5 \pm 4.0$ & $44.4 \pm 1.8$ & $25.2 \pm 3.1$ \\
\hline
\end{tabular}

aMean and standard error of the square root of the activity counts of 4 pairs of mice.

$\star P<0.05$; One-way ANOVA, Dunnet's multiple comparison 
TABLE $11 \mathrm{a}$

Effects of SKF 10,047 on Locomotor Activity

Mean Activity Counts \pm S.E.a

1. 15' Intervals over 2 Hours

\begin{tabular}{|c|c|c|c|c|c|c|c|c|}
\hline $\begin{array}{c}\text { Dose } \\
\text { (ing/kg sc) }\end{array}$ & $0-15^{\prime}$ & $15^{\prime}-30^{\prime}$ & $30^{\prime}-45^{\prime}$ & $45^{\prime}-60^{\prime}$ & $60^{\prime}-75^{\prime}$ & $75^{\prime}-90^{\prime}$ & $90^{\prime}-105^{\prime}$ & $105^{\prime}-120^{\prime}$ \\
\hline Control & $2059 \pm 1432$ & $2347 \pm 972$ & $2024 \pm 525$ & $2314 \pm 1008$ & $861 \pm 750$ & $194 \pm 52$ & $820 \pm 41$ & $1235 \pm 738$ \\
\hline 10 & $3163 \pm 97$ & $3482 \pm 99$ & $3228 \pm 180$ & $3012 \pm 17$ & $2125 \pm 444$ & $2194 \pm 343$ & $1760 \pm 390$ & $1761 \pm 41$ \\
\hline 20 & $3108 \pm 78$ & $3578 \pm 73$ & $3945 \pm 109$ & $3386 \pm 209$ & $2538 \pm 880$ & $2587 \pm 637$ & $2722 \pm 419$ & $2279 \pm 626$ \\
\hline 40 & $2888+74$ & $3206 \pm 188$ & $3423 \pm 353$ & $3466 \pm 321$ & $3169 \pm 433$ & $2632 \pm 421$ & $2048+55$ & $2231 \pm 571$ \\
\hline
\end{tabular}

2. $60^{\prime}$ Intervals over 6 Hours

\begin{tabular}{|c|c|c|c|c|c|c|}
\hline $\begin{array}{c}\text { Dose } \\
(\mathrm{mg} / \mathrm{kg} \mathrm{sc})\end{array}$ & $60^{\circ}$ & $120^{\circ}$ & $180^{\prime}$ & $\underline{240^{\prime}}$ & $300^{\prime}$ & $360^{\circ}$ \\
\hline Control & $8743 \pm 3938$ & $3108 \pm 1478$ & $3495 \pm 2160$ & $1248 \pm 285$ & $3287 \pm 1483$ & $2678 \pm 1381$ \\
\hline 10 & $12885 \pm 199$ & $7828 \pm 331$ & $4246 \pm 147$ & $2747 \pm 2038$ & $5007 \pm 576$ & $2981 \pm 122$ \\
\hline 20 & $14015 \pm 251$ & $10125 \pm 2563$ & $6304 \pm 2358$ & $2941 \pm 1356$ & $1817 \pm 1453$ & $2579 \pm 151$ \\
\hline 40 & $12983 \pm 936$ & $10080 \pm 228$ & $5572 \pm 1796$ & $2270 \pm 378$ & $1977 \pm 157$ & $644 \pm 156$ \\
\hline
\end{tabular}

a Mean and standard error of the activity counts of 4 pairs of mice. 
TABLE 12

The Effects of Acute Administration of Opiate Agonists, Antagonists, and Mixed Agonist-Antagonists on Apomorphine-Induced $\mathrm{Climbing}$ in Micea

Treatment

Vehiclec

Morphine

Naloxone

Nal trexone

Ethylketocyclazocined

20.0

Pentazocine

Cyclazocine

SKF $10,047^{d}$
Dose

$(\mathrm{mg} / \mathrm{kg})$

2.0

8.0

5.0

20.0

5.0

20.0

5.0

20.0

80.0

1.25

5.0

10.0

40.0

\% Change
Compared to Control

$+7$

$-6$

$+2$

$+2$

$-6$

$-21$

$-18$

$-52$

$-4$

$-2$

$+7$

$+4$

$-9$

$-25$

7
-6

sig. 
TABLE 13

Effects of SKF 10,047 and EKC on

Apomorphine-Induced Stereotypya

\begin{tabular}{lcccc} 
Treatment & $\begin{array}{c}\text { Dose } \\
(\mathrm{mg} / \mathrm{kg} \text { ip })\end{array}$ & $\begin{array}{c}\text { Stereotypy Score } \\
\underline{\bar{x}} \pm \text { S.E. }\end{array}$ & $\begin{array}{c}\text { \% Change } \\
\text { from Control }\end{array}$ & Sig.b \\
Vehicle & - & $5.63 \pm 0.26$ & - & -11 \\
SKF 10.047 & 40.0 & $5.00 \pm 0.50$ & -73 & * \\
EKCC & 20.0 & $1.50 \pm 0.98$ & \\
\hline
\end{tabular}

acute pretreatment 30 minutes prior to apomorphine at $1.5 \mathrm{mg} / \mathrm{kg} \mathrm{sc}$ $(n=8)$

bone-way ANOVA, Duncan's multiple-range test; $\star P<0.05$; significant difference compared to vehicle control.

${ }^{\mathrm{C}}$ General depressive effects were observed. 
TABLE 14

Effects of Acute Haloperidol Treatment on

Apomorphine $(0.4 \mathrm{mg} / \mathrm{kg})$-Induced Locomotor Activitya

Mean Activity Counts \pm S.E. b

1. 15' Intervals over 2 Hours

$\begin{array}{lcccccccc}\text { Treatment } & \underline{0-15^{\prime}} & \underline{15^{\prime}-30^{\prime}} & \underline{30^{\prime}-45^{\prime}} & \underline{45^{\prime}-60^{\prime}} & \underline{60^{\prime}-75^{\prime}} & \frac{75^{\prime}-90^{\prime}}{90^{\prime}-105^{\prime}} & \frac{105^{\prime}-120^{\prime}}{3} \\ \text { Vehicle } & 53.5 \pm 1.1 & 49.3 \pm 2.5 & 29.9 \pm 6.6 & 25.6 \pm 2.4 & 26.8 \pm 5.9 & 32.8 \pm 8.1 & 26.0 \pm 7.3 & 34.6 \pm 4.8 \\ \text { Haloperidol } & 48.6 \pm 2.4 & 50.3 \pm 1.9 & 38.7 \pm 5.7 & 34.7 \pm 4.5 & 20.2 \pm 7.0 & 20.0 \pm 5.8 & 27.0 \pm 10.7 & 26.4 \pm 3.1\end{array}$

2. $60^{\prime}$ Intervals over 2 Hours

$\begin{array}{cccccc}\text { Treatment } & \overline{\bar{x} \pm S E} & \frac{60^{\prime}}{\text { \& Change }} & \frac{120^{\prime}}{\text { from Control }} & \underline{\bar{x} \pm S E} & \frac{1 \text { Change }}{\text { from Control }} \\ \text { Vehicle } & 83.3 \pm 5.0 & - & 63.8 \pm 6.4 & - \\ \text { Haloperidol } & 87.6 \pm 6.0 & +5 & 52.8 \pm 5.0 & -17\end{array}$

aHaloperidol administered at $1.25 \mathrm{mg} / \mathrm{kg}$ ip followed by a $72-\mathrm{hr}$. drug-free period, then apomorphine at 0.4 $\mathrm{lng} / \mathrm{kg}$ SC.

bMcan and standard error of the square root of the activity counts of 8 pairs of mice.

$\star p<0.05$; " $t$ " test 


\section{TABLE 14a}

Effects of Acute Haloperidol Treatment on

Apomorphine $(0.4 \mathrm{mg} / \mathrm{kg})$-Induced Locomotor Activitya

Mean Activity Counts \pm S.E.

1. $15^{\prime}$ Intervals over 2 Hours

\begin{tabular}{|c|c|c|c|c|c|c|c|c|}
\hline Treatinent & $0-15^{\prime}$ & $15^{\circ}-30^{\prime}$ & $30^{\prime}-45^{\prime}$ & $45^{\prime}-60^{\prime}$ & $60^{\circ}-75^{\prime}$ & $\underline{75^{\prime}-90^{\prime}}$ & $90^{\prime}-105^{\prime}$ & $105^{\prime}-120^{\prime}$ \\
\hline Vehicle & $2861 \pm 115$ & $2447 \pm 232$ & $1024 \pm 458$ & $675 \pm 122$ & $823 \pm 352$ & $1273 \pm 467$ & $835 \pm 373$ & $1266 \pm 351$ \\
\hline aloperidol & $2377 \pm 236$ & $2539 \pm 185$ & $1595 \pm 471$ & $1264 \pm 351$ & $558 \pm 351$ & $504 \pm 234$ & $1072 \pm 582$ & $726 \pm 174$ \\
\hline
\end{tabular}

2. $60^{\prime}$ Intervals over 2 Hours

$\underline{60^{\circ}}$

$\begin{array}{ll}\text { Treatment } & \overline{\bar{x}} \pm \text { SE } \\ \text { Vehicle } & 7007 \pm 849\end{array}$

Haloperidol $\quad 7774 \pm 1063$

\section{x Change} from Control

$-$

$+11$

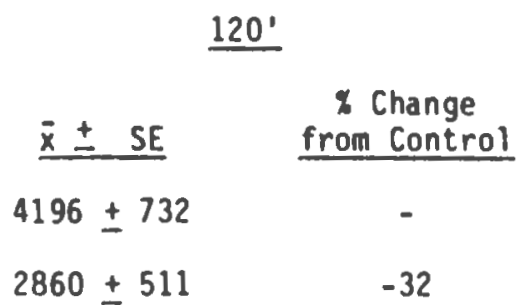

a Haloperidol administered at $1.25 \mathrm{mg} / \mathrm{kg}$ ip/day for five days followed by a $72-\mathrm{hr}$. drug-free period, then apoinorphine at $0.4 \mathrm{mg} / \mathrm{kg} \mathrm{sC}$.

b Mein and standard error of the activity counts of 8 pairs of mice. 
TABLE 15

Apomorphine-Induced Stereotyped Behavior

Effects of Haloperidol $(1.25 \mathrm{mg} / \mathrm{kg}) 72$ Hours Pretreatment

\begin{tabular}{|c|c|c|c|c|c|c|}
\hline $\begin{array}{c}\text { Apomorphine } \\
\text { Dose } \\
(\mathrm{mg} / \mathrm{kg} \mathrm{sc})\end{array}$ & Ireatment & $\underline{n}$ & $\begin{array}{c}\text { Stereotypy Score } \\
\underline{x \pm S E}\end{array}$ & ${ }^{x}{ }^{x}$ & $\begin{array}{c}x \text { Change } \\
\text { Compared to Control }\end{array}$ & sig. $^{b}$ \\
\hline \multirow[t]{2}{*}{0.4} & Vehicle & 8 & $2.63 \pm 0.38$ & 44 & - & - \\
\hline & Haloperidol & 8 & $2.88 \pm 0.55$ & 48 & +10 & - \\
\hline \multirow[t]{2}{*}{0.8} & Vehicle & 8 & $3.38 \pm 0.38$ & 56 & - & - \\
\hline & Haloperidol & 8 & $4.13 \pm 0.30$ & 69 & +22 & - \\
\hline
\end{tabular}

a $\%$ of stereotypy based on maximum score $=6$.

\% stereotypy $=\bar{x}$ of Dose Group $\times 100$

Max. score

$b$ " $t$ " test 
TABLE 16

Haloperidol-Induced Supersensitivity

in the Climbing Mice Assaya

\begin{tabular}{|c|c|c|c|c|c|}
\hline Treatment & $\begin{array}{c}\text { Dose } \\
(\mathrm{mg} / \mathrm{kg} \text { ip) }\end{array}$ & $\underline{n}$ & $\begin{array}{c}\text { Climbing Score } \\
\bar{x} \pm S E\end{array}$ & $\begin{array}{c}\% \\
\text { Change } \\
\end{array}$ & sig. \\
\hline Vehicle & - & 24 & $2.1 \pm 0.3$ & - & - \\
\hline Haloperidol & 1.25 & 24 & $4.8 \pm 0.3$ & +129 & * \\
\hline
\end{tabular}

acute injection of haloperidol 72 hours prior to apomorphine at 0.4 $\mathrm{mg} / \mathrm{kg} \mathrm{sC}$.

b"t" test, ${ }^{\prime}>0.001$ 
TABLE 17

Climbing Mice Supersensitivitya

Simultaneous Administration of Vehicle and Opiate Agonists, Antagonists and Mixed Agonist-Antagonists

\begin{tabular}{|c|c|c|c|}
\hline Treatment & $\begin{array}{c}\text { Dose } \\
(\mathrm{mg} / \mathrm{kg})\end{array}$ & $\begin{array}{c}\text { \% Change } \\
\text { Compared to Control }\end{array}$ & sig. $b$ \\
\hline Vehicle-Vehiclec & - & - & - \\
\hline \multirow{2}{*}{ Vehicle-Morphine } & 2 & +79 & - \\
\hline & 8 & -20 & - \\
\hline \multirow[t]{2}{*}{ Vehicle-Naloxone } & 5 & +27 & - \\
\hline & 20 & -32 & - \\
\hline \multirow[t]{2}{*}{ Vehicle-Nal trexone } & 5 & -20 & - \\
\hline & 20 & -4 & - \\
\hline \multirow[t]{2}{*}{ Vehicle-EKC } & 5 & +13 & - \\
\hline & 20 & +5 & - \\
\hline \multirow[t]{2}{*}{ Vehicle-Pentazocine } & 20 & +86 & - \\
\hline & 80 & 0 & - \\
\hline \multirow[t]{2}{*}{ Vehicle-Cyclazocine } & 1.25 & -7 & - \\
\hline & 5 & 0 & - \\
\hline \multirow[t]{2}{*}{ Vehicle-SKF 10,047} & 10 & -13 & - \\
\hline & 40 & -53 & - \\
\hline
\end{tabular}

a Acute simultaneous administration, 72-hr. pretreat, then apomorphine at $0.4 \mathrm{mg} / \mathrm{kg} \mathrm{SC}(\mathrm{n}=8$ per group).

b One-way ANOVA, Duncan's multiple-range test.

C Range of means over four experiments $(1.8-2.8)$. 
TABLE 18

Climbing Mice Supersensitivitya

Simultaneous Administration of Haloperidol and Opiate Agonists, Antagonists and Mixed Agonist-Antagonists

\begin{tabular}{|c|c|c|c|}
\hline Trea tment & $\begin{array}{c}\text { Dose } \\
(\mathrm{mg} / \mathrm{kg})\end{array}$ & $\begin{array}{c}\text { \% Change } \\
\text { Compared to Control }\end{array}$ & sig. ${ }^{b}$ \\
\hline Haloperidol-Vehiclec & 1.25 & - & - \\
\hline \multirow[t]{2}{*}{ Haloperidol-Morphine } & 2 & +11 & - \\
\hline & 8 & -29 & - \\
\hline \multirow[t]{2}{*}{ Haloperidol-Naloxone } & 5 & -9 & - \\
\hline & 20 & -44 & * \\
\hline \multirow[t]{2}{*}{ Haloperidol-Naltrexone } & 5 & -50 & - \\
\hline & 20 & -51 & * \\
\hline \multirow[t]{2}{*}{ Haloperidol-EKC } & 5 & -3 & - \\
\hline & 20 & -56 & * \\
\hline \multirow[t]{2}{*}{ Haloperidol-Pentazocine } & 20 & +11 & - \\
\hline & 80 & -42 & * \\
\hline \multirow[t]{2}{*}{ Haloperidol-Cyclazocine } & 1.25 & -53 & * \\
\hline & 5 & -64 & $\star$ \\
\hline \multirow[t]{2}{*}{ Haloperidol-SKF 10,047} & 10 & -54 & * \\
\hline & 40 & -75 & $\star$ \\
\hline
\end{tabular}

a Acute simultaneous administration, 72-hr. pretreat, then apomorphine at $0.4 \mathrm{mg} / \mathrm{kg} \mathrm{sC}(n=8$ per group).

b One-way ANOVA, Duncan's multiple-range test; $* p<0.05$

$c$ Range of means over four experiments $(4.3-5.6)$ 
TABLE 19

Climbing Mice Supersensitivity

Simultaneous Administration of Haloperidol and Naloxoned

\begin{tabular}{|c|c|c|c|c|}
\hline \multirow[b]{2}{*}{ Treatment } & \multicolumn{2}{|c|}{ Vehicle and Naloxone } & \multirow[b]{2}{*}{$\begin{array}{l}\text { \% Change } \\
\text { Compared } \\
\text { to Control } \\
\end{array}$} & \multirow[b]{2}{*}{ sig.b } \\
\hline & $\begin{array}{c}\text { Dose } \\
(\mathrm{mg} / \mathrm{kg})\end{array}$ & $\begin{array}{l}\text { Climbing Score } \\
\bar{x} \pm S E \\
\end{array}$ & & \\
\hline Vehicle-Vehicle & - & $2.00 \pm 0.42$ & - & - \\
\hline \multirow[t]{4}{*}{ Vehicle-Naloxone } & 5.0 & $2.13 \pm 0.40$ & +7 & - \\
\hline & 10.0 & $2.00 \pm 0.71$ & 0 & - \\
\hline & 20.0 & $2.88 \pm 0.64$ & +44 & - \\
\hline & 40.0 & $1.38 \pm 0.73$ & -31 & - \\
\hline \multicolumn{5}{|c|}{ Haloperidol and Naloxone } \\
\hline Irea tment & $\begin{array}{c}\text { Dose } \\
(\mathrm{mg} / \mathrm{kg}) \\
\end{array}$ & $\begin{array}{c}\text { Climbing Score } \\
\bar{x} \pm S E \\
\end{array}$ & $\begin{array}{l}\text { \% Change } \\
\text { Compared } \\
\text { to Control } \\
\end{array}$ & Sig. \\
\hline Haloperidol-Vehicle & 1.25 & $4.00 \pm 0.76$ & - & - \\
\hline \multirow[t]{4}{*}{ Haloperidol-Naloxone } & 5.0 & $2.50 \pm 0.54$ & -37 & - \\
\hline & 10.0 & $2.29 \pm 0.78$ & -43 & - \\
\hline & 20.0 & $1.63 \pm 0.26$ & -59 & * \\
\hline & 40.0 & $1.50 \pm 0.42$ & -62 & * \\
\hline \multicolumn{5}{|c|}{$\begin{array}{l}\text { acute simultaneous administration, haloperidol ip - naloxone sc, } 72-\mathrm{hr} \\
\text { pretreat, then apomorphine at } 0.4 \mathrm{mg} / \mathrm{kg} \text { sc ( } n=8 \text { per group). }\end{array}$} \\
\hline
\end{tabular}


TABLE 20

Climbing Mice Supersensitivity

Simultaneous Administration of Haloperidol and Naltrexonea

\begin{tabular}{|c|c|c|c|c|}
\hline \multicolumn{5}{|c|}{ Vehicle and Naltrexone } \\
\hline Treatment & $\begin{array}{c}\text { Dose } \\
(\mathrm{mg} / \mathrm{kg})\end{array}$ & $\begin{array}{c}\text { Climbing Score } \\
\bar{x} \pm S E \\
\end{array}$ & $\begin{array}{l}\text { \% Change } \\
\text { Compared } \\
\text { to Control } \\
\end{array}$ & Sig.b \\
\hline Vehicle-Vehicle & - & $2.38 \pm 0.53$ & - & - \\
\hline \multirow[t]{5}{*}{ Vehicle-Naltrexone } & 2.5 & $1.75 \pm 0.41$ & -26 & - \\
\hline & 5.0 & $2.13 \pm 0.40$ & -11 & - \\
\hline & 10.0 & $1.75 \pm 0.37$ & -26 & - \\
\hline & 20.0 & $1.38 \pm 0.50$ & -40 & - \\
\hline & \multicolumn{3}{|c|}{ Haloperidol and Naltrexone } & \\
\hline Treatment & $\begin{array}{c}\text { Dose } \\
(\mathrm{mg} / \mathrm{kg})\end{array}$ & $\begin{array}{c}\text { Climbing Score } \\
\bar{x} \pm S E \\
\end{array}$ & $\begin{array}{l}\text { \% Change } \\
\text { Compared } \\
\text { to Control } \\
\end{array}$ & $\underline{\text { sig. }}{ }^{-}$ \\
\hline Haloperidol-Vehicle & 1.25 & $4.00 \pm 0.46$ & - & - \\
\hline \multirow[t]{4}{*}{ Haloperidol-Naltrexone } & 2.5 & $2.63 \pm 0.53$ & -34 & - \\
\hline & 5.0 & $2.63 \pm 0.71$ & -34 & - \\
\hline & 10.0 & $2.13 \pm 0.42$ & -47 & * \\
\hline & 20.0 & $1.63 \pm 0.42$ & -59 & * \\
\hline
\end{tabular}

a Acute simultaneous administration, haloperidol ip - naltrexone sc, $72-\mathrm{hr}$ pretreat, then apomorphine at $0.4 \mathrm{mg} / \mathrm{kg} \mathrm{sc}(n=8$ per group).

b One-way ANOVA, Duncan's multiple-range test, $\star p<0.05$ 
TABLE 21

Climbing Mice Supersensitivity

Simultaneous Administration of Haloperidol and EKCa

Vehicle and EKC

$\begin{array}{lcccc}\text { Treatment } & \begin{array}{c}\text { Dose } \\ (\mathrm{mg} / \mathrm{kg})\end{array} & \begin{array}{c}\text { Climbing Score } \\ \bar{x} \pm S E\end{array} & \begin{array}{c}\text { \% Change } \\ \text { Compared } \\ \text { to Control }\end{array} & \text { Sig.b } \\ \text { Vehicle-Vehicle } & - & 1.25 \pm 0.49 & - & - \\ \text { Vehicle-EKC } & 2.5 & 1.38 \pm 0.53 & +10 & - \\ & 5.0 & 1.25 \pm 0.45 & 0 & - \\ & 10.0 & 1.38 \pm 0.53 & +10 & - \\ & 20.0 & 1.75 \pm 0.56 & +50 & -\end{array}$

Haloperidol and EKC

\begin{tabular}{|c|c|c|c|c|}
\hline Treatment & $\begin{array}{c}\text { Dose } \\
(\mathrm{mg} / \mathrm{kg})\end{array}$ & $\begin{array}{c}\text { Climbing Score } \\
\bar{x} \pm S E\end{array}$ & $\begin{array}{c}\text { \% Change } \\
\text { Compared } \\
\text { to Control } \\
\end{array}$ & Sig. ${ }^{b}$ \\
\hline Haloperidol-Vehicle & 1.25 & $2.88 \pm 0.52$ & - & - \\
\hline \multirow[t]{4}{*}{ Haloperidol-EKC } & 2.5 & $2.38 \pm 0.38$ & -17 & - \\
\hline & 5.0 & $1.88 \pm 0.81$ & -35 & * \\
\hline & 10.0 & $2.25 \pm 0.68$ & -22 & - \\
\hline & 20.0 & $1.25 \pm 0.86$ & -57 & * \\
\hline
\end{tabular}

a Acute simultaneous administration, haloperidol ip - EKC sc, 72-hr pretreat, then apomorphine at $0.4 \mathrm{mg} / \mathrm{kg}$ SC ( $n=8$ per group).

b One-way ANOVA, Duncan's multiple-range test, ${ }^{2} p<0.05$ 
TABLE 22

Climbing Mice Supersensitivity

Simultaneous Administration of Haloperidol and Pentazocinea

\begin{tabular}{|c|c|c|c|c|}
\hline Treatment & $\begin{array}{c}\text { Dose } \\
(\mathrm{mg} / \mathrm{kg})\end{array}$ & $\begin{array}{c}\text { Climbing Score } \\
\bar{x} \pm S E \\
\end{array}$ & $\begin{array}{l}\text { \% Change } \\
\text { Compared } \\
\text { to Control } \\
\end{array}$ & sig. ${ }^{b}$ \\
\hline Vehicle-Vehicle & - & $1.63 \pm 0.65$ & - & - \\
\hline \multirow[t]{5}{*}{ Vehicle-Pentazocine } & 10.0 & $1.63 \pm 0.53$ & 0 & - \\
\hline & 20.0 & $2.13 \pm 0.58$ & +31 & - \\
\hline & 40.0 & $1.88 \pm 0.58$ & +15 & - \\
\hline & 80.0 & $1.88 \pm 0.77$ & +15 & - \\
\hline & Haloperi & and Pentazocine & & \\
\hline Treatment & $\begin{array}{c}\text { Dose } \\
(\mathrm{mg} / \mathrm{kg})\end{array}$ & $\begin{array}{c}\text { Climbing Score } \\
\bar{x} \pm S E \\
\end{array}$ & $\begin{array}{l}\text { Change } \\
\text { Compared } \\
\text { to Control } \\
\end{array}$ & sig. \\
\hline Haloperidol-Vehicle & 1.25 & $3.50 \pm 0.80$ & - & - \\
\hline \multirow[t]{4}{*}{ Haloperidol-Pentazocine } & 10.0 & $4.50 \pm 0.50$ & +29 & - \\
\hline & 20.0 & $2.50 \pm 0.89$ & -29 & - \\
\hline & 40.0 & $2.25 \pm 0.80$ & -56 & * \\
\hline & 80.0 & $2.00 \pm 0.57$ & -63 & * \\
\hline
\end{tabular}

a Acute simultaneous administration, haloperidol ip - pentazocine sc, 72-hr pretreat, then apomorphine at $0.4 \mathrm{mg} / \mathrm{kg}$ sc ( $n=8$ per group).

b One-way ANova, Duncan's multiple-range test, $* p<0.05$ 
TABLE 23

Climbing Mice Supersensitivity

Simultaneous Administration of Haloperidol and Cyclazocinea

\begin{tabular}{|c|c|c|c|c|}
\hline Treatment & $\begin{array}{c}\text { Dose } \\
(\mathrm{mg} / \mathrm{kg})\end{array}$ & $\begin{array}{c}\text { Climbing Score } \\
\bar{x} \pm S E \\
\end{array}$ & $\begin{array}{l}\text { 6 Change } \\
\text { Compared } \\
\text { to Control } \\
\end{array}$ & Sig.b \\
\hline Vehicle-Vehicle & - & $1.88 \pm 0.74$ & - & - \\
\hline \multirow[t]{4}{*}{ Vehicle-Cyclazocine } & 0.625 & $2.25 \pm 0.49$ & +20 & - \\
\hline & 1.25 & $2.00 \pm 0.50$ & +6 & - \\
\hline & 2.5 & $1.88 \pm 0.58$ & 0 & - \\
\hline & 5.0 & $2.00 \pm 0.68$ & +6 & - \\
\hline
\end{tabular}

Treatment

Haloperidol-Vehicle

Haloperidol-Cyclazocine

Haloperidol and Cyclazocine

\% Change

Dose Climbing Score Compared

$(\mathrm{mg} / \mathrm{kg})$

1.25

0.625

1.25

2.5

5.0

$\bar{x} \pm S E$

$3.88 \pm 0.35$

$4.00+1.07$

$2.63+0.60$

$2.00 \pm 0.85$

$1.75 \pm 0.59$ to Control sig.

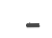

$+3$

$-32$

$-48$

$-55$

a Acute simultaneous administration, haloperidol ip - cyclazocine sc, 72-hr pretreat, then apomorphine at $0.4 \mathrm{mg} / \mathrm{kg}$ sc ( $n=8$ per group).

b One-way ANOVA, Duncan's multiple-range test, $* p<0.05$ 
TABLE 24

Climbing Mice Supersensitivity

Simultaneous Administration of Haloperidol and SKF 10,047a

Vehicle and SKF 10,047

$\begin{array}{lcccc}\text { Treatment } & \begin{array}{c}\text { Dose } \\ (\mathrm{mg} / \mathrm{kg})\end{array} & \begin{array}{c}\text { Climbing Score } \\ \overline{\mathrm{x}} \pm \mathrm{SE}\end{array} & \begin{array}{c}\text { \% Change } \\ \text { Compared } \\ \text { to Control }\end{array} & \text { Sig.b } \\ \text { Vehicle-Vehicle } & - & 1.88 \pm 0.48 & - & - \\ \text { Vehicle-SKF } 10,047 & 5.0 & 2.00 \pm 0.60 & +6 & - \\ & 10.0 & 1.38 \pm 0.38 & -27 & - \\ & 20.0 & 1.63 \pm 0.63 & -13 & - \\ & 40.0 & 1.75 \pm 1.00 & -7 & -\end{array}$

Haloperidol and SKF 10,047

\begin{tabular}{|c|c|c|c|c|}
\hline Treatment & $\begin{array}{c}\text { Dose } \\
(\mathrm{mg} / \mathrm{kg})\end{array}$ & $\begin{array}{c}\text { Climbing Score } \\
\bar{x} \pm \mathrm{SE} \\
\end{array}$ & $\begin{array}{l}\text { \% Change } \\
\text { Compared } \\
\text { to Control } \\
\end{array}$ & sig. $b$ \\
\hline Haloperidol-Vehicle & 1.25 & $3.50 \pm 0.57$ & - & - \\
\hline \multirow[t]{4}{*}{ Haloperidol-SKF 10,047} & 5.0 & $2.13 \pm 0.91$ & -39 & - \\
\hline & 10.0 & $1.63 \pm 0.57$ & -53 & * \\
\hline & 20.0 & $1.75 \pm 0.41$ & -50 & - \\
\hline & 40.0 & $0.88+0.48$ & -75 & * \\
\hline
\end{tabular}

a Acute simultaneous administration, haloperidol ip - SKF 10,047 sC, 72-hr pretreat, then apomorphine at $0.4 \mathrm{mg} / \mathrm{kg} \mathrm{sc}$ ( $n=8$ per group).

b One-way ANOVA, Duncan's multiple-range test, $\star p<0.05$ 
TABLE 25

Effects of Chronic Haloperidol Treatment on

Apomorphine $(0.4 \mathrm{mg} / \mathrm{kg})$ - Induced Locomotor Activitya

Mean Activity Counts \pm S.E.b

1. 15' Intervals over 2 Hours

\begin{tabular}{|c|c|c|c|c|c|c|c|c|}
\hline Treatment & $0-15^{\prime}$ & $15^{\prime}-30^{\prime}$ & $30^{\prime}-45^{\prime}$ & $45^{\prime}-60^{\prime}$ & $60^{\prime}-75^{\prime}$ & $75^{\prime}-90^{\prime}$ & $90^{\prime}-105^{\prime}$ & $105^{\prime}-120^{\prime}$ \\
\hline Vehicle & $53.3 \pm 1.9$ & $44.9 \pm 2.3$ & $28.6 \pm 4.9$ & $26.3 \pm 2.5$ & $35.7 \pm 5.7$ & $23.4 \pm 7.7$ & $31.6 \pm 12.2$ & $49.8 \pm 4.5$ \\
\hline loperi & $51.4 \pm 1.8$ & $52.7 \pm 0.7^{\star}$ & $41.4 \pm 2.5$ & $37.4 \pm 5.2$ & $44.1 \pm 1.7$ & $46.4 \pm 2.7 *$ & $35.2 \pm 7.9$ & \\
\hline
\end{tabular}

2. $60^{\prime}$ Intervals over 2 Hours

\begin{tabular}{|c|c|c|c|c|}
\hline \multirow[b]{2}{*}{ Treatment } & \multicolumn{2}{|c|}{$60^{\prime}$} & \multicolumn{2}{|c|}{$\underline{120^{\prime}}$} \\
\hline & $\bar{x} \pm S E$ & $\begin{array}{c}\text { \% Change } \\
\text { from Control } \\
\end{array}$ & $\overline{\bar{x}} \pm S E$ & $\begin{array}{c}5 \text { Change } \\
\text { from Control } \\
\end{array}$ \\
\hline Vehicle & $80.3 \pm 3.1$ & - & $76.5 \pm 8.7$ & - \\
\hline Haloperidol & $92.7 \pm 4.2$ & +15 & $78.2 \pm 6.6$ & +2 \\
\hline
\end{tabular}

allaloperidol administered at $1.25 \mathrm{mg} / \mathrm{kg}$ ip per day for five days followed by a 72-hr. drug-free period, then apomorphine at $0.4 \mathrm{mg} / \mathrm{kg} \mathrm{sc}$.

bMean and standard error of the square root of the activity counts of 8 pairs of mice.

*P<0.05, " $t$ " test 


\section{TABLE 25a}

Effects of Chronic Haloperidol Treatment on

Apomorphine $(0.4 \mathrm{mg} / \mathrm{kg})$-Induced Locomotor Activitya

Mean Activity Counts \pm S.E. b

1. 15' Intervals over 2 Hours

\begin{tabular}{|c|c|c|c|c|c|c|c|c|}
\hline Treatment & $0-15^{\circ}$ & $15^{\prime}-30^{\prime}$ & $30^{\prime}-45^{\prime}$ & $45^{\prime}-60^{\prime}$ & $60^{\prime}-75^{\prime}$ & $75^{\prime}-90^{\prime}$ & $90^{\prime}-105^{\prime}$ & $105^{\prime}-120^{\prime}$ \\
\hline Venicle & $2852 \pm 203$ & $2036 \pm 197$ & $887 \pm 321$ & $708 \pm 129$ & $1372 \pm 357$ & $723 \pm 426$ & $1439 \pm 752$ & $2536 \pm 416$ \\
\hline Haloperidol & $2654 \pm 183$ & $2782 \pm 74$ & $1729 \pm 210$ & $1479 \pm 391$ & $1955 \pm 145$ & $2175 \pm 145$ & $1428 \pm 522$ & $690 \pm 281$ \\
\hline
\end{tabular}

2. $60^{*}$ Intervals over 2 Hours

$60^{\prime}$

\begin{tabular}{|c|c|c|c|c|}
\hline Ireatment & $\bar{x} \pm S E$ & $\begin{array}{c}\text { \% Change } \\
\text { from Control } \\
\end{array}$ & $\bar{x} \pm S E$ & $\begin{array}{c}7 \text { Change } \\
\text { from Control }\end{array}$ \\
\hline Vehicle & $6483 \pm 485$ & - & $6070 \pm 1405$ & - \\
\hline Haloperidol & $8644 \pm 786$ & +33 & $6248 \pm 1060$ & +3 \\
\hline
\end{tabular}

a Haloperidol administered at $1.25 \mathrm{mg} / \mathrm{kg}$ ip per day for five days followed by a 72-hr. drug-free period, then apomorphine at $0.4 \mathrm{mg} / \mathrm{kg} \mathrm{sC}$.

b Mean and standard error of the activity counts of 8 pairs of mice. 
TABLE 26

$$
\begin{gathered}
\text { Apomorphine-Induced Stereotyped Behavior } \\
\text { Effects of 5-Day Administration of } \\
\text { Morphine }(10 \mathrm{mg} / \mathrm{kg} \mathrm{sC}) \text { and Haloperidol }(1.25 \mathrm{mg} / \mathrm{kg} \text { ip })^{a}
\end{gathered}
$$

Treatment

Vehicle-Vehicle

Vehicle-Haloperidol

Morphine-Vehicle

Morphine-Haloperidol
Stereotypy Score $\bar{x} \pm S E$

$2.25 \pm 0.37$

$5.50 \pm 0.27$

$4.88 \pm 0.44$

$5.63 \pm 0.26$
\% Change

from Control Sig.b

from con

$+144$

$+117$

$+150$

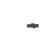

*

*

a Five days simultaneous administration, haloperidol ip - morphine sc followed by a 72-hr. drug-free period, then apomorphine at $0.4 \mathrm{mg} / \mathrm{kg}$ SC $(n=8$ per group).

b One-way ANOVA, Duncan's multiple-range test; ${ }^{*} P<0.05$ 
TABLE 27

\author{
Apomorphine-Induced Stereotyped Behavior \\ Effects of 5-Day Administration of \\ Naltrexone (40 mg/kg sc) and Haloperidol (1.25 mg/kg ip)a
}

Treatment

Vehicle-Vehicle

Vehicle-Haloperidol

Naltrexone-Vehicle

Naltrexone-Haloperidol

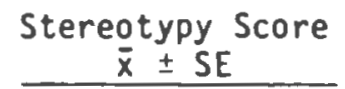

$2.13 \pm 0.44$

$5.13 \pm 0.40$

$2.63 \pm 0.53$

$5.25 \pm 0.31$
* Change

from Control sig.

$$
-
$$

$+140$

$+23$

$+146$

a Five days simultaneous administration, haloperidol ip - naltrexone SC followed by a $72-\mathrm{hr}$. drug-free period, then apomorphine at $0.4 \mathrm{mg} / \mathrm{kg}$ sc $(n=8$ per group).

b One-way ANOVA, Duncan's multiple-range test; $* p<0.05$ 
TABLE 28

Apomorphine-Induced Stereotyped Behavior

Effects of 5-Day Administration of

EKC (20 mg/kg sc) and Haloperidol (1.25 mg/kg ip)a

Treatment

Vehicle-Vehicle

Vehicle-Haloperidol

EKC-Vehicle

EKC-Ha loperidol
Stereotypy Score $\bar{x} \pm S E$

$2.75 \pm 0.53$

$5.25 \pm 0.37$

$2.88 \pm 0.13$

$5.13 \pm 0.40$
\% Change

from Control sig.b

$-$

$+91$

$+5$

$+87$

a Five days simultaneous administration, haloperidol ip - EKC SC followed by a 72-hr. drug-free period, then apomorphine at $0.4 \mathrm{mg} / \mathrm{kg}$ sc ( $n=8$ per group).

b One-way ANOVA, Duncan's multiple-range test; $\star p<0.05$ 
TABLE 29

Apomorphine-Induced Stereotyped Behavior

Effects of 5-Day Administration of

Cyclazocine $(2.5 \mathrm{mg} / \mathrm{kg} \mathrm{sc})$ and Haloperidol $(1.25 \mathrm{mg} / \mathrm{kg}$ ip)a

$\underline{\text { Treatment }}$

Vehicle-Vehicle

Vehicle-Haloperidol

Cyclazocine-Vehicle

Cyclazocine-Haloperidol
Stereotypy Score

$\bar{x} \pm S E$

$2.38 \pm 0.26$

$5.63+0.18$

$2.63 \pm 0.38$

$3.75+0.31$
\% Change

from Control sig.

$+137$

$+11$

$+58$

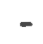

$\star$

$\star C$

a Five days simultaneous administration, haloperidol ip - cyclazocine sc followed by a $72-\mathrm{hr}$. drug-free period, then apomorphine at $0.4 \mathrm{mg} / \mathrm{kg}$ sc ( $n=8$ per group).

b One-way ANOVA, Duncan's multiple-range test; $* p<0.05$

c Significantly different from vehicle-haloperidol group and vehiclevehicle group. 
TABLE 30

Apomorphine-Induced Stereotyped Behavior

Effects of 5-Day Administration of

SKF 10,047 (40 mg/kg Sc) and Haloperidol (1.25 mg/kg ip)a

Treatment

Vehicle-Vehicle

Vehicle-Haloperidol

SKF $10,047-$ Vehicle

SKF 10,047-Haloperidol

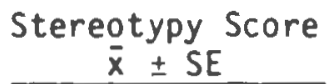

$1.88 \pm 0.35$

$4.88+0.48$

$1.13 \pm 0.40$

$1.88+0.55$
\% Change from Control sig.b

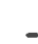

$+160$

$-40$

0

a Five days simultaneous administration, haloperidol ip - SKF 10,047 SC followed by a $72-\mathrm{hr}$. drug-free period, then apomorphine at $0.4 \mathrm{mg} / \mathrm{kg}$ sc $(n=8$ per group).

b One-way ANOVA, Duncan's multiple-range test; $\star p<0.05$ 
TABLE 31

Climbing Mice Supersensitivity

Chronic Simultaneous Administration of

Morphine and Haloperidola

Vehicle and Morphine

Treatment

Vehicle-Vehicle

Vehicle-Morphine
Dose
$(\mathrm{mg} / \mathrm{kg})$

Climbing Score $\bar{x} \pm S E$

$-\quad 2.13 \pm 0.52$

2.5

5.0

10.0

$3.25 \pm 0.37$
$+76$

$+70$

$+53$
\% Change

Compared to Control Sig. ${ }^{b}$

Haloperidol and Morphine

Treatment

Haloperidol-Vehicle

Haloperidol-Morphine
Dose Climbing Score $(\mathrm{mg} / \mathrm{kg})$

1.25

2.5

5.0

10.0 $\bar{x} \pm S E$

$5.38 \pm 0.80$

$5.50 \pm 0.38$

$5.38 \pm 0.50$

$5.25 \pm 0.49$
* Change Compared to Control Sig. b

a Five days simultaneous administration, haloperidol ip - morphine $s c$, followed by a 72 -hour drug-free period, then apomorphine at $0.4 \mathrm{mg} / \mathrm{kg}$ sc, $n=8$ per group.

b One-way ANOVA, Duncan's multiple-range test 
TABLE 32

\author{
Climbing Mice Supersensitivity \\ Chronic Simultaneous Administration of \\ Naloxone and Haloperidola
}

Vehicle and Naloxone

Treatment

Vehicle-Vehicle

Vehicle-Naloxone
Dose
$(\mathrm{mg} / \mathrm{kg})$

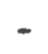

5.0

10.0

20.0

40.0

Haloperidol and Naloxone
\% Change

Compared to Control Sig.
Treatment

Haloperidol-Vehicle

Haloperidol-Naloxone
Dose Climbing Score $(\mathrm{mg} / \mathrm{kg})$

1.25

5.0

10.0

20.0

40.0 $\bar{x} \pm S E$

$6.13 \pm 0.35$

$5.50+0.57$

$5.88 \pm 0.40$

$6.13 \pm 0.48$

$5.13 \pm 0.52$
\% Change

Compared to Control Sig. ${ }^{b}$

a Five days simultaneous administration, haloperidol ip - naloxone sc, followed by a 72-hour drug-free period, then apomorphine at $0.4 \mathrm{mg} / \mathrm{kg}$ sc, $n=8$ per group.

b One-way ANOVA, Duncan's multiple-range test 
TABLE 33

$$
\text { Climbing Mice Supersensitivity }
$$

Chronic Simultaneous Administration of

Naltrexone and Haloperidola

Vehicle and Naltrexone

Dose Climbing Score \% Change

Treatment

(mg/kg) $\bar{x} \pm S E$ Compared to Control Sig. ${ }^{b}$

Vehicle-Vehicle

$-\quad 1.50 \pm 0.38$

vehicle-Naltrexone

$2.51 .63 \pm 0.32$

$+9$

$5.0 \quad 1.38 \pm 0.53$

$-8$

10.0

$2.13 \pm 0.58$

$+42$

20.0

$1.63 \pm 0.91$

$+9$

40.0

$2.00 \pm 0.76$

$+33$

Haloperidol and Naltrexone

\begin{tabular}{|c|c|c|c|c|}
\hline Treatment & $\begin{array}{c}\text { Dose } \\
(\mathrm{mg} / \mathrm{kg})\end{array}$ & $\begin{array}{c}\text { Climbing Score } \\
\bar{x} \pm S E \\
\end{array}$ & $\begin{array}{c}\text { \& Change } \\
\text { Compared to Control }\end{array}$ & sig. ${ }^{b}$ \\
\hline Haloperidol-Vehicle & 1.25 & $4.63 \pm 0.75$ & - & - \\
\hline \multirow[t]{5}{*}{ Haloperidol-Naltrexone } & 2.5 & $4.13 \pm 0.48$ & -11 & - \\
\hline & 5.0 & $3.38 \pm 0.60$ & -27 & - \\
\hline & 10.0 & $2.50 \pm 0.63$ & -46 & - \\
\hline & 20.0 & $3.00 \pm 0.78$ & -35 & - \\
\hline & 40.0 & $3.50 \pm 0.57$ & -24 & - \\
\hline
\end{tabular}

a Five days simultaneous administration, haloperidol ip - naltrexone sc, followed by a 72-hour drug-free period, then apomorphine at $0.4 \mathrm{mg} / \mathrm{kg}$ sc, $n=8$ per group.

b One-way ANOVA, Duncan's multiple-range test 
TABLE 34

\author{
Climbing Mice Supersensitivity \\ Chronic Simultaneous Administration of \\ EKC and Haloperidola
}

Vehicle and EKC

Treatment

Vehicle-Vehicle

Vehicle-EKC
Dose
(mg/kg)

Climbing Score $\bar{x} \pm S E$

$2.00 \pm 0.76$

2.5

$1.13 \pm 0.40$

5.0

$1.88 \pm 0.74$

10.0

$4.00 \pm 0.82$

20.0

$2.13 \pm 0.58$

Haloperidol and EKC

Treatment

Haloperidol-Vehicle

Haloperidol-EKC
Dose

$\mathrm{lmg} / \mathrm{kgl}$

1.25

2.5

5.0

Climbing Score $\bar{x} \pm S E$

$$
4.38 \pm 0.57
$$

$4.50 \pm 0.60$

$2.63 \pm 0.94$

$2.25 \pm 0.45$

$2.50 \pm 0.71$

10.0

20.0$$
2.50 \pm 0.71
$$

\& Change

Compared to Control sig.:

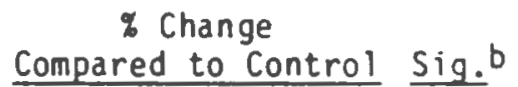

Compared to Control sig.
$-43$

$-6$

$+100$

$+7$ 
TABLE 35

Climbing Mice Supersensitivity

Chronic Simultaneous Administration of

Pentazocine and Haloperidola

Vehicle and Pentazocine

Treatment

Vehicle-Vehicle

Vehicle-Pentazocine
Dose Climbing Score \& Change

$(\mathrm{mg} / \mathrm{kg}) \quad \bar{x} \pm S E \quad$ Compared to Control Sig. ${ }^{b}$

$-\quad 2.13 \pm 0.40$

$10.0 \quad 2.13 \pm 0.79$

$20.0 \quad 1.25 \pm 0.37$

$40.0 \quad 1.87 \pm 0.64$

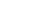

80.0

$1.75 \pm 0.45$

$-18$

Haloperidol and Pentazocine

\section{Treatment}

Haloperidol-Vehicle

Haloperidol-Pentazocine

\begin{tabular}{|c|c|c|c|}
\hline $\begin{array}{l}\text { Dose } \\
(\mathrm{mg} / \mathrm{kg})\end{array}$ & $\begin{array}{c}\text { Climbing Score } \\
\bar{x} . \pm S E \\
\end{array}$ & $\begin{array}{c}\text { \% Change } \\
\text { Compared to Control } \\
\end{array}$ & sig. \\
\hline 1.25 & $5.25 \pm 0.62$ & - & - \\
\hline 10.0 & $5.62 \pm 0.50$ & +7 & - \\
\hline 20.0 & $6.00 \pm 0.38$ & +14 & - \\
\hline 40.0 & $5.50 \pm 0.65$ & +5 & - \\
\hline 80.0 & $4.75 \pm 0.70$ & -10 & - \\
\hline
\end{tabular}

a Five days simultaneous administration, haloperidol ip - pentazocine sc, followed by a 72-hour drug-free period, then apomorphine at 0.4 $\mathrm{mg} / \mathrm{kg} \mathrm{SC}, \mathrm{n}=8$ per group.

b One-way ANOVA, Duncan's multiple-range test 
TABLE 36

Climbing Mice Supersensitivity

Chronic Simultaneous Administration of

Cyclazocine and Haloperidola

Vehicle and Cyclazocine

Dose Climbing Score \% Change

Treatment

$(\mathrm{mg} / \mathrm{kg})$

Compared to Control Sig. ${ }^{b}$

Vehicle-Vehicle

- $\quad 3.12 \pm 0.67$

Vehicle-Cyclazocine

$0.38 \quad 3.12 \pm 0.64$

0

$0.75 \quad 3.12 \pm 0.69$

0

$1.5 \quad 3.38 \pm 0.73$

$+8$

3.0

$2.63 \pm 0.53$

$-16$

Haloperidol and Cyclazocine

Treatment

Haloperidol-Vehicle

Haloperidol-Cyclazocine
Dose Climbing Score \% Change $(\mathrm{mg} / \mathrm{kg})-\overline{\mathrm{x}} \pm \mathrm{SE}$ Compared to Control Sig.

$1.25 \quad 5.88 \pm 0.48$

$0.38 \quad 3.63 \pm 0.37 \quad-38$

0.75

$3.38 \pm 0.80$

$-43$

$1.5 \quad 3.00 \pm 0.71$

$-49$

$3.0 \quad 3.12 \pm 1.09$

$-47$

a Five days simultaneous administration, haloperidol ip - cyclazocine sc, followed by a 72 -hour drug-free period, then apomorphine at 0.4 $\mathrm{mg} / \mathrm{kg} \mathrm{sc}, \mathrm{n}=8$ per group.

b One-way ANOVA, Duncan's multiple-range test; $\star p<0.05$ 
TABLE 37

Climbing Mice Supersensitivity

Chronic Simultaneous Administration of SKF 10,047 and Haloperidola

Vehicle and SKF 10,047

Treatment

Vehicle-Vehicle

Vehicle-SKF 10,047
Dose Climbing Score

(mg/kg)

-

5.0

10.0

-

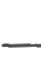

$2.38 \pm 0.60$

$2.50 \pm 0.38$

Venicle-sk 10,047

$1.75 \pm 0.62$

$2.75 \pm 0.67$

$2.14 \pm 0.80$

40.0

20.0

Haloperidol and SKF 10,047
* Change

Compared to Contral Sig.b

Treatment

Dose Climbing Score

$(\mathrm{mg} / \mathrm{kg})$ $\bar{x} \pm S E$

* Change Compared to Control Sig.

Haloperidol-Vehicle

1.25

$5.25 \pm 0.70$

Haloperidol-SKF 10,047
$+5$

$-26$

$+16$

$-10$

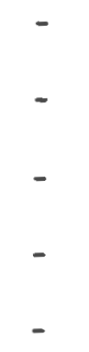

$5.0 \quad 3.50 \pm 0.57$

10.0

$3.12 \pm 0.69$

20.0

$2.38 \pm 0.91$

40.0 
TABLE 38

The Effects of Naloxone on

Apomorphine-Induced $\mathrm{Cl}$ imbing Behavior

\begin{tabular}{|c|c|c|c|c|c|}
\hline Treatimenta & $\begin{array}{c}\text { Dose } \\
(m g / \mathrm{kg} \text { ip) }\end{array}$ & $\underline{n}$ & $\begin{array}{c}\text { Climbing Score } \\
\bar{x} \pm \mathrm{SE} \\
\end{array}$ & 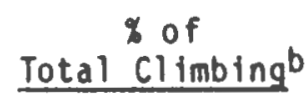 & $\begin{array}{c}\text { \% Change } \\
\text { Potentiation of } \mathrm{Cl} \text { imbingc } \\
\end{array}$ \\
\hline \multirow[t]{4}{*}{ Vehicle + Naloxone } & 0 & 8 & $0.00 \pm 0.00$ & 0 & - \\
\hline & 1 & 8 & $0.00 \pm 0.00$ & 0 & - \\
\hline & 3 & 8 & $0.00 \pm 0.00$ & 0 & - \\
\hline & 10 & 8 & $0.13 \pm 0.13$ & 2 & - \\
\hline \multirow[t]{4}{*}{ Aponorphine + Naloxone } & 0 & 8 & $1.50 \pm 0.42$ & 25 & - \\
\hline & 1 & 8 & $1.75 \pm 0.37$ & 29 & +17 \\
\hline & 3 & 8 & $2.75 \pm 0.41$ & 46 & +83 \\
\hline & 10 & 8 & $2.75 \pm 0.25$ & 46 & +75 \\
\hline
\end{tabular}

a Aponorphine $(0.4 \mathrm{mg} / \mathrm{kg} \mathrm{SC})$ and naloxone administered simultaneously 0 ' prior to testing.

b) $\%$ climbing based on maximum score $=6$

$\%$ climbing $=\frac{\bar{x} \text { of Dose Group }}{\text { Max. Score }} \times 100$

$C *$ Change Potentiation of Climbing $=\frac{(\text { Apo. }+ \text { Na } 1 .)-(\text { Veh. }+ \text { Nal. })}{(\text { Apo. }+ \text { Veh. })} \times 100$ 
TABLE 39

The Effects of Ethylketocyclazocine on

Apomorphine-Induced Climbing Behavior

\section{Treatinent a}

Vehicle + EKC

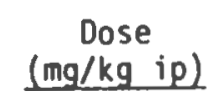

0

1

3

10

$\frac{n}{8}$
8
8
8

$$
\begin{gathered}
\frac{C_{\bar{x}} \pm S E}{0.00 \pm 0.00} \\
0.00 \pm 0.00 \\
2.38 \pm 0.92 \\
1.63 \pm 0.73
\end{gathered}
$$$$
8 \quad 1.63 \pm 0.63
$$$$
2.50 \pm 0.68
$$$$
2.38 \pm 0.26
$$$$
2.00 \pm 0.50
$$

\section{Tof} Total Climbing

X Change

Potentiation of Climbing

$\begin{array}{llll}0 & 8 & 1.63 \pm 0.63 & 27 \\ 1 & 8 & 2.50 \pm 0.68 \\ 3 & 8 & 2.38 \pm 0.26 \\ 10 & 8 & 2.00 \pm 0.50\end{array}$

0

$40^{d}$

$27^{d}$

27

42

40

33

$+17$

0

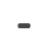

$-$

$+23$

a EKC administered 180' prior to testing; Apomorphine $(0.4 \mathrm{mg} / \mathrm{kg} \mathrm{SC})$ administered $0^{\prime} \mathrm{prior}$ to testing.

$b \%$ climbing based on maximum score $=6$

\% climbing $=\frac{\bar{x} \text { of Dose Group }}{\text { Max. score }} \times 100$

$c \%$ Change Potentiation of Climbing $=\frac{(A p o++E K C)-(\text { Veh. }+E K C)}{(A p o+V e h .)} \times 100$

d Hyperactivity rather than characteristic prolonged climbing seen after apomorphine. 
TABLE 40

The Effects of SKF 10,047 on

Apomorphine-Induced Climbing Behavior

Treatment a

Vehicle + SKF 10,047

$\begin{gathered}\text { Dose } \\ (\mathrm{mg} / \mathrm{kg} \text { ip })\end{gathered}$
0
1
3
10

Climbing Score

$\underline{\mathrm{n}}$

$8 \quad 0.13 \pm 0.13$

8

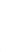

8

$0.25 \pm 0.25$

$0.50 \pm 0.27$

$8 \quad 2.00 \pm 0.76$

Apomorphine + SKF 10,047

$\begin{array}{lll}0 & 8 & 1.50 \pm 0.42 \\ 1 & 8 & 2.25 \pm 0.45 \\ 3 & 8 & 2.50 \pm 0.38 \\ 10 & 8 & 3.00 \pm 0.19\end{array}$

\begin{tabular}{|c|}
\hline Total ${ }^{x}$ of imbingb \\
\hline 2 \\
\hline 4 \\
\hline 8 \\
\hline $33^{d}$ \\
\hline
\end{tabular}

25

38

42

50 x Change

Potentiation of Climbing $c$

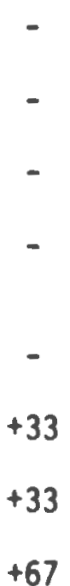

a SKF 10,047 administered 90' prior to testing; Apomorphine $(0.4 \mathrm{mg} / \mathrm{kg} \mathrm{sc})$ administered $0^{\prime}$ prior to testing.

b climbing based on maximum score $=6$

$\%$ climbing $=\frac{\bar{x} \text { of Dose Group }}{\text { Max score }} \times 100$

c * Change Potentiation of Climbing $=\frac{(\text { Apo. }+ \text { SKF } 10,047)-(\text { Veh. }+ \text { SKF 10,047) }}{(\text { Apo }+ \text { Veh. })} \times 100$

d Prolonged climbing similar to apomorphine-induced climbing. 
TABLE 41

Induction of Hyperactivity in Mice

by Ethylketocyclazocine at $5 \mathrm{mg} / \mathrm{kg} \mathrm{sc}$

\begin{tabular}{|c|c|c|}
\hline Pretreat (min.) & $\begin{array}{c}\text { Hyperactivity Scored } \\
\bar{x} \pm \text { SE } \\
\end{array}$ & X of Hyperactivity \\
\hline 30 & $0.00 \pm 0.00$ & 0 \\
\hline 60 & $0.00 \pm 0.00$ & 0 \\
\hline 90 & $0.00 \pm 0.00$ & 0 \\
\hline 120 & $0.38 \pm 0.26$ & 10 \\
\hline 150 & $1.13 \pm 0.64$ & 28 \\
\hline 180 & $1.88 \pm 0.58$ & 47 \\
\hline 210 & $1.88 \pm 0.48$ & 47 \\
\hline 240 & $0.75 \pm 0.53$ & 19 \\
\hline 270 & $1.00 \pm 0.65$ & 25 \\
\hline 300 & $0.88 \pm 0.40$ & 22 \\
\hline 330 & $0.75 \pm 0.53$ & 19 \\
\hline 360 & $0.38 \pm 0.38$ & 10 \\
\hline
\end{tabular}

a Hyperactivity measured in stick cages; $n=8$.

b $\%$ of hyperactivity based on maximum score $=4$

\% hyperactivity $=\frac{\bar{x} \text { of Pretreat Group }}{\text { Max. }} \times 100$ 
TABLE 42

Ethylketocyclazocine-Induced Hyperactivity in Mice

\begin{tabular}{|c|c|c|c|}
\hline $\begin{array}{c}\text { Dosed } \\
(\mathrm{mg} / \mathrm{kg} \mathrm{sc})\end{array}$ & $\begin{array}{c}\text { Hyperactivity Scoreb } \\
\bar{x} \pm S E\end{array}$ & x of Hyperactivityc & $\begin{array}{l}E D_{50} \\
\text { 95\% Confidence Limits }\end{array}$ \\
\hline 0 & $0.25 \pm 0.16$ & - & \multirow{5}{*}{$\frac{7.1}{(6.0-8.7)^{\mathrm{mg} / \mathrm{kg} \mathrm{sc}}}$} \\
\hline 1.25 & $1.88 \pm 0.93$ & 28 & \\
\hline 2.5 & $1.00 \pm 0.50$ & 13 & \\
\hline 5.0 & $2.50 \pm 0.75$ & 44 & \\
\hline 10.0 & $3.25 \pm 0.85$ & 57 & \\
\hline \multicolumn{4}{|c|}{$\begin{array}{l}\text { a } 180^{\prime} \text { pretreat; } n=8 \text {. } \\
\text { b Hyperactivity measured in stick cages. }\end{array}$} \\
\hline
\end{tabular}


TABLE 43

Ethylketocyclazocine-Induced Hyperactivity in Micea

Effects of Various Blocking Agents

\begin{tabular}{|c|c|c|c|c|}
\hline Compound & $\begin{array}{c}\text { Dose } \\
(\mathrm{mg} / \mathrm{kg} \text { ip) }\end{array}$ & Pretreat & $\begin{array}{c}\text { \% Change } \\
\text { Compared to Controlb }\end{array}$ & Sig. \\
\hline \multirow[t]{2}{*}{ Naloxone } & 10.0 & $10^{\prime}$ & -8 & - \\
\hline & 100.0 & $10^{\prime}$ & -17 & - \\
\hline Haloperidol & 1.0 & $180^{\prime}$ & -54 & * \\
\hline Apomorphine & 0.1 & $5^{\prime}$ & -65 & $\star$ \\
\hline Muscimol & 1.0 & $30^{\prime}$ & -63 & * \\
\hline Bicuclline & 1.0 & $30^{\prime}$ & 0 & - \\
\hline$\alpha-M P T$ & 300.0 & $4 \mathrm{hrs}$. & -81 & * \\
\hline Phentolamine & 10.0 & $60^{\prime}$ & -47 & * \\
\hline Prazosin & 2.5 & $30^{\prime}$ & -97 & * \\
\hline Yohimbine & 5.0 & $30^{\prime}$ & 0 & - \\
\hline Clonidine & 0.025 & $30^{\prime}$ & -35 & - \\
\hline Propranolol & 2.5 & $30^{\prime}$ & +20 & - \\
\hline PCPA & 300.0 & $72 \mathrm{hrs}$. & -46 & - \\
\hline Methysergide & 10.0 & $30^{\prime}$ & +7 & - \\
\hline Atropine & 5.0 & $30^{\prime}$ & -5 & - \\
\hline Reserpine & 5.0 & $17 \mathrm{hrs}$. & -74 & * \\
\hline \multirow[t]{2}{*}{ TBZ } & 5.0 & $60^{\circ}$ & -81 & * \\
\hline & 40.0 & $60^{\prime}$ & -90 & * \\
\hline
\end{tabular}

a EKC at $5 \mathrm{mg} / \mathrm{kg} \mathrm{SC} ; 180^{\prime}$ pretreat; Hyperactivity measured in stick cages.

b Control = EKC + vehicle; range of control means for 4 separate experiments--3.0-3.9; maximum score $=6 ; n=8$.

\% Change from corresponding control score.

c One-way ANOVA, Duncan's multiple-range test; $* P<0.05$ 
TABLE 44

Induction of Climbing Behavior in Mice

by SKF 10,047 at $40 \mathrm{mg} / \mathrm{kg}$ sC

Pretreat (min.)

30

60

90

120

150

180

$$
\text { Climbing Scorea }
$$
$\bar{x} \pm$ SE

$1.38 \pm 0.42$

$2.75 \pm 0.31$

$2.88 \pm 0.48$

$2.50 \pm 0.57$

$2.38 \pm 0.46$

$1.75 \pm 0.53$ x of climbing ${ }^{b}$

35

69

72

63

60

44

a $n=8$

b $x$ of climbing based on maximum score $=4$. x climbing $=\frac{\bar{x} \text { of Pretreat Group }}{\text { Max. score }} \times 100$ 


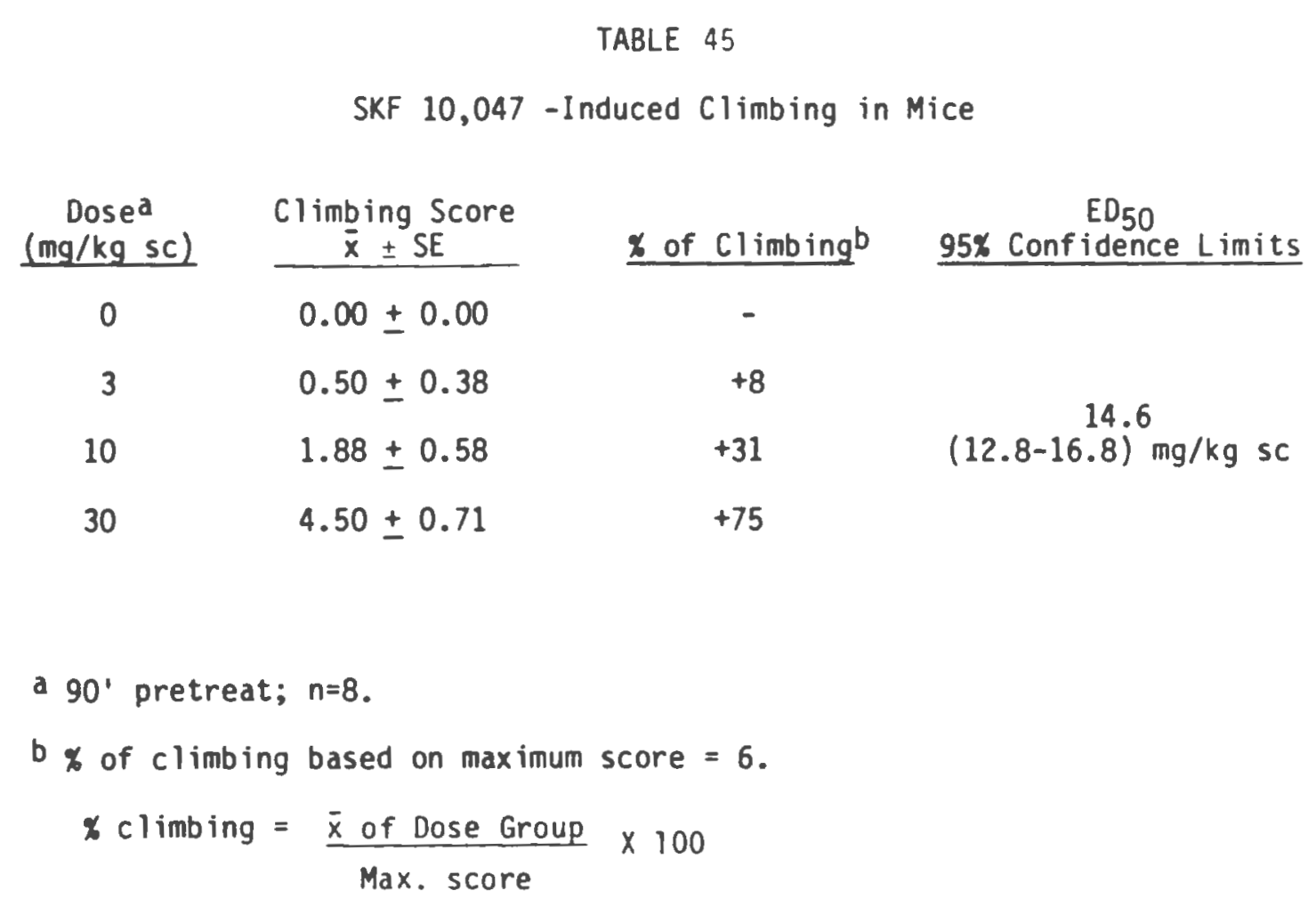


TABLE 46

SKF 10,047-Induced Cage Climbing in Micea

Effects of Various Blocking Agents

\begin{tabular}{|c|c|c|c|c|}
\hline Compound & $\begin{array}{c}\text { Dose } \\
(\mathrm{mg} / \mathrm{kg} \text { ip) }\end{array}$ & Pretreat & $\begin{array}{c}\text { \% Change } \\
\text { Compared to Control } \\
\end{array}$ & Sig. ${ }^{\circ}$ \\
\hline \multirow[t]{2}{*}{ Naloxone } & 10.0 & $10^{\prime}$ & -8 & - \\
\hline & 100.0 & $10^{\prime}$ & -12 & - \\
\hline Ha loperidol & 1.0 & $180^{\circ}$ & -73 & * \\
\hline Apomorphine & 0.1 & $5^{\prime}$ & -64 & * \\
\hline Muscimol & 1.0 & $30^{\prime}$ & -89 & * \\
\hline Bicuclline & 1.0 & $30^{\prime}$ & -9 & - \\
\hline$\alpha-$ MPT & 300.0 & $4 \mathrm{hrs}$. & -97 & * \\
\hline Phentolamine & 10.0 & $60^{\prime}$ & -37 & * \\
\hline Prazosin & 2.5 & $30^{\prime}$ & -90 & $\star$ \\
\hline Yohimbine & 5.0 & $30^{\prime}$ & -12 & - \\
\hline Clonidine & 0.025 & $30^{\circ}$ & -8 & - \\
\hline Propranolol & 2.5 & $30^{\prime}$ & +9 & - \\
\hline PCPA & 300.0 & 72 hrs. & +25 & - \\
\hline Methysergide & 10.0 & $30^{\prime}$ & -66 & * \\
\hline Atropine & 5.0 & $30^{\prime}$ & +48 & - \\
\hline Reserpine & 5.0 & 17 hrs. & -11 & - \\
\hline \multirow[t]{2}{*}{$T B Z$} & 5.0 & $60^{\prime}$ & -75 & * \\
\hline & 40.0 & $60^{\prime}$ & -97 & * \\
\hline
\end{tabular}

a SKF 10,047 at $40 \mathrm{mg} / \mathrm{kg} \mathrm{SC}$; $90^{\circ}$ pretreat.

b control $=\operatorname{SKF} 10,047+$ vehicle; range of control means for 4 separate experiments--3.9-5.0; maximum score $=6 ; n=8$.

\% Change from corresponding control score.

c One-way ANOVA, Duncan's multiple-range test; * $p<0.05$ 


\section{REFERENCES}

ACETO, M. AND MAY, E.: Antinociceptive studies of the optical isomers of n-allylnormetazocine (SKF 10,047). Eur. J. Pharmaco1. 91: 267-272, 1983.

ADAMS, P., BEAUCHAMP, R. AND ALSTON, C.: Potentiation of apomorphine and d-amphetamine effects by naloxone. Life Sci. 28: 629-634, 1981 .

ALLEN, R., LANE, J. AND BRAUCHI, J.: Amantadine reduces haloperidolinduced dopamine receptor hypersensitivity in the striatum. Eur. J. Pharmaco1. 65: 313-315, 1980.

AMIR, S., BROWN, Z. AND AMIT, Z.: The role of endorphins in stress: Evidence and speculations. Neurosci. Biobehav. Rev. 4: 77-86, 1980.

ANDEN, N. E., DAHLSTROM, A., FUXE, K. AND LARSSON, K.: Further evidence for the presence of nigro-neo-striatal dopamine neurons in the rat. Amer. J. Anat. 116:329-333, 1965.

ANDEN, N. E., DAHLSTROM, A., FUXE, K., OLSON, L. AND UNGERSTEDT, U.: Ascending monoamine neurons to the telencephalon and diencephalon. Acta Physio1. Scand. 67: 313-326, 1966.

ANGRIST, B. AND GERSHON, S.: The phenomenology of experimentally induced amphetamine psychosis, preliminary observation. Biol. Psychiatry 2: 95-107, 1970.

ARBILLA, S. AND LANGER, S.: Morphine and $\beta$-endorphin inhibit release of noradrenaline from cerebral cortex but not of dopamine from rat striatum. Nature 271: 559-560, 1978. 
ASPER, H., BAGGIOLINI, M., BURKI, H., LAUENER, H., RUCH, W. AND STILLE, G.: Tolerance phenomena with neuroleptics: Catalepsy, apomorphine stereotypies and striatal dopamine metabolism in the rat after single and repeated administration of loxapine and haloperidol. Eur. J. Pharmacol. 22: 287-294, 1973.

BALSARA, J., NANDAL, N., BURTE, N., JADHAV, J. AND CHANDORKAR, A.: Effects of naloxone on methamphetamine and apomorphine stereotypy and on haloperidol catalepsy in rats. Psychopharmacol. 82: 237-240, 1984.

BARALDI, M., GRANDISON, L. AND GUIDOTTI, A.: Distribution and metabolism of muscimol in the brain and other tissues of the rat. Neuropharmacology 18: 57-62, 1979.

BARONE, P., DAVIS, T., BRAUN, A. AND CHASE, T.: Dopaminergic mechanisms and motor function: Characterization of $D-1$ and $D-2$ dopamine receptor interactions. Eur. J. Pharmacol. 123: 109-114, 1986.

BAUME, S., PATEY, G., MARCAIS, H., PROTAIS, P., COSTENTIN, J. AND SCHWARTZ, J.: Changes in dopamine receptors in mouse striatum following morphine treatments. Life Sci. 24: 2333-2342, 1979.

BAXBAUM, D., YARBROUGH, G. AND CARTER, M.: Biogenic amines and narcotic effects. I. Modification of morphine-induced analgesia and motor activity after alteration of cerebral amine levels. J. Pharmaco1. Exp. Ther. 185: 317-327, 1973. 
BEAUMONT, K., CHILTON, W., YAMAMURA, H. AND ENNA, S.: Muscimol binding in rat brain: Association with synaptic gaba receptors. Brain Res. 148: 153-162, 1978.

BHARGAVA, H.: Cyclo (leucylglycine) inhibits the development of morphine induced analgesic tolerance and dopamine receptor supersensitivity in rats. Life Sci. 27: 117-123, 1980.

BHARGAVA, H.N.: Enhanced response to apomorphine in rats treated with multiple injections of human beta endomorphin and its blockade by proleu-gly-NH2 and cyclo (leu-gly). Life Sci. 29: 1945-1949, 1981.

BHARGAVA, $H_{0}$ : Binding of $(3 H)$ spiroperidol to striatal membranes of rats treated chronically with morphine. Neuropharmacology 22: 1357$1361,1983$.

Blanc, D., Cupo, A., CASTANAS, E., BOURHIM, N., GiRAud, P., BANNON, M. AND EIDEN, L.: Influence of acute, subchronic and chronic treatment with neuroleptic (haloperidol) on enkephalins and their precursors in the striatum of rat brain. Neuropeptides 5: 567-570, 1985 .

BLEULER, E.: Dementia Praecox; or, The Group of Schizophrenias. New York: International Universities Press, 1950.

BLUM, I., MUNITZ, H., SHALEV, A. AND ROBERT, E.: Naloxone may be beneficial in the treatment of tardive dyskinesia. Clin. Neuropharmacology $7: 265-267,1984$. 
BOWERS, M. AND ROZITIS, R.: Regional differences in homovanillic acid concentrations after acute and chronic administration of antipsychotic drugs. J. Pharm. Pharmacol. 26: 743-745, 1974.

BUNNEY, B. S. AND GRACE, S.: Acute and chronic haloperidol treatment: comparison of effects on nigral dopaminergic cell activity. Life Sci. $23: 1715-1728,1978$.

BUNNEY, W., MASSARI, V. AND PERT, A.: Chronic morphine-induced hyperactivity in rats is altered by nucleus accumbens and ventral tegmental lesions. Psychopharmacology 82: 318-321, 1984.

BUNNEY, B. S., WALTERS, J., ROTH, R. AND AGHAJANIAN, G.: Dopaminergic neurons: effect of antipsychotic drugs and amphetamine on single cell activity. J. Pharmaco1. Exp. Ther. 185: 560-571, 1973.

BURKI, H.: Biochemical methods for predicting the occurrence of tardive dyskinesia. Comm. Psychopharmacol. 3: 7-15, 1979a.

BURKI, H.: Extrapyramidal side-effects. Pharmacol. Ther. 5: 525-534, $1979 b$.

BURT, D. R., CREESE, I. AND SNYDER, S.: Antischizophrenic drugs: chronic treatment elevates dopamine receptor binding in brain. Science 196: 326-328, 1977.

BUXBAUM, D., YARBROUGH, G. AND CARTER, M.: Biogenic amines and narcotic effects. I. Modification of apomorphine-induced analgesia and motor activity after alteration of cerebral amine levels. J. Pharmacol. Exp. Ther. 185: 317-327, 1973. 
CABIB, S., PUGLISI-ALLEGRA, S. AND OLIVERIO, A.: Chronic stress enhances apomorphine-induced stereotyped behavior in mice: involvement of endogenous opioids. Brain Res. 298: 138-140, 1984.

CARLSON, K. AND ALMASI, J.: Behavioral supersensitivity to apomorphine following chronic narcotic treatment in the guinea pig. Psychopharmacology $57: 273-277,1978$.

CARLSON, K. AND ALMASI, J.: Time ruurse of dopaminergic hypersensitivity following chronic narcotic treatment. Pharmacol. Biochem. Behav. 11: 283-287, 1979.

CARLSON, K. AND SEEGER, T.: Interaction of opiates with dopamine receptors: Receptor binding and behavioral assays. Pharmacol. Biochem. Behav. 16: 119-124, 1982.

CARLSSON, A.: Dopaminergic autoreceptors: Background and implications. In Nonstriatal Dopaminergic Neurons (Advances in Biochemical Psychopharmacology series), ed. by E. Costa and G. L. Gessa, Vol. 16, pp. 439-441, Raven Press, New York, 1977.

CARLSSON, A. AND LINDQUIST, M.: Effect of chlorpromazine and haloperidol on formation of 3-methoxytyramine and normetanephrine in mouse brain. Acta Pharmacol. (Kbh.) 20: 140-144, 1963.

CASTELLANO, C. AND PUGLISI-ALLEGRA, S.: Effects of naloxone and naltrexone on locomotor activity in C57BL/6 and DBA/2 mice. Pharmacol. Biochem. Behav. 16: 561-563, 1982. 
CELSEN, B. AND KUSCHINSKY, K.: Effect of morphine on the kinetics of ${ }^{14}$ C-DA in rat striatal slices. Naunyn-Schmiedebergs Arch. Pharmacol. $284: 159-164,1974$.

CHANG, K., HAZUM, E. AND CUATRECASAS, P.: Novel opiate binding sites selective for benzomorphan drugs. Proc. Natl. Acad. Sci. 78: 4141$4145,1981$.

CHANG, K., HAZUM, E. AND CUATRECASAS, P.: Possible role of distinct morphine and enkephalin receptors in mediating actions of benzomorphine drugs (putative $k$ and $\sigma$ agonists). Proc. Natl. Acad. Sci. $77: 4469-4473,1980$.

CHOU, J., TANG, J., YANG, H.-Y. AND COSTA, E.: Increase of striatal Met ${ }^{5}$-enkephalin-arg 6 -phe ${ }^{7}$ (YGGFMRF) content elicited by long-term treatment with haloperidol. J. Pharmacol. Exp. Ther. 229: 171-174, 1984.

CHRISTENSEN, A., FJALLAND, B. AND MOLLER NIELSEN, I.: On the supersensitivity of dopamine receptors induced by neuroleptics. Psychopharmacology 48: 1-6, 1976.

CHRISTENSEN, A. AND MOLLER NIELSEN, I.: Dopaminergic supersensitivity: Influence of dopamine agonists, cholinergics, anticholinergics and drugs used for the treatment of tardive dyskinesia. Psychopharmacology, 62: 111-116, 1979. 
CONSTENTIN, J., PROTAIS, P. AND SCHWARTZ, J.: Rapid and dissociated changes in sensitivities of different dopamine receptors in mouse brain. Nature 257: 405-407, 1975.

CONTRERAS, P., RICE, K., JACOBSON, A. AND O'DONOHUE, T.: Stereotyped behavior correlates better than ataxia with phencyclidine-receptor interactions. Eur. J. Pharmacol. 121: 9-18, 1986.

COOPER, J., BLOOM, F. ANO ROTH, R.: Catecholamines II: CNS aspects. In: The Biochemical Basis of Neuropharmacology. Eds. J. Cooper, F. Bloom and R. Roth, pp. 161-195, 0xford University Press, New York, 1978.

COSTA, E., FRATTA, N., HONG, J., MOROUI, F. AND YANG, H.: Interaction between enkephalinergic and other neuronal systems. Adv. Biochem. Psychopharmaco1. 18: 217-226, 1978.

COSTALL, B. AND NAYLOR, R.: The behavioral effects of dopamine applied intracerebrally to areas of the mesolimbic system. Eur. J. Pharmacol. 32: 87-92, 1975 .

COSTALL, B. AND NAYLOR, R.: Antagonism of the hyperactivity induced by dopamine applied intracerebrally to the nucleus accumbens septi by typical neuroleptics and by clozapine, sulpiride and thioridazine. Eur. J. Pharmacol. 35: 161-168, 1976.

COSTALL, B. AND NAYLOR, R.: Mesolimbic and extrapyramidal sites for the mediation of stereotyped behavior patterns and hyperactivity by amphetamine and apomorphine in the rat. In Cocaine and other 
Stimulants: Advances in Beh. Biol., ed. by E. Ellinwood, Jr. and M. Kilbey, pp. 47-76, Plenum Press, New York, 1977.

COSTALL, B., NAYLOR, R., CANNON, J. AND LEE, T.: Differentiation of the dopamine mechanisms mediating stereotyped behavior and hyperactivity in the nucleus accumbens and caudate-putamen. J. Pharm. Pharmacol. 29: 337-342, 1977.

COSTALL, B., NAYLOR, R. AND NOHRIA, V.: Climbing behavior induced by apomorphine in mice: A potential model for the detection of neuroleptic activity. Eur. J. Pharmacol. 50: 39-50, 1978.

COSTALL, B., NAYLOR, R. AND NOHRIA, V.: Hyperactivity response to apomorphine and amphetamine in the mouse: the importance of the nucleus accumbens and caudate-putamen. J. Pharm. Pharmacol. 31: 259261,1979 .

COSTALL, B., NAYLOR, R. AND NOHRIA, V.: On the importance of mesolimbic mechanisms for the control of apomorphine induced climbing behavior in the mouse. Br. J. Pharmacol. 68: 175P-176P, 1980.

COSTALL, B., NAYLOR, R. AND PINDER, R.: Characterization of the mechanisms for hyperactivity induction from the nucleus accumbens by phenylethylamine derivatives. Psychopharmacology 48: 225-231, 1976.

COWAN, A.: Simple in vivo tests that differentiate prototype agonists at opiate receptors. Life Sci. 28: 1559-1570, 1981. 
COX, B., ARY, M. AND LOMAX, P.: Changes in sensitivity to apomorphine during morphine dependence and withdrawal in rats. J. Pharmacol. Exp. Ther. 196: 637-641, 1976.

CREESE, I.: Receptor binding as a primary drug screen. In: Neurotransmitter Receptor Binding, 2nd ed. Eds. H. Yamamura, S. Enna and M. Kuhar, pp. 189-233, Raven Press, New York, 1985.

CREESE, I., FEINBERG, A. AND SNYDER, S.: Butyrophenone influences on the opiate receptor. Eur. J. Pharmacol. 36: 231-235, 1976.

CREESE, I., BURT, D. AND SNYDER, S.: Dopamine receptor binding enhancement accompanies lesion-induced behavioral supersensitivity. Science 197: 596-598, 1977.

CREESE, I., MORROW, A., LEFF, S., SIBLEY, D. AND HAMBLIN, M.: Dopamine receptors in the central nervous system. In: International Review of Neurobiology, Eds. J. R. Smythies and R. J. Bradley, Vol. 23, Academic Press, New York, pp. 255-301, 1982.

CREESE, I., SIBLEY, D. AND LEFF, S.: Classification of dopamine receptors. In: CNS Receptors--From Molecular Pharmacology to Behavior, Eds. P. Mandel and F. V. DeFeudis, Raven Press, New York, pp. 256-266, 1983.

CROW, T. J., DEAKIN, J. AND LONGDEN, A.: The nucleus accumbens possible site of antipsychotic action of neuroleptic drugs? Psychological Med. 7:213-221, 1977. 
DAY, I. AND GREENBLATT, E.: Effects of neuroleptics on apomorphineinduced climbing and biting behavior in mice. Pharmacologist, 21: $240,1979$.

DINGLEDINE, R., IVERSEN, L. AND BRUEBER, E.: Naloxone as a GABA antagonist: Evidence from iontophoretic, receptor binding and convulsant studies. Eur. J. Pharmacol. 47: 19-27, 1978.

DOMSCHKE, W., DICKSCHAS, A. AND MITZNEGG, P.: CSF $\beta$-endorphin in schizophrenia. Lancet 2: 1024, 1979.

DOWNES, C., LEWIS, P. AND STONE, M.: A comparison of the binding of sigma opioids and phencyclidine, and the interaction with antipsychotic drugs in rat brain membranes. Br. J. Pharmacol. 88: $231-237,1986$

DRAY, A., GONYE, T., DAKLEY, N. AND TANNER, T.: Evidence for the existence of a raphe projection to the substantia nigra in rat. Brain Res. 113: 45-57, 1976.

DRAY, A. AND STRAUGHAN, W.: Synaptic mechanisms in the substantia nigra. J. Pharm. Pharmacol. 28: 400-405, 1976.

DUBOCOVICH, M. AND WEINER, N.: Enkephalins modulate $\left({ }^{3} \mathrm{H}\right)$ dopamine release from rabbit retina in vitro. J. Pharmacol. Exp. Ther. 234: $634-639,1983$.

DUNN, R. W., FIELDING, S., LAL, H. AND SPAULDING, T.: SKF 10,047induced cage climbing in mice. Fed. Proc. 43: 940, 1984. 
DUNN, R.W., KRUSE, H., GEYER, H., NOVICK, W. AND FIELDING, S.: The effects of GABA agonists and antagonists on apomorphine-induced climbing behavior. GABA Neurotransmission, Brain Res. Bull. 5: 433$437,1980$.

EMRICH, H., HOLLT, V., BERGMANN, M., KISSLING, W., SCHMID, W., ZERSSEN, D. AND HERZ, A.: Plasma levels of $\beta$-endorphin in schizophrenic patients: Failure of naloxone to counter curative effects of neuroleptic drugs. In: Neural Peptides and Neuronal Communications ed. by E. Costa and M. Trabucchi, Raven Press, New York, 1980, pp. 489-502.

ENNA, S. AND MAGGI, A.: Minireview: Biochemical pharmacology of gabaergic agonists. Life Sci. 24: 1727-1738, 1979.

ERNST, A.: Mode of action of apomorphine and dexamphetamine on gnawing compulsion in rats. Psychopharmacologia 10: 316-323, 1967.

ERNST, A. AND SMELIK, P.: Site of action of dopamine and apomorphine on compulsive gnawing behavior in rats. Experientia 22: 837-838, 1966.

EZRIN-WATERS, C. AND SEEMAN, P.: L-dopa reversal of hyperdopaminergic behavior. Life Sci. 22: 1027-1037, 1978.

FAYLE, P., JACKSON, D., JENKINS, 0. AND LAFFERTY, P.: The effect of dopamine receptor agonist treatment on haloperidol-induced supersensitivity in mice. Pharmacol. Biochem. Beh. 23: 715-720, 1985. 
FERRIS, R., RUSSELL, A., TANG, F. AND MAXWELL, R.: The labeling in vivo of sigma opioid receptors in mouse brain with $(+)-(3 H)-S K F-$ 10,047. Soc. Neurosci. Abstr. 11: 582, 1985.

FERRIS, R., TANG, F., CHANG, K. AND RUSSELL, A.: Evidence that the potential antipsychotic agent rimcazole (BW 234U) is a specific, competitive antagonist of sigma sites in brain. Life Sci. 38: 2329$2337,1986$.

FREEMAN, A. AND BUNNEY, B.: Effects of phencyclidine (PCP) and the enantiomers of $\mathrm{N}$-allyl-normetazocine (SKF 10,047) on midbrain dopamine (DA) neuronal activity. Pharmacologist 25: 198, 1983.

FREEMAN, A. AND BUNNEY, B.: The effects of phencyclidine and n-allynormetazocine on midbrain dopamine neuronal activity. Eur. J. Pharmacol. 104: 287-293, 1984.

FRENCH, E.: Effects of n-allynormetazocine (SKF 10,047), phencyclidine and other psychomotor stimulants in the rat following 6hydroxydopamine lesion of the ventral tegmental area. Neuropharmacology $25: 447-450,1986$.

FRENCH, E. AND VANTINI, G.: Phencyclidine-induced locomotor activity in the rat is blocked by 6-hydroxydopamine lesion of the nucleus accumbens: Comparisons to other psychomotor stimulants. Psychopharmacology 82: 83-88, 1984 . 
FRIEDHOFF, A. J., BONNET, K. AND ROSENGARTEN, H.: Reversal of two manifestations of dopamine receptor supersensitivity by administration of L-dopa. Res. Commun. Chem. Pathol. Pharmacol. 16: 411-423, 1977.

GALE, K.: Alteration of GABA receptors in rat substantia nigra after chronic treatment with antischizophrenic drugs. Brain Res. Bul1. 5: $897-904,1980$.

GALE, K., COSTA, E., TOFFANO, G., HONG, J. AND GUIDOTTI, A.: Evidence for a role of nigral gamma-aminobutyric acid and substance $P$ in the haloperidol-induced activation of tyrosine hydroxylase. J. Pharmacol. Exp. Ther. 206: 29-37, 1978.

GALE, K. AND GUIDOTTI, A.: GABA-mediated control of rat neostriatal tyrosine hydroxylase revealed by intranigral muscimol. Nature (Lond.) $263: 691-693,1976$.

GALLAGER, D. W., PERT, A. AND BUNNEY, W.: Haloperidol-induced presynaptic dopamine supersensitivity is blocked by chronic lithium. Nature 273: 309-312, 1978.

GARDNER, E., ZUKIN, S. AND MAKMAN, M.: Modulation of opiate receptor binding in striatum and amygdala by selective mesencephalic lesions. Brain Res. 194: 232-239, 1980.

GARZON, J., SANCHEZ-BLAZQUEZ, P. AND LEE, N.: (3H) ethylketocyclazocine binding to mouse brain membranes: evidence for a kappa opioid receptor type. J. Pharmacol. Exp. Ther. 231: 33-37, 1984. 
GAVEND, M. M., SERRE, F., GAVEND, M. R., RAGOUCY, C. AND CARON, P.: Effects of acute administration of cyclazocine on the metabolism of biogenic amines in different regions of rat brain. Psychopharmacology 75 : 79-83, 1981 .

GEORGE, S. AND VAN LOON, G.: B-endorphin alters dopamine uptake by the dopamine neurons of the hypothalamus and striatum. Brain Res. $248: 293-303,1982$.

GIANUTSOS, G., HYNES, M., PURI, S., DRAWBAUGH, R. AND LAL, H.: Effect on apomorphine and nigrostriatal lesions on aggression and striatal dopamine turnover during morphine withdrawal: Evidence for dopaminergic supersensitivity during protracted abstinence. Psychopharmacologia 34: 37-44, 1974.

GIANUTSOS, G. AND MOORE, $K_{*}$ : Dopaminergic supersensitivity in striatum and olfactory tubercle following chronic administration of haloperidol or clozapine. Life Sci. 20: 1585-1592, 1977.

GILBERT, P. AND MARTIN, $W .:$ The effects of morphine- and nalorphinelike drugs in the nondependent, morphine-dependent and cyclazocinedependent chronic spinal dog. J. Pharmacol. Exp. Ther. 198: 66-82, 1976.

GILLON, M., KOSTERLITZ, H. AND MAGNAN, J.: Unexpected antagonism in the rat vas deferens by benzomorphans which are agonists in other pharmacological tests. Br. J. Pharmacol. 72: 13-15, 1981. 
GOLDSTEIN, M., LEW, J., ASANO, T. AND UETA, K.: Alterations in dopamine receptors: Effect of lesion and haloperidol treatment. Commun. Psychopharmaco1 . 4: 21-25, 1980.

GOODMAN, R. AND SNYDER, S.: Autoradiographic localization of kappa opiate receptors to deep layers of the cerebral cortex may explain unique sedative and analgesic effects. Life Sci. 31: 1291-1294, 1982.

GOODMAN, R., SNYDER, S., KUHAR, M. AND YOUNG, W.: Differentiation of delta and mu opiate receptor localizations by light microscopic autoradiography. Proc. Nat. Acad. Sci. 77: 6239-6243, 1980.

GRABOWSKA, M.: Influence of midbrain raphe lesion on some pharmacological and biochemical effects of apomorphine in rats. Psychopharmacol. 39: 315-322, 1974.

GREENBERG, B. AND SEGAL, D.: Evidence for multiple opiate receptor involvement in different phencyclidine-induced unconditioned behaviors in rats. Psychopharmacol. 88: 44-53, 1986.

GUNDLACH, A., LARGENT, B. AND SNYDER, S.: Phencyclidine and sigma opiate receptors in brain: Biochemical and autoradiographical differentiation. Eur. J. Pharmacol. 113: 465-466, 1985.

GWYNN, G. J. AND DOMINO, E.: Genotype-dependent behavior sensitivity to mu vs. kappa opiate agonists. I. Acute and chronic effects on mouse locomotor activity. J. Pharmacol. Exp. Ther. 231: 306-311, 1984. 
HALL, M., JENNER, P., MARSDEN, C. AND RUPNIAK, N.: Comparison of treatment of rats for 9 months with haloperidol or clozapine on striatal and mesolimbic dopamine receptor function. Br. J. Pharmacol. 79: $409 P, 1983$.

HALPERIN, R., GUERIN, J. AND DAVIS, K.: Chronic administration of three neuroleptics: Effects of behavioral supersensitivity mediated by two different brain regions in the rat. Life Sci. 33: 585-592, 1983.

HERLING, S. AND WOODS, J.: Discriminative stimulus effects of narcotics: Evidence for multiple receptor-mediated actions. Life Sci. $28: 1571-1584,1981$.

HESTER, J., RUDZIK, A., KEASLING, H. AND VELDKAMP, W.: 4'-Fluoro-4$(1,4,5,6$-tetrahydroazepino $) 4,5-b)$ indo $1-3(2 \mathrm{H})-y l))$ butyrophenones. J. Med. Chem. 13:23-26, 1970.

HILLER, J. AND SIMON, E.: Specific high affinity (3H) ethylketocyclazocine binding in rat central nervous system: Lack of evidence for $k$ receptors. J. Pharmacol. Exp. Ther. 214: 516-519, 1980.

HIRSCHHORN, I. D., HITNER, D., GARDNER, E., CUBELLS, J. AND MAKMAN, M.: Evidence for a role of endogenous opioids in the nigrostriatal system: Influence of naloxone and morphine on nigrostriatal dopaminergic supersensitivity. Brain Res. 270: 109-117, 1983. 
HITRI, A., WEINER, W., BORISON, R., DIAMOND, B., NAUSIEDA, P. AND KLAWANS, H.: Dopamine binding following prolonged haloperidol pretreatment. Ann. Neuro 1. 3: 134-140, 1978.

HOLT, V. AND BERGMANN, M.: Effects of acute and chronic haloperidol treatment on the concentrations of immunoreactive $\beta$-endorphin in plasma, pituitary and brain of rats. Neuropharmacology 21: 147-154, 1982.

HOLTZMAN, S.: Phencyclidine-like discriminative effects of opioids in the rat. J. Pharmacol. Exp. Ther. 214:614-619, 1980.

HOLTZMAN, S. AND JEWETT, R.: Some actions of pentazocine on behavior and brain monoamines in the rat. J. Pharmacol. Exp. Ther. 181: 345$356,1972$.

HOLTZMAN, S. AND JEWETT, R.: Stimulation of behavior in the rat by cyclazocine: Effects of naloxone. J. Pharmacol. Exp. Ther. 187: 380$390,1973$.

HONG, J., YANG, H., FRATTA, W. AND COSTA, E.: Rat striatal methionine enkephalin content after chronic treatment with cataleptogenic and non-cataleptogenic antischizophrenic drugs. J. Pharmacol. Exp. Ther. 205: $141-147,1978$.

HONG, J., YANG, H. AND COSTA, E.: On the location of methionine enkephalin neuron in rat striatum. Neuropharmacology 16: 451-453, 1977. 
HONG, J., YANG, H., GILLIN, J., DIGIULIO, A., FRATTA, W. AND COSTA, E.: Chronic treatment with haloperidol accelerates the biosynthesis of enkephalins in rat striatum. Brain Res. 160: 192-195, 1979.

IVERSEN, L., GLOWINSKI, J. AND AXELROD, J.: The uptake and storage of $\mathrm{H}^{3}$-norepinephrine in the reserpine-pretreated rat heart. $\mathrm{J}$. Pharmacol. Exp. Ther. 150: 173-183, 1965.

IWAM0T0, E.: Pharmacologic effects off $N$-allylnormetazocine (SKF 10,047). In: Problems of Drug Dependence, Ed. L. Harris, NIDA Research Monograph 34, U.S. Govt. Printing 0ffice, 1980, pp. 82-88.

IWAMOTO, E.: Locomotor activity and antinociception after putative mu, kappa and sigma opioid receptor agonists in the rat: Influence of dopaminergic agonists and antagonists. J. Pharmacol. Exp. Ther. 217 : $451-460,1981$.

IWAMOTO, E., HO, I. AND WAY, L.: Elevation of brain dopamine during naloxone-precipitated withdrawal in morphine-dependent mice and rats. J. Pharmacol. Exp. Ther. $187: 558-567,1973$.

IWAMOTO, E. AND WAY, E.: Circling behavior and stereotypy induced by intranigral opiate microinjections. J. Pharmacol. Exp. Ther. 203: $347-359,1977$.

IWATSUBO, K. AND CLOUET, D.: Effects of morphine and haloperidol on the electrical activity of rat nigrostriatal neurons. J. Pharmacol. Exp. Ther. 202 : 429-436, 1977. 
JACKSON, D., ANDEN, N., ENGEL, J. AND LILJEQVIST: The effect of longterm penfluridol treatment on the sensitivity of the dopamine receptors in the nucleus accumbens and in the corpus striatum. Psychopharmacologia 45 : 151-155, 1975.

JACQUET, Y. AND MARKS, N.: The C-fragment of B-lipotropin: An endogenous neuroleptic or antipsychotogen? Science 194: 632-635, 1976.

JANOWSKY, D. AND DAVIS, J.: Dopamine psychomotor stimulants and schizophrenia: Effects of methylphenidate and the stereoisomers of amphetamine in schizophrenics. In: Neuropsychopharmacology of Monoamines and Their Regulatory Enzymes, ed. by E. Usdin, pp. 317-323, Raven Press, New York, 1974.

JOHNSON, K. AND SNELL, L.: Effects of phencyclidine (PCP) -like drugs on turning behavior, ${ }^{3} \mathrm{H}$-dopamine uptake, and ${ }^{3} \mathrm{H}-\mathrm{PCP}$ binding. Pharmaco1. Biochem. Beh. 22 : 731-735, 1985.

KEATS, A. AND TELFORD, J.: Narcotic antagonists as analgesics, clinical aspects. In: Molecular Modification in Drug Design Advances in Chemistry series 45, ed. by R. F. Gould, Am. Chemical Soc. (Applied Pubs., Washington, DC, $1964, \mathrm{p} .70$.

KEBABIAN, J. AND CALNE, D.: Multiple receptors for dopamine. Nature $277: 93-96,1979$. 
KELLEY, A., STINUS, L. AND IVERSEN, S.: Interaction between D-Alamet-enkephalin, Alo dopaminergic neurons and spontaneous behavior in the rat. Beh. Brain Res. 1: 3-24, 1980.

KELLY, P., SEVIOUR, P. AND IVERSEN, S.: Amphetamine and apomorphine responses in the rat following 6-OHDA lesions of the nucleus accumbens septi and corpus striatum. Brain Res. 94: 507-522, 1975.

KING, R., RAESE, J., HUBERMAN, B. AND BARCHAS, J.: Dopamine neuronal instability: A model of schizophreniform psychosis. Psychopharmacol. Bu11. 18: 70-72, 1982 .

KIRK, R.: Experimental Design: Procedures for the Behavioral Sciences. Brooks/Cole Publishing Co., Belmont, Calif., 1968.

KLAWANS, H. AND RUBOVITS, H.: An experimental model of tardive dyskinesia. J. Neural Transm. 33: 235-246, 1972.

KOSTERLITZ, H. AND PATERSON, S.: Characterization of opioid receptors in nervous tissue. Proc. R. Soc. Lond. 210: 113-122, 1980.

KOSTERLITZ, H., PATERSON, S. AND ROBSON, L.: Characterization of the k-subtype of the opiate receptor in the guinea pig brain. Br. J. Pharmaco1. 73 : 939-949, 1981.

KURUVILLA, A., FUNG, Y. AND URETSKY, N.: Behavioral and biochemical changes caused by muscimol in mice withdrawn from haloperidol administration. Neuropharmacology $21: 891-897,1982$. 
KUSCHINSKY, K.: Are cholinergic mechanisms involved in morphine's effects on motility? Naunyn-Schmiedebergs Arch. Pharmacol. 281: 167173,1974

KUSCHINSKY, K.: Dopamine receptor sensitivity after repeated morphine administration to rats. Life Sci. 17: 43-48, 1975.

KUSCHINSKY, K. AND HORNYKIEWICZ, 0.: Effects of morphine on striatal dopamine metabolism: Possible mechanisms of its opposite effect on locomotor activity in rats and mice. Eur. J. Pharmacol. 26: 41-50, 1974 .

LAL, H.: Narcotic dependence, narcotic action and dopamine receptors. Life Sci. 17: 483-496, 1975.

LAL, H., GIANUTSOS, G. AND PURI, S.: A comparison of narcotic analgesics with neuroleptics on behavioral measures of dopaminergic activity. Life Sci. 17: 29-34, 1975.

LERNER, P., NOSE, P., GORDON, E. AND LOVENBERG, W.: Haloperidol: Effect of long-term treatment on rat striatal dopamine synthesis and turnover. Science 197: 181-183, 1977.

LEVENTER, S. AND JOHNSON, K.: Phencyclidine-induced inhibition of striatal acetylcholine release: Comparisons with mu, kappa and sigma opiate agonists. Life Sci. 34: 793-801, 1984.

LINDSTROM, L., WIOERLOV, E., GRUNNE, L., WAHLSTROM, A. AND TERENIUS, L.: Endorphins in human cerebrospinal fluid: clinical correlations to some psychotic states. Acta Psychiatr. Scand. 57: 153-164, 1980. 
LIST, S. AND SEEMAN, P.: Dopamine agonists reverse the elevated $3 \mathrm{H}-$ neuroleptic binding in neuroleptic-pretreated rats. Life Sci. 24: $1447-1452,1979$.

LJUNGBERG, T. AND UNGERSTEDT, U.: Classification of neuroleptic drugs according to their ability to inhibit apomorphine-induced locomotion and gnawing: Evidence for two different mechanisms of action. Psychopharmacology 56: 239-247, 1978.

LLORENS-CORTES, C., POLLARD, H., SCHWARTZ, J., PRADELLES, P., GROS, C. AND DRAY, F.: Endorphins in several regions of rat brain: Large differences between radioimmunoassay and radioreceptor assay. Eur. J. Pharmaco1. 46: 73-74, 1977.

LO, C., WEN, H. AND HO, W.: Cerebrospinal fluid (met ${ }^{5}$ ) enkephalin level in schizophrenics during treatment with naloxone. Eur. J. Pharmacol. 92: 77-81, 1983.

LOH, H., HITZEMANN, R. AND WAY, E.: Effect of acute morphine administration on the metabolism of brain catecholamine. Life Sci. $12: 33,1973$.

LOH, H., BRASE, D., SAMPATH-KHANNA, S., MAR, J. AND WAY, E.: Bendorphin in vitro inhibition of striatal dopamine release. Nature $264: \quad 567-568,1976$.

LORD, J., WATERFIELD, A., HUGHES, J. AND KOSTERLITZ, H.: Endogenous opioid peptides: Multiple agonists and receptors. Nature 267: 495, 1977. 
MAGGI, A. AND ENNA, S.: Characteristics of muscimol accumulation in mouse brain after systemic administration. Neuropharmacology 18: 361$366,1979$.

MAILMAN, R., SCHULZ, D., LEWIS, M., STAPLES, L., ROLLEMA, H. AND DEHAVEN, D.: SCH-23,390: A selective $D_{1}$ antagonist with potent $D_{2}$ behavioral actions. Eur. J. Pharmacol. 101: 159-160, 1984.

MAO, E., CHENEY, D., MARCO, E., REVUELTA, A. AND COSTA, E.: Turnover times of gamma-aminobutyric acid and acetylcholine in nucleus caudatus, nucleus accumbens, globus pallidus and substantia nigra: Effects of repeated administration of haloperidol. Brain Res. 132: $375-379,1977$.

MARTIN, B., KATZEN, J., WOODS, J., TRIPATHI, H., HARRIS, L. AND MAY, E.: Stereoisomers of $\left({ }^{3} \mathrm{H}\right)-\mathrm{N}-\mathrm{Ally}$ lnormetazocine bind to different sites in mouse brain. J. Pharmacol. Exp. Ther. 231: 539-544, 1984.

MARTIN, J. AND TAKEMORI, A.: Increased sensitivity to dopamine agonists following a single dose of morphine or levorphanol in mice. Eur. J. Pharmacol. 119: 75-84, 1985.

MARTIN, J. AND TAKEMORI, A.: Chronically administered morphine increases dopamine receptor sensitivity in mice. Eur. J. Pharmacol. $121: 221-229,1986$.

MARTIN, W., EADES, C., THOMPSON, J., HUPPLER, R. AND GILBERT, P.: The effects of morphine- and nalorphine-like drugs in the nondependent and 
morphine-dependent chronic spinal dog. J. Pharmacol. Exp. Ther. 197: $517-532,1976$.

MARTRES, M. P., CONSTENTIN, J., BANDY, M., MARCAis, H., PROTAIS, P. AND SCHWARTZ, J.: Long-term changes in the sensitivity of pre- and postsynaptic dopamine receptors in mouse striatum evidenced by behavioral and biochemical studies. Brain Res. 136: 319-337, 1977.

MAURER, R., CORTES, R., PROBST, A. AND PALACIOUS, J.: Multiple opiate receptor in human brain: An autoradiographic investigation. Life Sci. $33: 231-234,1983$.

MENDELSOHN, L., KALRA, V., JOHNSON, B. AND KERCHNER, G.: Sigma opioid receptor: Characterization and co-identity with the phencyclidine receptor. J. Pharmacol. Exp. Ther. 233: 597-602, 1985.

MILLER, J., RICHARDSON, T., FIBIgER, H. AND McLENNA, H.: Anatomical and electrophysiological identification of a projection from the mesencephalic raphe to the caudate-putamen in the rat. Brain Res. 97: $133-138,1975$.

MISHRA, R., GARDNER, E., KATZMAN, R. AND MAKMAN, M.: Enhancement of dopamine-stimulated adenylate cyclase activity in rat caudate after lesions in substantia nigra: Evidence for denervation supersensitivity. Proc. Nat. Acad. Sci. 71: 3883-3887, 1974.

MOLLOY, A. AND WADDINGTON, J.: Dopaminergic behavior stereospecifically promoted by the $D_{1}$ agonist R-SK\&F 38393 and 
selectively blocked by the $D_{1}$ antagonist SCH 23390. Psychopharmacology 82: 409-410, 1984.

MOLLOY, A. AND WADDINGTON, J.: Sniffing, rearing and locomotor responses to the D-1 dopamine agonist R-SK\&F 38393 and to apomorphine: Differential interactions with the selective D-1 and D-2 antagonists SCH 23390 and metoclopramide. Eur. J. Pharmacol. 108: 305-308, 1985.

MOORE, N., PULLAR, I. AND TYE, N.: Selective enhancement of dopamine (induced behaviors) following chronic neuroleptic treatment. Proceedings of the B.P.S. 16th-18th Dec. 269P, 1980.

MURRIN, C., COYLE, J. AND KUHAR, M.: Striatal opiate receptors: Preand postsynaptic localization. Life Sci. 27: 1175-1183, 1980.

NAMBA, M., QUOCK, R. AND MALONE, M.: Narcotic antagonist potentiation of L-dopa in the reversal of reserpine induced catalepsy. Proc. West. Pharmacol. Soc. 23: 285-289, 1980.

NOHRIA, V.: A critical assessment of behavioral test procedures used to analyze dopaminergic and antidopaminergic drugs. Meth. Find. Exp. Clin. Pharmacol. 5: 357-364, 1983.

OKA, T., NEGISHI, K., SUDA, M., MATSUMIYA, T., INAZU, T. AND UEKI, M.: Rabbit vas deferens: A specific bioassay for opioid k-receptor agonists. Eur. J. Pharmaco1. 73: 235-236, 1980.

OWEN, R. T.: Neuropharmacological supersensitivity - clinical and experimental correlations and methodological considerations. Meth. Anal. Find. Exp. Clin. Pharmacol. 2: 89-95, 1980. 
PARKER, R.: Mouse locomotor activity: Effect of morphine, narcotic antagonists and the interaction of morphine and narcotic antagonists. Psychopharmacologia (Ber1.) 38: 15-23, 1974.

PASTERNAK, G.: Multiple opiate receptors: $\left({ }^{3} H\right)$ Ethylketocyclazocine receptor binding and ketocyclazocine analgesia. Proc. Nat. Acad. Sci. USA $77: 3691-3694,1980$.

PASTERNAK, G., CARROLL-BUATTI, M. AND SPIEGEL, K.: The binding and analgesic properties of a sigma opiate, SKF 10,047. J. Pharmacol. Exp. Ther. 219: 192-198, 1981 .

PERT, A., DE WALD, L. AND GALLAGER, D.: Effects of opiates on nigrostriatal dopaminergic activity: electrophysiological and behavioral analyses. In: Catecholamines: Basic and Clinical Frontiers ed. by E. Usdin, pp. 1041-1043, Pergamon, New York, 1979.

PERT, A., ROSENBLATT, J., SIVIT, C., PERT, C. AND BUNNEY, W.: LONgterm treatment with lithium prevents the development of dopamine receptor supersensitivity. Science 201: 171-173, 1978.

PERT, A. AND SIVIT, C.: Neuroanatomical forms for morphine and enkephalin-induced hypermotility. Nature 265: 645-647, 1977.

PERT, C. AND SNYDER, S.: Opiate receptors: Demonstration in nervous tissue. Science 179: 1011-1014, 1973.

PFEIFFER, A. AND HERZ, A.: Demonstration and distribution of an opiate binding site with high affinity for ethylketocyclazocine and SKF 10,047. Biochem. Biophys. Res. Commun. 101: 38-44, 1981. 
PFEIFFER, A., PASI, A., MEHRAEIN, P. AND HERZ, A.: Opiate receptor binding sites in human brain. Brain Res. 248: 87-96, 1982.

PICKAR, D., VARTANIAN, F., BUNNEY, W., MAIER, H., GASTPAR, M., PRAKASH, R., SETHI, B., LIDEMAN, R., BELYAEV, B., TSUTSULKOVSKAJA, M., JUNGKUNZ, G., NEDOPIL, N., VERHOEVEN, W. AND VAN PRAAG, H.: Shortterm naloxone administration in schizophrenic and manic patients. Arch. Gen. Psychiatry 39: 313-319, 1982.

PIJNENBERG, A., HONIG, W., VAN DER HEYDEN, J. AND VAN ROSSUM, J.: Effects of chemical stimulation of the mesolimbic dopamine system upon locomotor activity. Eur. J. Pharmacol. 35: 45-58, 1976.

PIJNENBERG, A., HONIG, W., AND VAN ROSSUM, J.: Inhibition of damphetamine-induced locomotor activity by injection of haloperidol into the nucleus accumbens of the rat. Psychopharmacologia 41: 87-95, 1975.

PIJNENBERG, A. AND VAN ROSSUM, J.: Stimulation of locomotor activity following injection of dopamine into the nucleus accumbens. J. Pharm. Pharmacol. 25: 1003 1005, 1973.

PLETSCHER, A., BROSSI, A. AND GEY, K.: Benzoquinolizine derivatives: A new class of monamine decreasing drugs with psychotropic action. Int. Rev. Neurobiol. $4: 275-306,1962$.

POLLARD, H., LLORENS, C., BONNET, J., CONSTENTIN, J. AND SCHWARTZ, J.: Opiate receptors on mesolimbic dopaminergic neurons. Neurosci. Lett. 7 : 295-299, 1977a. 
POLLARD, H., LLORENS-CORTES, C. AND SCHWARTZ, J.: Enkephal in receptors on dopaminergic neurons in rat striatum. Nature (Lond.) $268: 745-747,1977 b$.

POLLARD, H., LLORENS, C., SCHWARTZ, J., GROS, C. AND DRAY, F.: Localization of opiate receptors and enkephalins in the rat striatum in relationship with the nigrostriatal dopaminergic system: Lesion studies. Brain Res. 151 : 392-398, 1978.

PONZIO, F., CONSDAZIONE, A., CALDERINI, G., ACHILLI, G., ROCCHETTI, M. AND ALGERI, S.: Biochemical effects of quipazine on rat striatal dopaminergic system. Life Sci. 29: 83-91, 1981.

PRECHT, W. AND YOSHIDA, M.: Blockage of caudate-evoked inhibition of neurons in the substantia nigra by picrotoxin. Brain Res. 32: 229$233,1971$.

PROTAIS, P., COSTENTIN, J. AND SCHWARTZ, J.: Climbing behavior induced by apomorphine in mice: A simple test for the study of dopamine receptors in striatum. Psychopharmacology 50:1-6, 1976.

PUGH, M., O'BOYLE, K., MOLLOY, A. AND WADDINGTON, J.: Effects of the putative D-1 antagonist SCH 23390 on stereotyped behavior induced by the D-2 agonist RU 24213. Psychopharmacology 87: 308-312, 1985.

PURI, S. AND LAL, H.: Effect of dopaminergic stimulation or blockade on morphine-withdrawal aggression. Psychopharmacologia (Berl.) 32 : $113-120,1973$. 
PURI, S., VOLICER, L. AND LAL, H.: Effect of apomorphine on dopamine turnover and adenosine $3^{\prime}-5^{\prime}$-monophosphate content in striatum of morphine-dependent rats. Neuropharmacology 16: 205-209, 1977.

PURI, S., SPAULDING, T. AND MANTIONE, C.: Dopamine antagonist binding: A significant decrease with morphine dependence in the rat striatum. Life Sci. 23: 637-642, 1978.

PYCOCK, C., HORTON, R. AND CARTER, C.: Interactions of 5hydroxytryptamine and gamma-aminobutyric acid with dopamine. Adv. Biochem. Psychopharmacol. 19: 323-341, 1978.

QUINN, G., SHORE, P. AND BRODIE, B.: Biochemical and pharmacological studies of R01-9569 (tetrabenazine), a non-indole tranquilizing agent with reserpine-like effects. J. Pharmacol. Exp. Ther. 127: 103-109, 1959.

QUOCK, R.: Naloxone potentiation of apomorphine-induced stereotypic climbing in mice and interaction with mu-, sigma- and kappa-opiate drugs. Life Sci. 31: 2907-2911, 1982.

QUOCK, R.: The potentiating effect of naloxone upon apomorphineinduced hyperthermia. Life Sci. 20: 2005-2012, 1977.

QUOCK, R., BLOOM, A. AND SADOWSKI, J.: Possible noradrenergic involvement in naloxone potentiation of apomorphine-induced stereotypic climbing in mice. Pharmacol. Biochem. Beh. 21: 733-736, 1984. 
QUOCK, R. AND LUCAS, T.: Enhancement of apomorphine-induced climbing in mice by reversible and irreversible narcotic antagonist drugs. Life Sci. 28: 1421-1424, 1981.

QUOCK, R.M. AND LUCAS, T. S.: Potentiation by naloxone of the antioxotremorine effect of L-dopa. Eur. J. Pharmacol. 95: 193-198, 1983.

QUOCK, R. AND WELSH, T.: Potentiation of apomorphine-induced rotational behavior by naloxone. J. P'arm. Pharmacol. 33: 111-113, 1981.

RANDRUP, A. AND MUNKVAD, I.: Stereotyped activities produced by amphetamine in several animal species and man. Psychopharmacologia 11 : $300-310,1967$.

RANDRUP, A. AND MUNKVAD, I.: Pharmacology and physiology of stereotyped behavior. J. Psychiatr. Res. 11: 1-10, 1974.

RECHES, A., BURKE, R., KUHN, C., HASSAN, M., JACKSON, V. AND FAHN, S.: Tetrabenazine, an amine-depleting drug, also blocks dopamine receptors in rat brain. J. Pharmacol. Exp. Ther. 225: 515-521, 1983.

RECHES, A., WAGNER, H., JIANG, D., JACKSON, V. AND FAHN, S.: The effect of chronic I-dopa administration on supersensitive pre- and postsynaptic dopaminergic receptors in rat brain. Life Sci. 33: 37$44,1982$.

RETHY, C., SMITH, C. AND VILLARREAL, J.: Effects of narcotic analgesics upon the locomotor activity and brain catecholamine content of the mouse. J. Pharmacol. Exp. Ther. 176:472-479, 1971. 
ROBSON, L. AND KOSTERLITZ, H.: Specific protection of the binding sites of $\mathrm{D}-\mathrm{Al} \mathrm{a}^{2}-\mathrm{D}$-Leu ${ }^{5}$-enkephalin (a receptors) and dihydromorphine ( $\mu$ receptor). Proc. R. Soc. Lond. B. Biol. Sci. 205: 425-432, 1979.

ROFFLER-TARLOV, S., SHARMAN, D. AND TEGERDINE, P.: 3,4-Dihydroxyphenylacetic acid and 4-hydroxy-3-methoxyphenylacetic acid in the mouse striatum: A reflection of intra- and extraneuronal metabolism of dopamine? Br. J. Pharmacol. 42:343-351, 1971.

ROLINSKI, Z. AND SCHEEL-KRUGER, J.: The effect of dopamine and noradrenaline antagonists on amphetamine-induced locomotor activity in mice and rats. Acta Pharmacol. (Kbh.) 33: 385-399, 1973.

RUPNIAK, N., JENNER, P. AND MARSDEN, C.: The effect of chronic neuroleptic administration on cerebral dopamine receptor function. Life Sci. 32: 2289-2311, 1983.

SALLER, C. AND SALAMA, A.: D-1 and D-2 dopamine receptor blockade: Interactive effects in vitro and in vivo. J. Pharmacol. Exp. Ther. 236: $714-720,1986$.

SANDYK, R.: The endogenous opioid system in neurological disorders of the basal ganglia. Life Sci. 37: 1655-1663, 1985.

SCHEEL-KRUGER, J. AND RANDRUP, A.: Stereotyped hyperactive behavior produced by dopamine in the absence of noradrenaline. Life Sci. 6: $1389-1398,1967$.

SCHWARTZ, J., BAUDRY, M., MARTRES, M., CONSTENTIN, J. AND PROTAIS, P.: Increased in vivo binding of $3 \mathrm{H}$-pimozide in mouse striatum following 
repeated administration of haloperidol. Life Sci. 23: 1785-1790, 1978.

SEEGER, T. F., GARDNER, E. AND BRIDGEN, $W_{*}:$ Increase in mesolimbic electrical self-stimulation after chronic haloperidol: Reversal by Ldopa or 1ithium. Brain Res. 215: 404-409, 1981.

SEEGER, T. F., NAZZARO, J. AND GARDNER, E.: Selective inhibition of mesolimbic behavioral supersensitivity by naloxone. Eur. J. Pharmacol. 65: 435-438, 1980.

SEWELL, R., SPENCER, P. AND UPTON, N.: Antinociceptive activity of some $\mu$ - and k-opiate agonists determined by a combined nociceptive testing method. Br. J. Pharmacol. 74: 284p, 1981.

SHEARMAN, G. AND HERZ, A.: Nonopioid psychotomimetic-like discrimination stimulus properties of $n$-allylnormetazocine (SKF 10,047) in the rat. Eur. J. Pharmaco1. 82: 167-172, 1982.

SIBLEY, D., DeLEAN, A. AND CREESE, I.: Anterior pituitary dopamine receptor: Demonstration of interconvertible high and low affinity states of the D-2 dopamine receptor. J. Biol. Chem. 257: 6351-6361, 1982.

SINEGER, E., HORVATH, K., MIGLECZ, E., TARNAWA, I., ANDRASI, F. AND SZEKELY, J.: Morphine and (d-met ${ }^{2}$, pro $^{5}$ ) enkephalinamide do not show specific neuroleptic activity. Eur. J. Pharmacol. 80: 359-368, 1982.

SIRCAR, R., NICHTENHAUSER, R., IENI, J. AND ZUKIN, S.: Characterization and autoradiographic visualization of $(+) \quad\left({ }^{3} H\right)$ SKF 10,047 
binding in rat and mouse brain: Further evidence for phencyclidine/"sigma opiate" receptor commonality. J. Pharmacol. Exp. Ther. $237: 681-688,1986$.

SMITH, J. AND SIMON, E.: Selective protection of stereospecific enkephalin and opiate binding against inactivation by $\mathrm{N}$ ethylmaleimide: Evidence for two classes of opiate receptors. Proc. Nat. Acad. Sci. USA $77: 281-284,1980$.

SNELL, L., MUELLER, Z., GANNON, R., SILVERMAN, P. AND JOHNSON, K.: A comparison between classes of drugs having phencyclidine like behavioral properties on dopamine efflux in vitro and dopamine metabolism in vivo. J. Pharmacol. Exp. Ther. 231: 261-269, 1984.

SNYDER, S.: The opiate receptor and morphine-like peptides in the brain. Am. J. Psychiatry 135: 645-652, 1978.

SNYDER, S. AND GOODMAN, R.: Multiple neurotransmitter receptors. J. Neurochem. 35: 5-15, 1980.

SPECTOR, S., SJOERDSMA, A. AND UDENFRIED, S.: Blockade of endogenous norepinephrine synthesis by alpha-methyltyrosine, and inhibitor of tyrosine hydroxylase. J. Pharmacol. Exp. Ther. 147: 86-95, 1965.

STAUNTON, D., MAGISTRETTI, P., SHOEMAKER, W., DEYO, S. AND BLOOM, F.: Effects of chronic lithium treatment on dopamine receptors in the rat corpus striatum. II. No effect on denervation or neuroleptic-induced supersensitivity. Brain. Res. 232: 401-412, 1982a. 
STAUNTON, D., MAGISTRETTI, P., SHOEMAKER, W. AND BLOOM, F.: Effects of chronic lithium treatment on dopamine receptors in the rat corpus striatum. I. Locomotor activity and behavioral supersensitivity. Brain Res. 232: 391-400, $1982 b$.

STOLK, J. AND RECH, R.: Antagonism of d-amphetamine by a-methyl-ptyrosine. Behavioral evidence for the participation of catecholamine stores and synthesis in the amphetamine stimulant response. Neuropharmacology 12: 853-866, 1973.

STROMBOM, U. AND SVENSSON, T.: Antagonism of morphine-induced central stimulation in mice by small doses of catecholamine-receptor agonists. J. Neural Trans. 42: 169-179, 1978.

SU, T.: Psychotomimetic opioid binding: Specific binding of $\left({ }^{3} \mathrm{H}\right)$ SKF10,047 to etorphine-inaccessible sites in guinea pig brain. Eur. $\mathrm{J}$. Pharmaco1. 75: 81-82, 1981 .

Su, T.: Evidence for sigma opioid receptor: Binding of ( $\left.{ }^{3} H\right)$ SKF-10,047 to etorphine-inaccessible sites in guinea pig brain. J. Pharmacol. Exp. Ther. 223: 284-290, 1982.

SU, T., WEISSMAN, A. AND YEH, S.: Endogenous ligands for sigma opioid receptors in the brain ("sigmaphin"): Evidence from binding assays. Life Sci. 38: 2199-2210, 1986.

SUBRAMANIAN, N., MITZNEGG, P., SPRUGEL, W., DOMSCHKE, W., DOMSCHKE, S., WUNSCH, E. AND OEMLING, L.: Influence of enkephalin on $\mathrm{K}^{+}$-evoked efflux of putative neurotransmitters in rat brain: Selective 
inhibition of acetylcholine and dopamine release. NaunynSchmiedeberg's Arch. Pharmacol. 299: 163-165, 1977.

SUGRUE, M.: The effects of acutely administered analgesics on the turnover of noradrenaline and dopamine in various regions of the rat brain. Br. J. Pharmacol. 52: 159-165, 1974.

TAM, S.: Naloxone-inaccessible sigma receptor in rat central nervous system. Proc. Natl. Acad. Sci. USA 80: 6703-6707, 1983.

TAM, S.N.: $(+)-\left({ }^{3} H\right)$ SKF 10,047, $(+)-\left({ }^{3} H\right)$ Ethylketocyclazocine, mu, kappa, delta and phencyclidine binding sites in guinea pig brain membranes. Eur. J. Pharmacol. 109: 33-41, 1985.

TAM, S. AND COOK, L.: Haloperidol and certain other antipsychotic drugs displace $(+)-\left({ }^{3} H\right)$ SKF 10,047 sigma binding in guinea pig brain membranes. Fed. Proc. 43: 1093, 1984.

TANG, F., SCHWARTZ, J. AND COSTA, E.: Increase of proenkephal in on RNA and enkephalin content of rat striatum following daily injections of haloperidol for two to three weeks. Proc. Nat. Acad. Sci. USA 80: $3841-3844,1983$.

TARSY, D. AND BALDESSARINI, R.: Behavioral supersensitivity to apomorphine following chronic treatment with drugs which interfere with the synaptic function of catecholamines. Neuropharmacology 13: $927-940,1974$. 
TEAL, J. AND HOLTZMAN, S.: Discrimination stimulus effects of prototype opiate receptor agonists in monkeys. Eur. J. Pharmacol. 68: 110,1980 .

TEPPER, P. AND WOODS, J.: Changes in locomotor activity and naloxoneinduced jumping in mice produced by WIN 35,197-2 (ethylketocyclazocine) and morphine. Psychopharmacology 58: 125-129, 1978.

TERRENIUS, L., WAHLSTROM, A., LINDSTROM, L. AND WIDERLOV, E.: Increased CSF levels of endorphins in chronic psychosis. Neurosci. Lett. 3: 157-162, 1976.

THEODOROU, A., GOMMEREN, W., CLOW, A., LEYSEN, J., JENNER, P. AND MARSDEN, C.D.: Chronic neuroleptic treatment specifically alters the number of dopamine receptors in rat brain. Life Sci. 28: 1621-1627, 1981.

THORNBURG, J. AND MOORE, K.: The relative importance of dopaminergic and noradrenergic neuronal systems for the stimulation of locomotor activity induced by amphetamine and other drugs. Neuropharmacology 12: 853-866, 1973.

TYERS, M.: A classification of opiate receptors that mediate antinociception in animals. Br. J. Pharmacol. 69: 503-512, 1980.

UNGERSTEDT, U.: Stereotaxic mapping of the monoamine pathways in the rat brain. Acta Physiol. Scand. Suppl, 367: 1-48, 1971.

UPTON, N., SEWELL, R. AND SPENCER, P.: Analgesic actions of $\mu-$ and $k-$ opiate agonists in rats. Arch. Int. Pharmacodyn. 262: 199-207, 1983. 
UPTON, N., SEWELL, R. AND SPENCER, P.: Differentiation of potent $\mu-$ and $k$-opiate agonists using heat and pressure antinociceptive profiles and combined potency analysis. Eur. J. Pharmacol. 78: 421-429, 1982.

URETSKY, N. AND IVERSEN, L.: Effects of 6-hydroxydopamine on catecholamine containing neurons in the rat brain. J. Neurochem. 17: 269$278,1970$.

VALE, W., RIVIER, J., GUILLEMIN, R. AND RIVIER, C.: Effects of purified CRF and other substances on the secretion of ACTH and Bendorphin-like immunoreactivities by cultured anterior or neurointermediate pituitary cells. In: Central Nervous System Effects of Hypothalamic Hormones and Other Peptides ed. by Coller, pp. 163-176, Press, New York, 1979.

VANCE, M. AND BLUMBERG, J.: Effect of catecholamines on locomotor activity and cyclic AMP in nucleus accumbens in rats. J. Pharm. Pharmacol. 35: 402-404, 1983.

VAN REE, J. AND DE WIED, D.: Endorphins in schizophrenia. Neuropharmacology 20: 1271-1277, 1981 .

VEREBEY, K., VOLAVKA, J., MULE, S. AND RESNICK, R.: Naltrexone: Disposition, metabolism and effects after acute and chronic dosing. Clin. Pharmacol. Ther. 20: 315-328, 1976.

VEREBEY, K., VOLAVKA, J. AND CLOUET, D.: Endorphins in psychiatry. An overview and a hypothesis. Arch. Gen. Psychiatry, 35: 877-888, 1978. 
VERIMER, T., GOODALE, D., LONG, J. AND FLYNN, J.: Lithium effects on haloperidol-induced pre- and postsynaptic dopamine receptor supersensitivity. J. Pharm. Pharmacol. 32:665-666, 1980.

VON VOIGTLANDER, P.F., LOSEY, E. AND TRIEZENBERG, H.: Increased sensitivity to dopamine agents after chronic neuroleptic treatment. J. Pharmacol. Exp. Ther. 193: 88-94, 1975.

WADDINGTON, J. AND CROSS, A.: Baclofen and muscimol: Behavioral and neurochemical sequelae of unilateral intranigral administration and effects on ${ }^{3} \mathrm{H}$-GABA receptor binding. Arch. Pharmacol. 306: 275-280, 1979.

WADDINGTON, J. AND GAMBLE, S.: Spontaneous activity and apomorphine stereotypy during and after withdrawal from $3 \frac{1}{2}$ months continuous administration of haloperidol: Some methodological issues. Psychopharmacology 71: 75-77, 1980.

WARD, S. AND TAKEMORI, A.: Relative involvement of mu, kappa and delta receptor mechanisms in opiate-mediated antinociception in mice. J. Pharmacol. Exp. Ther. 224: 525-530, 1983.

WATSON, S., BERGER, P., AKIL, H., MILLS, M., AND BARCHAS, J.: Effects of naloxone on schizophrenia: Reduction in hallucinations in a subpopulation of subjects. Science 201:73-76, 1978.

WAUQUIER, A., NIEMEGEERS, J. E. AND LAL, H.: Differential antagonism by naloxone of inhibitory effects of haloperidol and morphine on brain self-stimulation. Psychopharmacologia (Ber1.) 37: 303-310, 1974. 
WEINER, W., GOETZ, C. AND KLAWANS, H.: Serotonergic and antiserotonergic influences on apomorphine-induced stereotyped behavior. Acta Pharmacol. Toxicol. 36: 155-160, 1975.

WEISSMAN, A., KOE, B. AND TENEN, S.: Anti-amphetamine effects following inhibition of tyrosine hydroxylase. J. Pharmacol. Exp. Ther. $151: 339-352,1966$.

WOLOZIN, B., NISHIMURA, S. AND PASTERNAK, G.: The binding of $k$ - and o-opiates in rat brain. J. Neurosci. 2: 708-713, 1982.

WOOD, P. AND CHARLESON, S.: High affinity $\left({ }^{3} H\right)$-ethylketocyclazocine binding: Evidence for specific $k$ receptor. Neuropharmacology 21: $215-219,1982$.

WOOD, P., STOTLAND, M., RICHARD, J. AND RACKHAM, A.: Actions of mu, kappa, sigma, delta and agonist/antagonist opiates on striatal dopaminergic function. J. Pharmacol. Exp. Ther. 215: 697-703, 1980.

WOOD, P., CHARLESON, S., LANE, D. AND HUDGIN, R.: Multiple opiate receptors: Differential binding of $\mu, \kappa$ and $\sigma$ agonists. Neuropharmacol. 20: 1215-1220, 1981.

WOOD, P. AND RICHARD, J.: Morphine and nigrostriatal function in the rat and mouse: the role of nigral and striatal opiate receptors. Neuropharmacology 21: 1305-1310, 1982.

YOUNG, G., NEISTADT, L. AND KHAZAN, N.: Differential neuropharmacological effects of mu, kappa and sigma opioid agonists on cortical 
EEG power spectra in the rat. Res. Commun. Psychol. Psychiatry Behav. $6: 365-376,1981$.

ZUKIN, S.: Differing stereospecificities distinguish opiate receptor subtypes. Life Sci. 31: 1307-1310, 1982.

ZUKIN, S., BRADY, K., SLIFER, B. AND BALSTER, R.: Behavioral and biochemical stereoselectivity of sigma opiate/PCP receptors. Brain Res. 294 : 174-177, 1984.

ZUKIN, R. AND ZUKIN, S.: Demonstration of $\left({ }^{3} \mathrm{H}\right)$ cyclazocine binding to multiple opiate receptor sites. Mo1. Pharmaco1, 20: 246-254, 1981a.

ZUKIN, R. AND ZUKIN, S.: Multiple opiate receptors: Emerging concepts. Life Sci. 29: 2681-2690, 1981 b. 